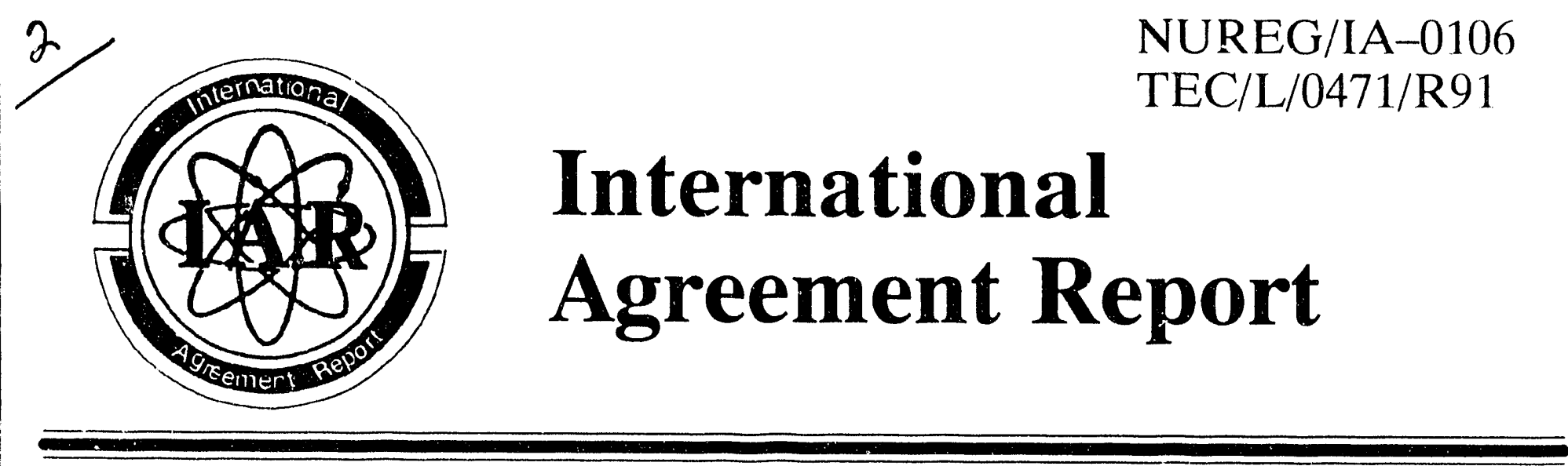

\title{
Assessment of PWR
}

Steam Generator Modelling

in RELAP5/MOD2

Prepared by

J. M. Putney, R. J. Preece

RECEIVED

JIII $\triangle 81993$

National Power

Technology and Environmental Centre

Kelvin Avenue

Leatherhead

Surrey, KT22 7SE

United Kingdom

Office of Nuclear Regulatory Research

U.S. Nuclear Regulatory Commission

Washington, DC. 20555

\section{June 1993}

Prepared as part of

The Agreement on Research Participation and Technical Exchange under the International Thermal-Hydraulic Code Assessment and Application Program (ICAP)

Published by U.S. Nuclear Regulatory Commission 


\section{NOTICE}

This report was prepared under an international cooperative agreement for the exchange of technical information. Neither the United States Government nor any agency thereof, or any of their employees, makes any warranty, expressed or implied, or assumes any legal liability or responsibility for any third party's use, or the results of such use, of any information, apparatus product or process disclosed in this report, or represents that its use by such third party would not infringe privately owned rights.

Available from

Superintendent of Documents

U.S. Government Printing Office P.O. Box 37082

Washington, D.C. 20013-7082

and

National Technical Information Service Springfield, VA 22161 
NUREG/IA-0106

TEC/L/0471/R91

\section{International} Agreement Report

\section{Assessment of PWR Steam Generator Modelling in RELAP5/MOD2}

Prepared by

J. M. Putney, R. J. Preece

National Power

Technology and Environmental Centre

Kelvin Avenue

Leatherhead

Surrey, KT22 7SE

United Kingdom

Office of Nuclear Regulatory Research

U.S. Nuclear Regulatory Commission

Washington, DC 20555

June 1993

Prepared as part of

The Agreement on Research Participation and Technical Excriange under the International Thermal-Hydraulic Code Assessment and Application Program (ICAP)

Published by

U.S. Neclear Regulatory Commission 
NOTICE

This report is based on work performed under the sponsorship of the United Kingdom Atomic Energy Authority. The information in this report has been provided to the USNRC under the terms of the International code Assessment and ApFlication Program (ICAP) between the United States and the United Kingdom (Administrative Agreement - WH 36047 between the United States Nuclear Regulatory Commission and the United Kingdom Atomic Energy Authority Relating to Collaboration in the Field of Modelling of Loss of coolant Accidents, February 1985). The United Kingdom has consented to the publication of this report as a USNRC document in order to allow the widest possible circulation among the reactor safety community. Neither the United States Government nor the United Kingdom or any agency thereof, or any of their employees makes any warranty, expressed or implied, or assumes any legal liability of responsibility for any third party's use, or the results of such use, or any information, apparatus, product or process disclosed in this report, or represents that its use by such third party would not infringe privately owned rights. 


\title{
ASSESSMENT OF PWR STEAM GENERATOR MODELLING IN RELAP5/MOD2
}

\author{
$\mathrm{J}$ M Putney and $\mathrm{R} \mathrm{J}$ Preece
}

Addressee: $\quad$ Mr P Lightfoot, Nuclear Electric, PPG

\section{SUMMARY}

An assessment of Steam Generator (SG) modelling in the PWR thermal-hydraulic code RELAP5/MOL2 is presented. The assessment is based on a review of code assessment calculations performed in the UK and elsewhere, detailed calculations against a series of commissioning tests carried out on the Wolf Creek PWR and analytical investigations of the phenomena involved in normal and abnormal SG operation. A number of modelling deficiencies are identified and their implications for PWR safety analysis are discussed - including methods for compensating for the deficiencies through changes to the input deck. Consideration is also given as to whether the deficiencies will still be present in the successor code RELAP5/MOD3.

\section{Conclusions}

1. RELAP5/MOD2 under-predicts SG heat transfer under steady-state normal operating and start-up conditions. If the code is initialised with the correct primary side conditions, this is reflected by an under-prediction of the secondary side pressure. The effect is seen in both plant and rig calculations, although it tends to reduce as both reactor power and scale reduce. For the Sizewell ' $B$ ' SG operating at full load conditions, the error in secondary side pressure is around 3.5 bar. The deficiency can be attributed to the application of the Chen correlation, which was developed using data from flows in tubes and annuli, to calculate the boiling heat transfer coefficient on the secondary side of the U-tube bundle. Although RELAP5/MOD2 incorporates a modification to this correlation which enhances heat transfer as the void fraction reduces, the enhancement is not sufficient for plant calculations. It also exacerbates an incorrect trend with bundle elevation. Various methods are available for compensating for the deficiency, but in most cases the most defensible approach is to artificially increase the U-tube thermal conductivity. In general, the errors in SG heat transfer behaviour do not hold serious implications for PWR safety analysis, although they are likely to be worse in RELAP5/MOD3 as the Chen correlation is applied in its standard form.

2. At steady-state normal operating conditions, RELAP5/MOD2 under-predicts the SG secondary side liquid inventory if the recirculation ratio is calculated correctly. The deficiency can be attributed to an over-prediction of void fraction in the SG bundle, caused by an over-prediction of the interphase drag force (which is a known deficiency in the code). The error in inventory that results, which tends to reduce as reactor power reduces, affects the prediction of the downcomer level following a reactor trip and the calculated time of SG dryout in loss of feedwater accidents. The latter holds the more serious implications for PWR safety analysis and is particularly severe for transients in which most of the boildown occurs under decay heat levels - as the excess inventory on the plant 
takes a long time to boiloff. As a result, the predicted dryout may be advanced by around $1000 \mathrm{~s}$, which has a dramatic affect on the timings of all subsequent events. Although the initial inventory may be artificially increased by increasing the downcomer flow area or the recirculation ratio (through raising the initial SG level or reducing the flow losses), the adjustments recuired to compensate for the void fraction errors may not be physically sensible. The initial inventory can also be 'corrected' by specifying a very large hydraulic diameter on the secondary side of the U-tube bundle $(\simeq 250 \mathrm{~cm})$. However, this may be difficult to justify. The calculation of SG inventory is expected to be better in RELAP5/MOD3 due to the new interphase drag models.

3. For fast SG boildown transients typical of those occurring under full power conditions, RELAP5/MOD2 tends to over-predict the rate at which the downcomer level falls, in addition to under-predicting the initial inventory. Moreover. increasing the initial inventory by increasing the downcomer flow area or recirculation ratio, does not have a significant effect on this rate - it only serves to delay the time at which SG dryout occurs. These effects arise because, in addition to determining the initial inventory, the interphase drag models in the bundle have a direct effect on the mixture and downcomer level trajectories during the boildown process itself. The effect is less noticeable for slow boildown transients where the vapour generation rate is relatively low, as the errors in initial inventory tend to dominate. Theoretical analyses also indicate that in order to predict the correct level behaviour during boildown, it is necessary to calculate both the local and profile slip components of the drag force correctly. In contrast, in order to obtain the correct initial inventory, it is only necessary to calculate the total drag force correctly. This implies that attempts to correct the initial inventory by specifying a large secondary side hydraulic diameter, which only affects the calculation of the local drag force, may not necessarily produce the co"rect level behaviour. It also means that this type of problem should provide a good test for the new interphase drag models in RELAP5/MOD3.

4. During SG boildown and blowdown transients, RELAP5/MOD2 tends to over-predict wall heat transfer above the mixture level. The evidence available indicates that the code predicts wet wall conditions for the whole of the bundle until the SG has virtually dried out, and that this is due to the calculation of excessive liquid entrainment from the mixture region. It is believed that this problem is a consequence of the known deficiencies in the bundle interphase drag model, exacerbated by the absence of a proper vertical stratified flow model and, possibly, the criteria applied to determine wet/dry wall conditions. Some improvement may be expected in RELAP5/MOD3 due to the new interphase drag and vertical stratification models.

5. The deficiencies in the bundle interphase drag model are believed to be responsible for a tendency of RELAP5/MOD2 to calculate excessive dynamic level swell in response to steam discharge from the SG. They may also be the cause of instabilities seen in the calculated separator performance, although the non-mechanistic nature of the separator model may also be a contributing factor. In the past. a tendency to over-predict liquid entrainment to the break in steam line break transients have been attributed to shortcoming in interphase drag modelling. Recent studies however, have indicated that this is not the case, and the most likely explanation is the failure to model the accumulation of liquid on structures in the upper SG. Other deficiencies in SG modelling in the code include the modelling of counter current flow limitation (CCFL) and liquid hold-up in the U-tubes and inlet plena. These reflect a general problem in modelling flooding type phenomena in RELAP5/MOD2 over a range of geometries and may be linked to the interphase drag models and flow regime maps - although in many cases the primary source of the deficiency lies outside the area of SG modelling. Nevertheless, some improvement may be expected in RELAP5/MOD3, primarily as a result of the new user controlled CCFL model. 
6. In practice, the above deficiencies in SG modelling do not diminish the value of RELAP5/MOD2 for performing safety case calculations for the majority of PWR LOCAs and intact primary fault sequences of interest. The only real exception concerns the modelling of transients in which the SG boils dry very slowly, when the under-prediction of initial inventory will result in the SG being calculated to dry out too early. A typical example is a total loss of feedwater accident with normal reactor trip and closure of the MSIV. Due to the inaccuracies in the timing of major events. it may be difficult to use the results of the calculation for safety assessment purposes.

Task No. T5401

Project No. PGD2600
Approved:

Contents, classification and distribution

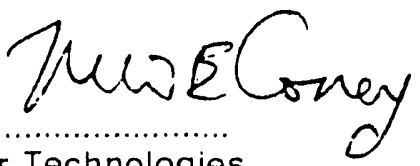

Power Technologies

Date

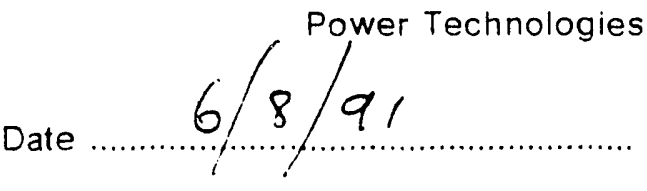




\section{CONTENTS}

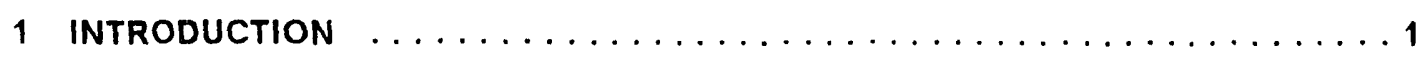

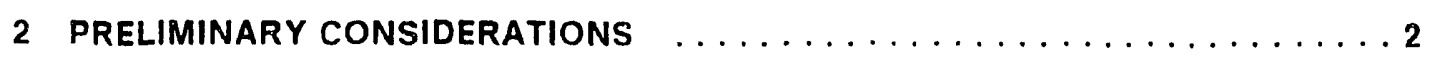

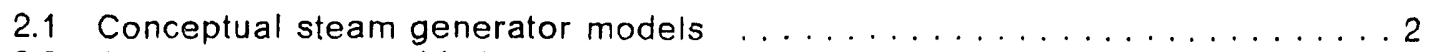

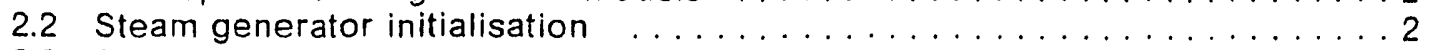

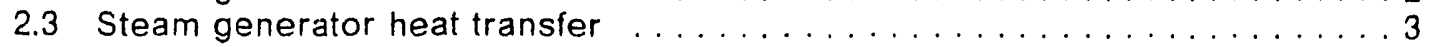

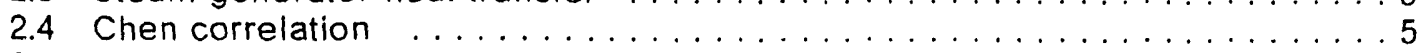

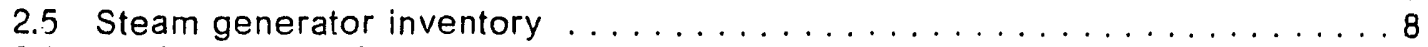

2.6 Modelling practices and their effect on heat transfer and inventory . . . . . 8

2.7 Measure of steam generator heat transfer $\ldots \ldots \ldots \ldots \ldots \ldots \ldots \ldots$

\section{REVIEW OF RELAP5/MOD2 ASSESSMENT CALCULATIONS $\ldots \ldots \ldots \ldots \ldots 12$}

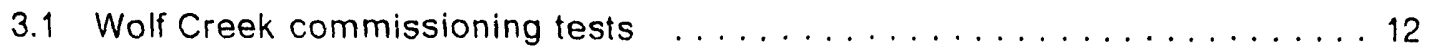

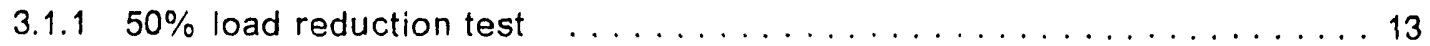

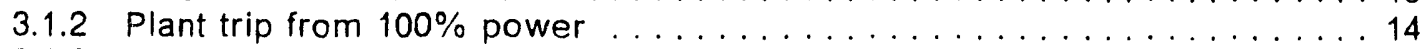

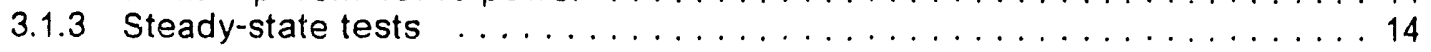

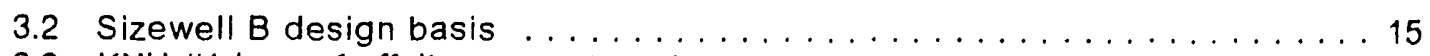

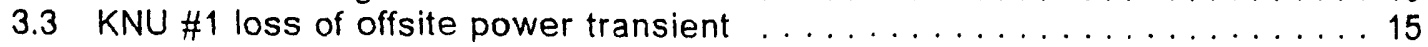

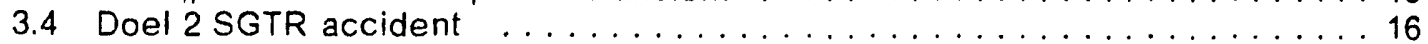

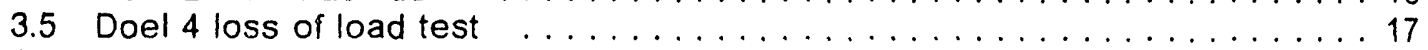

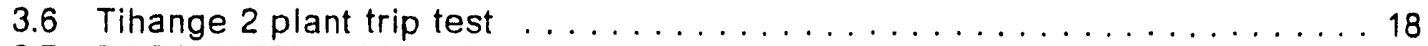

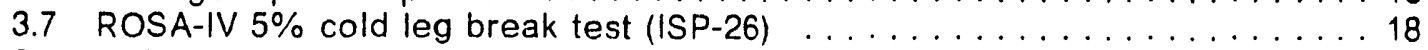

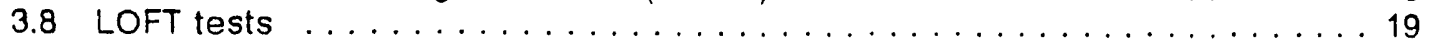

3.8.1 Steam generator steady-state heat transfer $\ldots \ldots \ldots \ldots \ldots \ldots \ldots \ldots$

3.8.2 Separator performance ........................ 21

3.8.3 LOCA tests LP-SB-01, LP-SB-02, LP-SB-03, L2-5, L3-5, L3-6 and L3-7 . . . 22

3.8.4 Intact circuit fault tests $L P-F W-01, L 9-3$ and $L 9-4 \ldots \ldots \ldots \ldots \ldots$

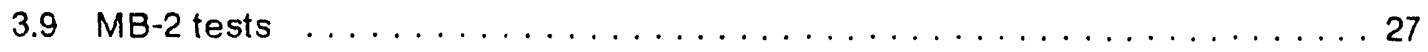

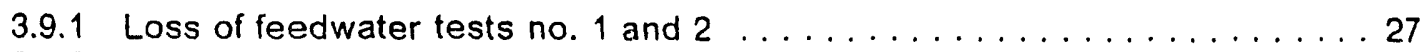

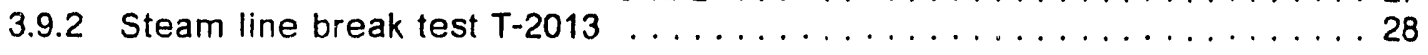

3.10 SPES loss of feedwater test $($ ISP-22) $\ldots \ldots \ldots \ldots \ldots \ldots \ldots \ldots \ldots \ldots \ldots \ldots$

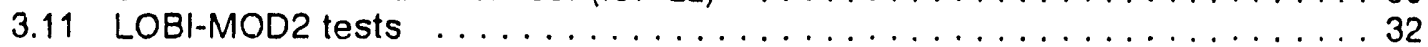

3.11.1 Steam generator steady-state heat transfer $\ldots \ldots \ldots \ldots \ldots \ldots \ldots \ldots$

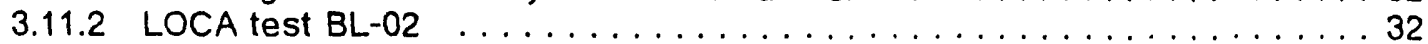

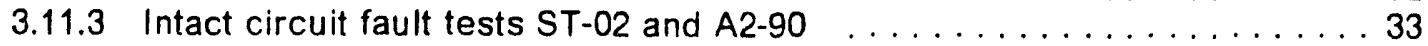

3.11 .4 Steam generator tube rupture test $\mathrm{BL}-21 \ldots \ldots \ldots \ldots \ldots \ldots \ldots \ldots \ldots$

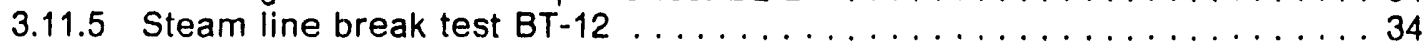

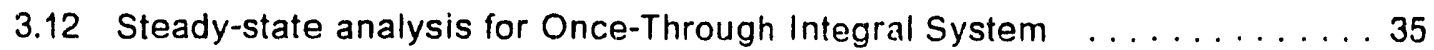

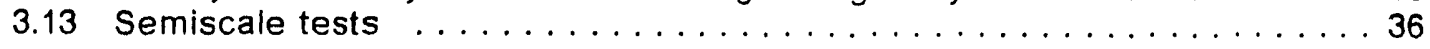

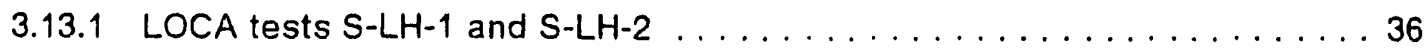

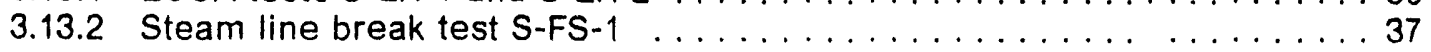

3.14 Studies performed at Texas A\&M University $\ldots \ldots \ldots \ldots \ldots \ldots$

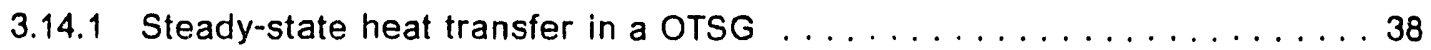

3.14.2 Steady-state heat transfer in a U-tube $S G \ldots \ldots \ldots \ldots \ldots \ldots \ldots$ 


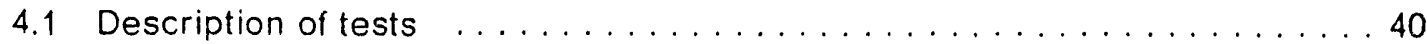

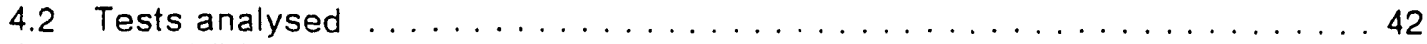

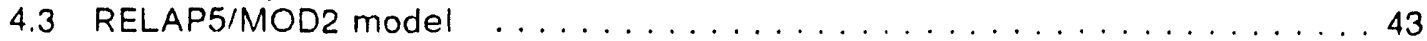

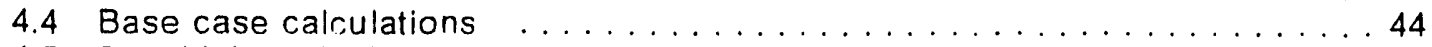

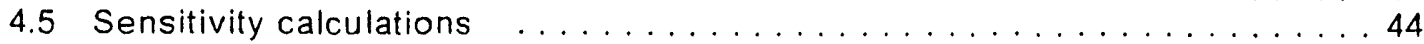

\section{ASSESSMENT OF STEAM GENERATOR MODELLING DEFICIENCIES . . . . . 45}

5.1 Primary to secondary heat transfer under normal operating conditions . . . 46

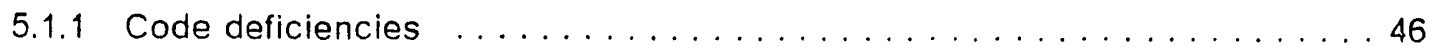

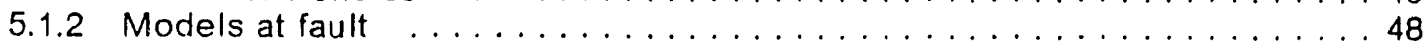

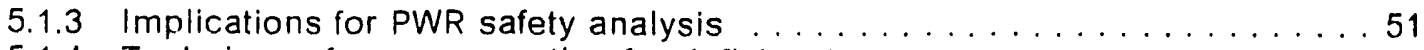

5.1 .4 Techniques for compensating for deficiencies $\ldots \ldots \ldots \ldots \ldots \ldots \ldots \ldots$

5.1 .5 RELAP5/MOD3 considerations ....................... 54

5.2 Secondary side inventory under normal operating conditions $\ldots \ldots 55$

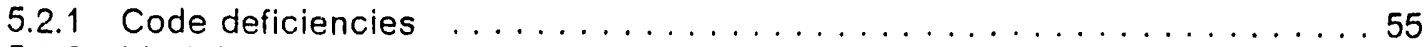

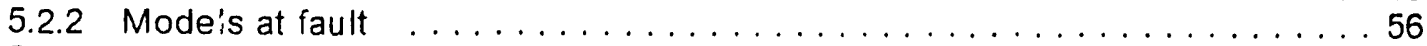

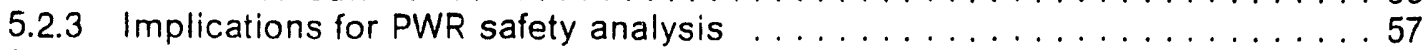

5.2.4 Techniques for compensating for deficiencies . . . . . . . . . . . . . 57

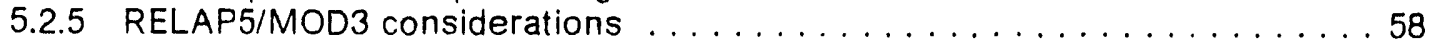

5.3 Level trajectories during fast boildown transients $\ldots \ldots \ldots \ldots$

5.3.1 Code deficiencies and models at fault . . . . . . . . . . . . . . 58

5.3.2 Implications for PWR safety analysis and compensation of deficiencies . 60

5.3.3 RELAP5/MOD3 considerations ......................60

5.4 Wall heat transfer above mixture level ..................... 61

5.5 Dynamic level swell . . . . . . . . . . . . . . . . . . . . . . 62

5.6 Liquid carryover during steam line break transients . . . . . . . . . . 63

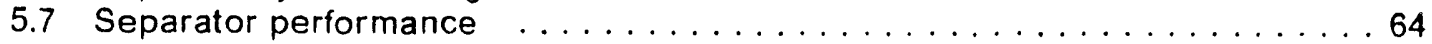

5.8 CCFL and liquid hold-up on primary side . . . . . . . . . . . . . . 65

5.9 Secondary side condensation effects during repressurisation transients . . .66

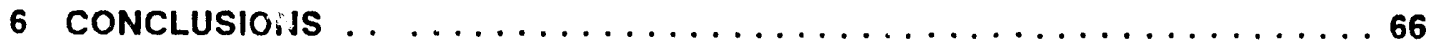

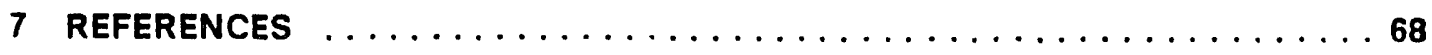

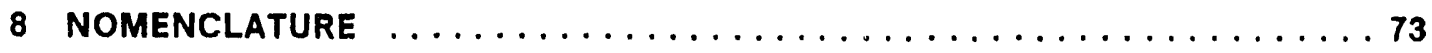

Appendix A CONCEPTUAL STEAM GENERATOR MODELS $\ldots \ldots \ldots \ldots$

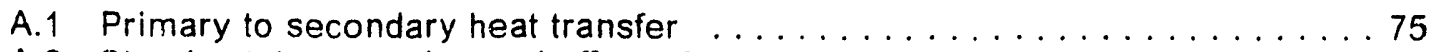

A.2 Steady-state operation and effect of recirculation flow . . . . . . . . . . . 76

A.2.1 Conceptual model ............................ 76

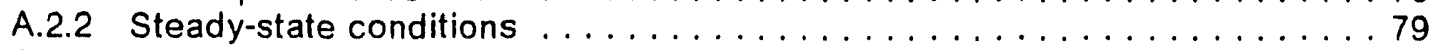

A.2.3 Effect of recirculation flow on RELAP5 separator performance $\ldots \ldots \ldots$

A.2.4 Effect of recirculation flow on $S G$ inventory . . . . . . . . . . . . 80

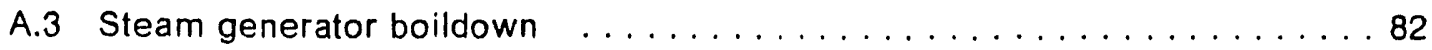

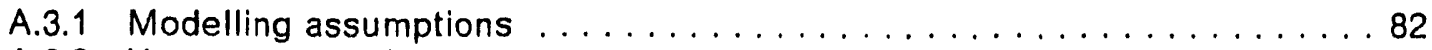

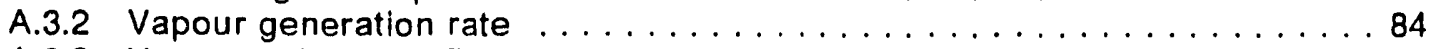

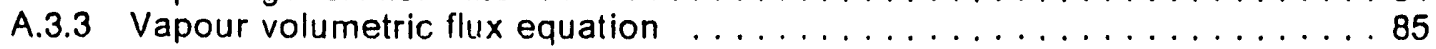




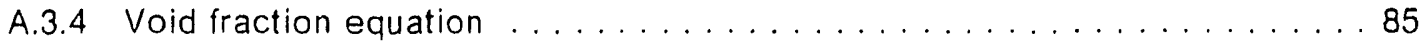

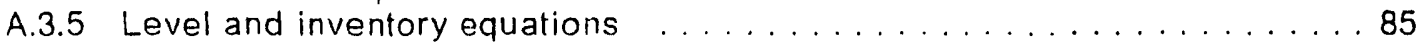

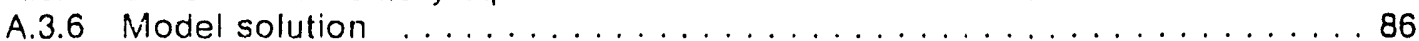

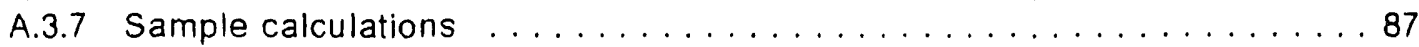

Appendix B MEASUREMENT UNCERTAINTIES FROM COMBINED ERRORS $\ldots . .90$ TABLES

Table 1. Summary of FWR plants and facilities considered in review . . . . . . 91

Table 2. Errors in total SG heat transfer coefficient HTC-A . . . . . . . . . . . 92

Table 3. Errors in total SG heat transfer coefficient HTC-O . . . . . . . . . . 95

Table 4. Wolf Creek $S G$ data ............................. 97

Table 5. SG heat transfer adjustment factors for Wolf Creek analysis . . . . . 98 98

FIGURES

Fig. 1. Sensitivity of increasing $S G$ heat transfer . . . . . . . . . . . . . . 99

Fig. 2. Sensitivity of decreasing $S G$ heat transfer . . . . . . . . . . . . . 99

Fig. 3. Variation of boiling heat transfer coefficient with heated diameter . . . 100

Fig. 4. Variation of boiling heat transfer coefficient with mass flux . . . . . . . 100

Fig. 5. Variation of boiling heat transfer coefficient with quality . . . . . . . . . 101

Fig. 6. Locations of special instrumentation in Wolf Creek steam generator . 102

Fig. 7. Nodalisation of the model ' $F$ ' steam generator . . . . . . . . . . . . . 103

Fig. 8. Errors in the calculated SG dome pressure, Wolf Creek . . . . . . . . . . 104

Fig. 9. Component presslie drop below mid-deck plate level, Wolf Creek . . 104

Fig. 10. Component pressure drop above mid-deck plate level, Wolf Creek . . 105

Fig. 11. Component pressure drop across the mid-deck plate, Wolf Creek . . . 105

Fig. 12. RELAP5/MOD2 SG secondary side HTC for Wolf Creek at $99 \%$ loud . . 106

Fig. 13. RELAP5/MOD2 SG secondary side HTC for Wolf Creek at $36 \%$ load . . 106

Fig. 14. Comparison of Chen correlation with data from Semiscale SG . . . . . . 107

Fig. 15. Liquid level trajectories for simple SG boildown transient . . . . . . . . 107

Fig. 16. Inventory trajectories for simple SG boildown transient . . . . . . . . . 108

Fig. 17. Mixture level trajectories for simple SG boildown transient . . . . . . 108

Fig. 18. Errors in HTC-A vs SG heat flux . . . . . . . . . . . . . . . . . 109

Fig. 19. Errors in HTC-O vs SG heat flux . . . . . . . . . . . . . . . . 110

Fig. 20. Errors in HTC-A vs primary to secondary temperature difference . . . 111 


\section{INTRODUCTION}

Steam Generators (SGs) play an important role in controlling the behaviour of PWRs under a wide range of normal and abnormal conditions. In some transients for example. the SG acts as an excessive heat sink, while in others its heat sink capacity may be lost completely. The SG also creates the driving force for natural circulation in the primary loops following a failure of the reactor coolant pumps, and provides the operators with a key heat removal option for controlled reactor cooldown during many types of small break LOCAs. In steam generator tube rupture accidents, the fluid conditions in the SG can have an important effect on the retention of radioactive species.

An accurate modelling of SG behaviour is therefore an important requirement for thermal-hydraulic computer codes used for PWR safety analysis. In the past however, this requirement has often been circumvented by using pessimistic modelling assumptions as a means of producing appropriate bounding solutions. With the move towards the use of best-estimate methods for licensing purposes, and an increased awareness of the role played by the SG in accident mitigation and recovery, the need to validate codes in the area of SG modelling has become increasingly evident.

The RELAP5/MOD2 code (Ransom, Wagner, Trapp, Johnsen, Miller. Kiser and Riemke, 1987) is currently being used by Nuclear Electric for the analysis of small break LOCAs and intact primary circuit fault transients in the Sizewell 'B' PWR. Since its release as a 'frozen code' in April 1985, numerous assessment calculations have been carried out in the UK and elsewhere using data from a large number of integral and separate effects experiments. Although these studies provide a wealth of information relevant to SG modelling in the code, this information has never been assessed together with this objective in mind.

The purpose of the present study is to carry out an assessment of SG modelling in RELAP5/MOD2. Particular areas of interest are SG heat transfer under steady-state conditions and transient level behaviour. The assessment includes the following tasks

- A review of RELAP5/MOD2 assessment calculations in which deficiencies in SG modelling have been identified (even though they may not have been highlighted).

- Detailed calculations of SG performance for a series of steady-state commissioning tests carried out on the Wolf Creek PWR at various load conditions.

- Analytical investications of the phenomena involved in normal and abnormal SG operation.

The objectives of the stı,dy are to identify code deficiencies in SG modelling together with the specific models responsible, quantify the errors involved and assess the implications for PWR safety analysis. Methods for compensating for the code deficiencies through changes to the input deck are also discussed. Consideration is also given as to whether the deficiencies identified will still be present in the successor code RELAP5/MOD3, and recommendations for future code development and assessment studies are made. These may be addressed in a subsequent study aimed at assessing SG modelling in RELAP5/MOD3. 


\section{PRELIMINARY CONSIDERATIONS}

\subsection{Conceptual steam generator models}

In order to obtain a better understanding of SG behaviour and its sensitivity to key parameters, it is useful to construct simple analytical models of the main phenomena involved in normal and abnormal operation. A number of such 'conceptual' models are developed in Appendix $A$, and the results from these models are referred to in the main body of this report. The particular areas addressed are

- Primary to secondary heat transfer.

- Steady-state operation and effect of recirculation flow.

- Steam generator boildown.

Although the models developed are very simple and somewhat idealistic, they are still believed to be representative. In the context of the present study, they are particularly useful for interpreting the results of RELAP5 analyses and for identifying modelling deficiencies responsible for apparent code deficiencies.

\subsection{Steam generator initialisation}

Part of the present study is concerned with the ability of RELAP5/MOD2 to model SG performance under steady-state, normal operating (or start-up) conditions. Before carrying out an assessment, it is instructive to examine how many of the major SG parameters may be specified directly to be equal to plant values, and the key phenomena which govern the calculation of the others.

To focus the discussion, consider the steady-state solution for a single SG which has been isolated from the rest of the NSSS, using a time dependent junction (TDJ) and volume (TDV) connected to the SG inlet plenum to set the primary loop flow rate and hot leg temperature. A second TDV attached to the SG outlet plenum may be used to fix the primary side pressure in the pump suction leg, which completely defines the primary side boundary conditions. The pressure specified in the hot leg TDV only affects the properties of the fluid entering the SG inlet plenum and may therefore be controlled to be equal to the pressure calculated in the inlet plenum. The fluid temperature specified in the pump suction TDV has no effect on the calculation (provided forward flow is specified).

On the secondary side, the required feedwater temperature may be specified using a TDV connected to the top of the downcomer. A TDV at the top of the steam dome may be used to set outlet pressure, and this may be controlled to achieve the desired pump suction leg temperature, thereby ensuring that the total power delivered to the SG matches that measured on the plant. The SG can be operated over a range of values of downcomer water level and thus, in principle', the water level in the calculation may be controlled to match the plant value. The recirculation flow can also be fixed at the plant value by adjusting loss coefficients in the recirculation loop.

With the above arrangement, steady-state conditions can be imposed by controlling the feedwater flow (via a TDJ) to be equal to the calculated steam outlet flow. This leaves three major parameters to be found by the code and which could therefore differ from those measured on the plant: secondary side pressure, steam/feedwater flow and liquid inventory (i.e. the total mass of liquid in the SG). Since the primary side power and temperature are effectively fixed at plant values by the boundary conditions, the secondary side pressure calculated by the code will correspond to the

1 As discussed later, in practice, this may not always be possible. 
value viecessary to deliver this power into the secondary side. Any error in this pressure may therefore be attributed to errors in primary to secondary side heat transfer modelling - e.g. if the models under-predict heat transfer overall, the code will compensate by lowering the secondary side pressure relative to the plant value. An error in the steam/feedwater flow on the other hand. may be attributed to errors in the vapour generation rate models. The accuracy of the liquid inventory pledicted by the code will depend on the accuracy of the liquid distribution calculation.

The above specification is often adopted when initialising a SG for whole plant calculations, as it allows the reactor thermal power (including the pump power) and primary side temperatures to be matched with the measured values. Clearly, steady-state solutions could also be obtained with different sets of parameters specified as boundary conditions. For example, the feedwater and steam flows may be set equal to plant values and the steam outlet pressure left uncontrolled, leaving the pump suction leg temperature to be determined by the code. In this case, the predicted secondary side pressure will correspond to the value for which the total steam generation rate in the heated riser is equal to the specified steam outlet flow rate. The accuracy of this prediction will depend on the accuracies of the code's models for both vapour generation and primary to secondary side heat transfer. Since the calculaied pressure effectively forces the total steam generation rate to be equal to the plant value, an error in the pump suction leg temperature may then be attributed soiely to errors in the vapour generation rate models.

The important point to note is that, when initialising a SG, there are three major parameters that cannot be specified directly to match plant values. Two of these parameters relate to the thermal performance of the SG, and their prediction depends on the modelling of primary to secondary side heat transfer and vapour generation. However, since most of the SG fluid will be at saturation, it is likely that the calculation of vapour generation will be relatively accurate. Thus, in both examples described above, any errors in the thermal modelling of the SG are likely to be seen mainly in the predicted secondary side pressure.

The other phenomenon where modelling deficiencies could cause a major parameter to differ from a plant value is the calculation of the liquid distribution throughout the SG. In the above examples, in which the downcomer level and recirculation flow were specified, the pertinent parameter was the liquid inventory. This is the most likely situaticn, as the downcomer level and recirculation flow are generally well known on the plant, whereas the inventory is not.

The present study includes an assessment of RELAP5/MOD2's modelling of SG steady-state heat transfer and inventory, for which a number of analysts have suggested that deficiencies may be present.

\subsection{Steam generator heat transfer}

In order to examine the calculation of SG heat transfer in RELAP5/MOD2 in more detail and to acquire a feeling for its sensitivity to key parameters, it is useful to construct a simple model of the processes taking place. Consider therefore, the heat transfer across a short length of a single tube. In Appendix A.1, it is shown that by solving the steady-state 10 heat conduction equation, the total heat transfer rate between the primary and secondary sides, $Q$ (Watts), may be approximated by:

$$
Q=\frac{2 \pi R_{P} \delta L\left(T_{P}-T_{S}\right)}{\left[\frac{R_{P}}{R_{P}+t}\right] \frac{1}{H_{S}}+\frac{1}{H_{P}}+\frac{t}{k}}
$$

where

$T_{p} \quad$ primary side temperature 


$\begin{array}{ll}T_{s} & \text { secondary side temperature } \\ \delta L & \text { length of tube considered } \\ R_{p} & \text { tube radius on primary side } \\ t & \text { tube thickness } \\ k & \text { tube thermal conductivity } \\ H_{S} & \text { secondary side heat transfer coefficient } \\ H_{p} & \text { primary side heat transfer coefficient }\end{array}$

The principal assumptions behind this result are that the thermal conductivity is constant across the tube and that the tube thickness is sufficiently small such that $\ln \left(1+t / R_{p}\right) \simeq t / R_{p} .^{2}$

Equation (1) shows how various SG parameters affect the local heat transfer across a short length of tube. Furthernivie, by taking $T_{p}$ and $T_{s}$ to represent appropriate average primary and secondary temperatures, and setting $\delta L$ equal to the combined length of all tubes, it may also be used to 'characterise' the overall primary to secondary heat transfer. The equation then shows that, for a given average primary to secondary temperature difference, an increase in SG heat transfer may be achieved by increasing one or all of the following parameters

- primary or secondary heat transfer coefficient

- tube conductivity

- heated length

Also, although less obvious, for a fixed primary side radius, an increase in heat transfer may be achieved by decreasing the tube wall thickness.

Equation (1) also enables rough estimates to be obtained for the sensitivity of SG heat transfer to changes in the individual parameters. For the Sizewell ' $B$ ' SG (Harwood, 1986)

$$
\begin{aligned}
& R_{p}=7.724 \times 10^{-3} \mathrm{~m} \\
& t=1.016 \times 10^{-3} \mathrm{~m}
\end{aligned}
$$

and for normal operating conditions

$$
\mathrm{k} \simeq 19 \mathrm{~W} \mathrm{~m}^{-1}{ }^{\circ} \mathrm{K}^{-1}
$$

In addition typical 'representative' values for the primary and secondary heat transfer coefficients are 40000 and 30000 , respectively. Using these parameter values to evaluate the terms in the denominator of equation (1) gives

$$
\begin{aligned}
& {\left[\frac{R_{P}}{R_{P}+t}\right] \frac{1}{H_{S}}=2.9 \times 10^{-5}} \\
& \frac{1}{H_{P}}=2.5 \times 10^{-5} \\
& \frac{t}{k}=5.3 \times 10^{-5}
\end{aligned}
$$

2 For the Sizewell ' $B$ ' PWR, $\ln \left(1+t / R_{p}\right)=0.1235$ and $t / R_{p}=0.1315$. 
These terms are all of a similar magnitude, which indicates that heat transfer behaviour at normal operating conditions is not dominated by any one of the three processes described - i.e. primary side heat transfer, secondary side heat transfer, or tube conduction. Also, as evident from the nature of equation (1), the heat transfer rate will not be particularly sensitive to an increase in the primary or secondary side heat transfer coefficient on its own, or the tube wall conductance (i.e. k/t). Moreover, successive increases in these parameters will have a diminishing effect on increasing heat transfer. This is illustrated in Fig. 1, which shows the factor increase in heat transfer rate for a given temperature difference that results from an increase in the primary or secondary heat transfer coefficients, thermal conductivity or heated length, or a decrease in the tube thickness. In particular, for the values assumed, the maximum increase in heat transfer that could result from an increase in the secondary side heat transfer coefficient is less than $40 \%$. Note also that Fig. I shows that the increase in wall conductance that results from a reduction in tube wall thickness (for a fixed primary side radius), outweighs the corresponding decrease in heat transfer area.

In the case of a decrease in heat transfer coefficient or wall conductance, the opposite effect occurs as the corresponding term in equation (1) quickly dominates the heat transfer behaviour. This is clearly evident from Fig. 2, where it can be seen that a decrease in the heat transfer rate varies in a linear manner with a decrease in the primary or secondary heat transfer coefficient, tube conductivity or heated length, or an increase in tube thickness.

It must be stressed that Fig. 1 and Fig. 2 are based on typical representative values, and thus the quantitative results shown should only be taken as a guide to the heat transfer sensitivity. Nevertheless, many of the qualitative effects remonstrated are believed to be correct. In particular, both figures clearly show that the heat transfer is most sensitive to the heated length, which indicates the importance of obtaining an accurate estimate for this parameter ${ }^{3}$. Also, Fig. 1 indicates that, if an increase in the calculated heat transfer rate is desired, it is more effective to artificially increase the thermal conductivity than either the primary or secondary side heat transfer coefficients, although an increase in the heated length would have an even greater effect. Fig. 2 on the other hand, while initially presented to illustrate the sensitivity of SG heat transfer to a decrease in heat transfer coefficient or wall conductance, also shows the situation that could arise if the primary or secondary heat transfer coefficient degrades.

\subsection{Chen correlation}

One of the issues under consideration in the present study is a tendency for RELAP5/MOD2 to under-predict SG heat transfer under steady-state, normal operating conditions. Several analysts have attributed this deficiency to the use of the Chen (1966) correlation (albeit modified) to represent boiling heat transfer in a tube bundle, noting in particular that the correlation was developed using data from experiments carried out in tubes and annuli. Thus, before carrying out a review of RELAP5/MOD2 calculations which have exhibited this deficiency, it is useful to state the Chen correlation and the modifications adopted in the code.

\section{Saturated boiling}

The Chen correlation may be applied to both saturated and subcooled boiling but has different forms in each case. For saturated boiling (i.e. saturated nucleate boiling and forced convection vaporisation), the standard form of the correlation is

$$
q^{\prime \prime} w=H_{m i c}\left(T_{w}-T_{s}\right)+H_{m a c}\left(T_{w}-T_{f}\right)
$$

3 In RELAP5, the heated length need not be equal to the hydraulic length and, in fact. different heated lengths may be specified independently on the primary and secondary sides. 
where

$$
\begin{aligned}
& H_{\text {mic }}=\left[\frac{0.00122 k_{f}^{0.79} C_{p f}^{0.45} \rho_{f}^{0.49} \Delta T_{s a t}^{0.24} \Delta P_{s a t}^{0.75}}{\sigma^{0.5} \mu_{f}^{0.29} h_{q f}^{0.24} \rho_{g}^{0.24}}\right] \mathrm{S} \\
& H_{\text {mac }}=\left[0.023 \frac{k_{1}}{D_{e}} \operatorname{Pr}_{f}^{0.4} \operatorname{Re}_{f}^{0.8}\right] \mathrm{F} \\
& R e_{f}=\frac{(1-x) G D_{e}}{\mu_{f}} \\
& F=1.0 \quad X_{t t}^{-1} \leq 0.1 \\
& =2.35\left(X_{t t}^{-2}+0.213\right)^{0.736} X_{t t}^{-1}>0.1 \\
& \mathrm{X}_{\mathrm{tt}}^{-1}=\left(\frac{\mathrm{x}}{1-\mathrm{x}}\right)^{0.9}\left(\frac{\rho_{\mathrm{f}}}{\rho_{\mathrm{g}}}\right)^{0.5}\left(\frac{\mu_{\mathrm{g}}}{\mu_{\mathrm{f}}}\right)^{0.1} \quad \text { Martinelli flow parameter } \\
& S=\left[1+0.12\left(R e_{T P}\right)^{1.14}\right]^{-1} \quad R e_{T P}<32.5 \\
& =\left[1+0.52\left(R_{T} e_{T P}\right)^{0.78}\right]^{-1} \quad 32.5 \leq R e_{T P}<70.0 \\
& =0.1 \quad R e_{T P} \geq 70.0 \\
& R e_{T P}=\frac{(1-x) G D_{e}}{\mu_{f}} F^{1.25} \times 10^{-4}
\end{aligned}
$$

and the rest of the notation is defined in the Nomenclature section. Note that for saturated boiling, $T_{1}=T_{s}$ (essentially), and thus equation (2) may be written

$$
q^{\prime \prime}{ }_{w}=\left(H_{\text {mic }}+H_{\text {mac }}\right)\left(T_{w}-T_{s}\right)
$$

The term $\mathrm{H}_{\text {mic }}$ in the Chen correlation represents the contribution to heat transfer due to nucleate boiling, or microconvection, and is derived from the Forster-Zuber correlation for pool boiling (Forster and Zuber, 1955). The factor $S$ in equation (3) accounts for a suppression of nucleate boiling under forced convection conditions and increasing flow rate, due to a reduction in the thermal boundary layer thickness and, consequently, a degradation of the conditions for growth of vapour bubbles. The term $\mathrm{H}_{\mathrm{mac}}$ in the Chen correlation represents the contribution from single phase convection, or macroconvection, and is based on the Dittus-Boelter (Dittus and Boelter, 1930) equation with a modifying factor $F$ to account for an enhancement of heat transfer due to an increase in the mixture velocity.

In RELAP5/MOD2, the following modifications are made to the Chen correlation (Dimenna, Larson, Johnson, Larson, Miller, Streit, Hanson and Kiser, 1988):

1. The actual value of $\mathrm{H}_{\text {mac }}$ used in equation (2) is taken as the maximum of that given by equation (4) and a heat transfer coefficient for forced convection to fully developed laminar flow:

$$
H=4.36 \frac{k_{f}}{D_{e}}
$$

For normal SG operating conditions, equation (4) will always provide the maximum value.

2. The suppression factor $S$ is replaced by the modified suppression factor, $S^{*}$ :

$$
\begin{aligned}
S^{*} & =1 \\
& =1-2(1-S)(\alpha-0.3) \quad 0.3<\alpha \leq 0.8 \\
& =S \quad \alpha>0.8
\end{aligned}
$$

This has the effect of increasing heat transfer for void fractions below 0.8 . 
3. The value of $S$ for $R e_{T p} \geq 70$ is set to 0.0797 rather than 0.1 (see equation (8)). presumably to make $S$ vary continuously with $R_{T}$.

4. Further modifications may be made if vertical stratified flow is predicted to occur in a volume, but these need not be considered at the present stage of the investigation.

The code assumes that saturated boiling occurs if post-CHF conditions have not been reached and if

$$
T_{w} \geq T_{s} \text { and } T_{f} \geq T_{s}-5^{\circ} \mathrm{C}
$$

and deposits the heat transferred from the wall into the liquid phase (i.e. the wall is assumed to be wet).

\section{Subcooled boiling}

For subcooled boiling, the Chen correlation is generally applied with the following modifications

$$
F=1, \quad R e_{T P}=\frac{G D_{e}}{\mu_{f}}
$$

Also, in equation (2), $T$, is no longer equal to $T_{s}$.

In RELAP5/MOD2, the following modifications are introduced

1. $F$ is linearly interpolated between the saturated value at zero subcooling and the subcooled value (i.e. 1) at $5{ }^{\circ} \mathrm{C}$ subcooling, so that $H_{\text {mac }}$ varies smoothly between subcooled and saturated boiling.

2. A modified suppression factor, $S^{*}$, is calculated from equation (11) and then multiplied by a 'boiling heat transfer factor' which is linearly interpolated between 0 and 1 over the range

$$
\left[\Delta T_{\text {onb }}-2, \Delta T_{\text {onb }}\right], \text { or }\left[\Delta T_{\text {nvg }}-2, \Delta T_{\text {nvg }}\right]
$$

where $\Delta T_{\text {onb }}$ is the wall superheat required for the onset of nucleate boiling, $\Delta T_{\text {nvo }}$ is the wall superheat required for net vapour generation, and the maximum value calculated is used4. This procedure is designed to ensure that $H_{\text {mic }}$ is introduced smoothly. However, the formulation of the boiling heat transfer factor assumes that subcooled boiling will only take place while the void fraction is below 0.3 , in which case the modified suppression factor $S^{*}$ will be unity. The present authors have observed that this is not always true in RELAP5/MOD2 calculations of boiling heat transfer in a SG riser. Consequently, a potential discontinuity exists in the code in the transition of $H_{\text {mic }}$ between subcooled and saturated boiling, due to the change in the effective liquid flow rate used in the calculation of the unmodified suppression factor.

3. As for saturated boiling, further modifications may be made if vertical stratified flow is predicted to occur in a volume, but again these need not be considered at the present stage of the investigation.

Outside the above interpolation procedures, the code assumes that subcooled boiling occurs if saturated conditions have not been reached and

$$
T_{w} \geq T_{s} \text { and } T_{f}<T_{s}-5{ }^{\circ} \mathrm{C}
$$

For $T_{w}<T_{3}$, the code assumes convective heat transfer to single phase liquid and, for turbulent forced convection conditions, applies the Dittus-Boelter equation (i.e. $H_{\text {mac }}$ with $\left.F=1\right)$.

\footnotetext{
4 Separate equations are used to calculate $\Delta T_{\text {onb }}$ and $\Delta T_{\text {mgg }}$.
} 


\subsection{Steam generator inventory}

The previous two sections have highlighted a number of aspects relating to $S G$ heat transfer modelling in RELAP5/MOD2. As discussed in Section 2.2 however, another important area where modelling deficiencies can lead to inaccurate predictions of SG performance is the calculation of liquid distribution on the secondary side. Further, for the particular case where the SG is initialised with a given downcomer level and recirculation flow, such deficiencies will be manifested in an incorrect calculation of the initial liquid inventory.

Results obtained from a number of code assessment studies that have been reported in the literature do seem to indicate that RELAP5/MOD2 under-predicts SG inventory under steady-state conditions. These calculations will be reviewed later. It should be noted however, that the true inventory may not always be known accurately, and often an inaccuracy in the calculation of initial inventory may only be inferred from errors in the prediction of a related parameter during the course of a transient analysis.

The calculation of SG inventory in RELAP5/MOD2 depends, primarily, on both the code's models for interphase friction and subcooled void, and the geometric modelling of the SG components (e.g. downcomer flow area). The latter should not be overlooked, as the appropriate details are not always known accurately and additional errors may be introduced when setting up a 1D representation. Nevertheless, a number of previous studies (e.g. Putney, 1988; 1989) have shown that RELAP5/MOD2 over-predicts interphase friction in the bubbly and slug regimes for low flow conditions in PWR-type fuel assemblies. Evidently, if this deficiency is also present for flows in a SG tube bundle at normal operating conditions, it will tend to lower the inventory prediction.

It should also be recognised that the calculations of SG heat transfer and inventory in RELAP5/MOD2 are not totally independent. For example, for a fixed SG power or feedwater/steam flow, an under-prediction of SG heat transfer will result in a lower secondary side pressure, which will tend to increase the voidage and thus reduce the inventory. (An incorrect pressure distribution in the heated riser may also have an effect). Also, since the modified Chen suppression factor ( $S^{*}$ ) used in the code reduces with increasing void fraction in the range $0.3<\alpha<0.8$ (equation (11)), an over-prediction of interphase friction may result in a lower suppression factor and thus reduce the secondary side heat transfer coefficient. The actual situation is a little more complex than this because the code evaluates the Chen correlation using calculated values of volume fraction and phase velocity (rather than quality), but the variation of $S^{\text {" }}$ with void fraction is likely to dominate.

\subsection{Modelling practices and their effect on heat transfer and inventory}

Before carrying out a review of RELAP5/MOD2 calculations which have revealed deficiencies in SG modelling, it is important to point out certain practices that are sometimes adopted in plant modelling that can have a significant impact on code predictions, and thus obscure the performance of the physical models.

The first point to note is that the tendency for RELAP5/MOD2 to under-predict SG heat transfer at steady-state conditions has been known for some time, and is often compensated for by adjusting appropriate input parameters. Thus, when reviewing calculations with the aim of quantifying the modelling errors and establishing any effects of scale, it is important to ascertain whether the results under consideration were obtained using a physically correct geometric description and best-estimate values of thermal conductivity. On a related issue, the different definitions of the secondary side heated diameter (D.) used by analysts include hydraulic diameter, tube $O D$ and inter-tube gap. For the Sizewell ' $B$ ' $S G$, the corresponding values are $2.765,1.748$ and $0.741 \mathrm{~cm}$, respectively. Fig. 3 shows how the RELAP5/MOD2 form of the Chen correlation (Section 2.4) varies with diameter for a set of 
thermal-hydraulic conditions 'typical' of the upper regions of the hot side of a PWR $S G$ at full power ${ }^{5}$. It can be seen that as the heated diameter is reduced from the hydraulic diameter to the inter-tube gap, the heat transfer coefficient increases by approximately a factor of 2 (the increase is slightly more for the standard form of the Chen correlation). Although Section 2.3 showed that the primary to secondary side heat transfer rate is not particularly sensitive to increases in the secondary side heat transfer coefficient, a factor of 2 increase could typically result in an increase of around $10 \%$ or more in the local heat transfer rate (Fig. 1), which is not insignificant.

The diameter dependence of the Chen and modified Chen correlations arises from the suppression factor in $H_{\text {mic }}$ and the Dittus-Boelter equation in $H_{\text {mac }}$. The Forster-Zuber equation in $H_{m i c}$ and the $F$ factor in $H_{m a c}$ are both independent of diameter (see equations (2) to (8)). Fig. 3 shows that the suppression factor is more sensitive to diameter over the range of interest. At very small diameters however, the Dittus-Boelter contribution, which varies as $\mathrm{D}_{\theta}^{-02}$, increases dramatically.

Another area where input parameters for RELAP5/MOD2 calculations may be set differently from the true plant values concerns the performance of the SG separator. Several analysts have encountered difficulties in obtaining acceptable steady-state conditions due to the periodic emptying and filling of this component or the occurrence of steam carryunder into the downcomer. Such difficulties may well be a consequence of an under-prediction of the liquid inventory, and some analysts have overcome the problem by setting the liquid level in the downcomer artificially high, or by reducing the friction losses in the recirculation loop. As shown in Appendix A.2, both practices result in an increase in the recirculation flow, which has the effect of reducing the void fraction of the fluid entering the separator, thereby reducing or eliminating steam carryunder ${ }^{6}$. However, as also shown in Appendix A.2, an increase in the recirculation flow will result in an increase in the liquid inventory (more so if it is achieved by raising the SG water level), which makes it difficult to quantify deficiencies in the models governing the inventory calculation.

An increase in the recirculation flow may also affect the calculation of the primary to secondary heat transfer. Fig. 4 shows how an increase of $40 \%$ in recirculation ratio' affects the boiling heat transfer coefficient calculation in RELAP5/MOD2, for the typical conditions considered in Fig. 3 and a heated diameter equal to the Sizewell ' $B$ ' tube nominal OD. Evidently, the increase in mass flux results in an increase in $H_{\text {mac }}$ (through the Dittus-Boelter contribution) and a decrease in $H_{\text {mic }}$ (through the suppression factor). For the particular conditions examined, these two effects largely cancel and the total heat transfer coefficient is relatively constant.

In reality however, as demonstrated in Appendix A.2, an increase in mass flux will also tend to reduce the quality and thus void fraction throughout the saturated boiling region in the SG riser (but leave the beginning of saturated boiling largely unchanged). Fig. 5 shows how changes in quality affect the boiling heat transfer coefficient calculation in RELAP5/MOD2 for a fixed mass flux and the same typical conditions considered in Fig. 4. For qualities between 0.04 and 0.2 , the heat transfer coefficient used in RELAP5 increases significantly with decreasing quality, whereas outside this range it is largely independent of quality. This variation with quality is evidently a consequence of the void fraction dependence of the modified suppression factor, $S^{*}$, and the variation of void fraction with quality. In contrast, the standard form

5 When evaluating the modified suppression factor in Fig. 3 (equation (11)), the RELAP5/MOD2 models for interphase and wall friction were extracted from the code and used to determine void fraction from quality and mass fux for steady-state, fully developed flow conditions.

6 In RELAP5/MOD2, steam carryunder from the separator is modelled as a simple function of the total liquid fraction.

7 The recirculation ratio is defined as the total downcomer flow divided by the feedwater flow, with some allowance for the blowdown flow. 
of the Chen correlation, which has no direct dependence on void fraction, is relatively unaffected by changes in quality.

It may therefore be concluded that an increase in the recirculation flow is likely to lead to an increase in the secondary side heat transfer coefficient used by RELAP5/MOD2.

Finally, in the initialisation procedure described in Section 2.2 it was conveniently assumed that the code would be forced to calculate the correct recirculation flow by adjusting appropriate pressure loss coefficients. This however, may not always be the case, which further complicates an assessment of modelling deficiencies. Moreover, the failure to predict the correct recirculation flow using physically correct loss coefficients, should strictly be attributed to deficiencies in the modelling of two-phase friction effects (and liquid distribution). However, since the two-phase loss coefficients are not generally well known, and, apart from the recirculation ratio, errors in the two-phase friction modelling are unlikely to have a very large influence on predicted SG performance, this area of SG modelling will not be addressed in the present study.

\subsection{Measure of steam generator heat transfer}

As mentioned earlier, one area of particular interest in the present study is the ability of RELAP5/MOD2 to model SG heat transfer under steady-state, normal operating (or start-up) conditions. In order to quantify modelling errors in this area and to establish their dependence on SG conditions and scale, it is desirable to define a parameter which provides a measure of the overall primary to secondary heat transfer. This parameter should have some physical meaning, but be simple enough to be evaluated from the information normally reported in plant assessment studies (i.e. measured and calculated initial values for the main plant variables). An obvious candidate is the secondary side pressure, as most RELAP5 analyses attempt to match calculated and measured primary side conditions at steady-state, and thus any deficiencies in SG heat transfer modelling will manifest themselves in an error in the predicted secondary side pressure (see Section 2.2). However, the magnitude of this error may not provide a particularly useful measure of the underlying modelling errors as the pressure error would be expected to reduce with reactor power (as the primary to secondary side temperature difference reduces), making it difficult, for example, to establish whether the modelling errors vary with local heat flux. Also, the error in secondary side pressure takes no account of inaccuracies in the values of the other parameters which affect SG heat transfer (e.g. cold leg temperature).

A better measure of SG heat transfer is provided by the total primary to secondary heat transfer coefficient defined by

$$
H T C=\frac{\bar{q}^{\prime \prime}}{\Delta T}=\frac{\bar{q}^{\prime \prime}}{T_{P}-T_{S}}
$$

where

$$
\bar{q}^{\prime \prime}=\frac{W \Delta h}{N_{t} \pi D_{0} \bar{L}}=\frac{W\left[h_{f}\left(T_{1}, P\right)-h_{f}\left(T_{0}, P\right)\right]}{N_{t} \pi D_{0} \bar{L}}
$$

Here $\bar{q}^{\prime \prime}$ is the average $S G$ heat flux and $T_{p}$ and $T_{S}$ are appropriate average primary and secondary side temperatures, respectively. Other variables in equations (15) and (16) are defined as

$W$ total mass flow rate on primary side of SG U-tubes $\left(\mathrm{kg} \mathrm{s}^{-1}\right)$

$T_{i}, T_{0}$ inlet and outlet primary side temperatures

$P \quad$ primary side pressure 
h, liquid enthalpy (from steam tables)

$N_{1} \quad$ total number of U-tubes

Do OD of U-tubes

$\bar{L}$ average length of U-tubes

Since most of the fluid on the secondary side of a SG U-tube bundle is close to saturation conditions, $T_{s}$ in equation (15) may be approximated by the saturation temperature. An appropriate value for $T_{p}$ is less obvious, particularly as most RELAP5 analyses reported in the literature only quote initial values for $T_{i}$ and $T_{0}$. However, for the Wolf Creek calculations described in Section 4, the U-tube length-weighted average primary side temperature is given by

$$
T_{P L}=\omega T_{1}+(1-\omega) T_{0}
$$

where $\omega$ lies between 0.324 and 0.332 for reactor powers in the range 36 to $99 \%$ load (i.e. the temperature profile is essentially load independent). There is no guarantee that this result applies to other plants and facilities, or even that it represents the 'effective' primary temperature that controls the SG heat transfer. Nevertheless, it is reasonable to assume that the appropriate value of $T_{p}$ lies somewhere between the arithmetic average of the inlet and outlet primary side temperatures:

$$
T_{A}=0.5\left(T_{i}+T_{0}\right)
$$

and the outlet temperature itself (i.e. To).

For the purposes of the present study therefore, two definitions of HTC have been considered; one based on $T_{P}=T_{A}$, the other based on $T_{P}=T_{0}$. These parameters will be referred to as HTC-A and HTC-O respectively, and the corresponding primary to secondary temperature differences in equation (15) will be denoted by DT-A and DT-O.

The parameter HTC just described combines the important variables which control SG heat transfer, to provide a gross measure of the overall primary to secondary side heat transfer effect. In particular, it accounts for the reduction in the primary to secondary temperature difference with decreasing reactor power, and its calculation is sensitive to inaccuracies in both the primary and secondary side fluid conditions. Also, from the simple analysis performed in Section 2.3, the parameter woulo be expected to behave as

$$
\frac{2 \pi R_{p} N_{t} L}{\left[\frac{R_{p}}{R_{p}+t}\right] \frac{1}{H_{S}}+\frac{1}{H_{p}}+\frac{t}{k}}
$$

where the variables are defined under equation (1) (or above) and represent appropriate average values.

An indication of the extent of any SG modelling errors in a RELAP5 analysis may therefore be obtained by evaluating the \% error in the value of HTC calculated by the code; i.e.

$$
100 \times \frac{H T C_{\text {calc }}-H T C_{\text {meas }}}{H T C_{\text {meas }}}
$$

(so that a negative error is indicative of an under-prediction of SG heat transfer). This has been done for all RELAP5/MOD2 analyses found in the literature, which provide sufficient information on the measured and predicted initial conditions. The results are summarised in Table 2 (HTC-A) and Table 3 (HTC-O), along with some other details of the calculations. These results will be referred to and discussed in subsequent sections. 
One drawback of using the parameter HTC to quantify errors in SG heat transfer modelling errors is that, because $\Delta h$ and $\Delta T$ can be small (particularly at low power), the uncertainty in the measurer value can be large. Thus, in order to make it easier to ascertain whether errors in the calculated values of HTC are significant. Table 2 and Table 3 also include an estimate of this uncertainty. It must be stressed however, that these estimates are very approximate and should only really be used as a guide to the likely data uncertainty. They were obtained using information available on the measurement errors for the datasets considered (where available) and some engineering judgement. The actual procedure adopted was as follows.

- Individual uncertainties were determined for $W, \Delta T$ and $\Delta h$. For $\Delta h$ and $\Delta T$, the uncertainties were evaluated as the RMS combination of the uncertainties in the individual components.

- For each of $W, \Delta h$ and $\Delta T$ alone, the corresponding uncertainty in HTC was evaluated.

- An uncertainty in HTC due to the uncertainties in both $W$ and $\Delta h$ was calculated as the RMS combination of the uncertainties due to each parameter alone. An uncertainty in HTC due to the uncertainties in both $W$ and $\triangle T$ was calculated in the same way.

- The total uncertainty in HTC was calculated as the arithmetic average ${ }^{8}$ of the above results. This was felt to provide a better indication of the true uncertainty than the RMS combination of the uncertainties due to $W, \Delta h$ and $\Delta T$ alone, as in many situations, some error cancellation may be expected between the uncertainties in $\Delta \mathrm{h}$ and $\Delta \mathrm{T}$.

\section{REVIEW OF RELAP5/MOD2 ASSESSMENT CALCULATIONS}

This section presents a review of RELAP5/MOD2 analyses carried out in the UK and elsewhere (mainly under ICAP or CSNI), that have revealed potential code deficiencies in the area of SG modelling. The review considers calculations against both full sized PWRs and scaled experimental facilities, and the deficiencies identified are discussed for each plant/facility in turn in the order of decreasing geometric scale. A brief description of each plant/facility is also included and a summary of the important SG characteristics for all cases considered is given in Table 1.

\subsection{Wolf Creek commissioning tests}

Wolf Creek is one of two fully operational PWRs based on the Westinghouse Standardised Nuclear Unit Power Plant System (SNUPPS) design, which is the basis for the Sizewell ' $B$ ' PWR. The plant consists of four loops and has a rated thermal power of $3425 \mathrm{MW}$. The SGs are Westinghouse U-type Model ' $F$ '. The Nuclear Steam Supply System (NSSS) is essentially the same as Sizewell ' $B$ ', although there are some differences in the Balance of Plant (BOP).

\subsection{1 $50 \%$ load reduction test}

Keevill (1989) presents results from a RELAP5/MOD2 analysis of a Wolf Creek commissioning test which involved a $50 \%$ load reduction from $100 \%$ power (test SU7-0010.2). The calculation performed by Nuclear Electric Technology Division (NE TD) using a modified version of a four-loop model developed for the Sizewell ' $B$ ' PWR.

8 The averaging process was applied to the minimum (i.e. negative) and maximum (i.e. positive) uncertainties separately, so that the final values did not account for any cancellation of uncertainties having opposite signs. 
In initialising the SG model, the stean flow at the MSIV was adjusted to obtain the correct cold leg temperature, and the feedwater flow was varied to match the calculated steam flow and achieve the correct SG level (see Section 2.2). The initial steady-state values that resulted were in good agreement with plant values on the SG primary side (i.e. loop flow rate and hot and cold leg temperatures), but the secondary side pressure was under-predicted by some 2.4 bar - indicating an under-prediction of the overall primary to secondary heat transfer mechanism. This conclusion is supported by the corresponding errors in HTC-A and HTC-O, which as shown in Table 2 and Table 3, are equal to -9.6 and $-24.4 \%$ respectively, and lie somewhat outside the uncertainty in the data. Examination of the steam and feed flows calculated by the code show only small differences from the plant values, confirming the assertion made in Section 2.2 that the code's vapour generation rate models are sufficiently accurate for the conditions present ${ }^{9}$.

Keevill (1989) also found that recirculation ratio calculated by RELAP5 at full load was about 5, compared with a plant value of 3.5. The author points out that, if necessary, the calculated recirculation ratio could be reduced by altering the loss coefficients at the junction between the downcomer and riser. However, he also states that the code predicts approximately the correct SG inventory and, as shown in Section 2.6. reducing the recirculation ratio would probably result in a lower inventory prediction. Section 2.6 also shows that reducing the recirculation ratio is likely to result in a decrease in the heat transfer coefficient on the secondary side of the SG tubes implying that the under-prediction of SG pressure may be worse if the recirculation ratio was calculated correctly.

Despite the errors in SG initial conditions, Keevill (1989) found that the Wolf Creek load reduction transient was generally well predicted by RELAP5 when the core power, steam pressure and feed flow were specified as boundary conditions, and the steam pressure values were normalised to the values calculated by the code for the initial steady-state - i.e. the secondary side pressure boundary condition was set artificially low in the transient to compensate for the under-prediction in heat transfer at full power conditions. The main phenomena of interest were the pressuriser pressure response during an insurge and in the presence of pressuriser spray, and both effects were calculated correctly. However, once the system had settled down after the initial load reduction transient, the cold and hot leg temperatures were under-predicted by around $1{ }^{\circ} \mathrm{C}$ and $3{ }^{\circ} \mathrm{C}$, respectively. Although these errors are relatively small and could probably be explained by measurement uncertainties, they could also suggest that the pressure error needed to compensate for the under-prediction of SG heat transfer at full power conditions, over compensates for the deficiencies at $50 \%$ load. This conclusion is supported by results from RELAP5 calculations against steady-state commissioning tests at Wolf Creek (see below). which show that the pressure error tends to decrease with load (Fig. 8). It is also interesting to note that the relative magnitudes of the errors in the predicted hot and cold leg temperatures, are broadly consistent with the contributions that these temperatures make to the SG length weighted average primary temperature (see Section 2.7).

Some differences from the plant measurements were also evident in the calculated SG liquid level during the load reduction transient, and these were attribuied to instabilities in the RELAP5 separator model and measurement uncertainties

\subsubsection{Plant trip from $100 \%$ power}

NE TD (Proctor, 1990a) have recently applied RELAP5/MOD2 and a modified two-loop model of Sizewell ' $B$ ' to analyse a commissioning test at Wolf Creek involving a plant trip from 100\% power (Test SU7-0011). As with the load reduction test, the initial secondary side pressure was under-predicted by the code, indicating an

9 This feature was evident in all calculations reviewed and thus will not be remarked upon again. 
under-prediction of SG heat transfer, while the other initial conditions were calculated correctly. For the plant trip test however, the pressure error is smaller, 1.3 bar against 2.4 bar and, as shown in Table 2 and Table 3, the corresponding errors in HTC-A and HTC.-O are also smaller by approximately a factor of 2 . Interestingly, the calculated initial conditions for both tests are virtlially identical, and the apparent improvement in SG heat transfer seen in the plant trip test occurs primarily as a result of a lower measured SG pressure. The present authors believe that the results for the load reduction test provide the more reliable indication of the errors in heat transfer modelling, for the following reasons:

- Proctor (1990a) notes that the quality of the data for the plant trip test is questionable and an uncertainty of \pm 1 bar in SG presslire is not unicalistic (Proctor, 1990b private communication).

- The results for the load reduction test are broadly consistent with those obtained in the analysis of a steady-state commissioning test at $98.89 \%$ power (see below). where the SG pressure was measured by a Heise gauge having an accuracy of \pm 0.1 bar.

Due to the failure of part of the data acquisition system, plant measurements for the transient phase of the plant trip test were only available from strip chart recordings (for $30 \mathrm{~s}$ after the trip) and an independent data logger set up to monitor a single SG. For the RELAP5 analysis of this period, the c'laracteristics of the steam and feed flow were imposed as secondary side boundary conditions, as well as the SG pressure recorded by the strip charts. Examination of the results presented by Proctor (1990a) shows that the strip chart pressure is typically 1.5 bar lower than the pressures recorded by the data logger over the latter part of the transient. Furthermore, at the time of trip, the strip chart pressure agrees with the initial steady-state pressure calculated by the code. It is suggested that imposing the strip chart pressure as a boundary condition may have had the effect of compensating for the under-prediction of SG heat transfer. Although Proctor (1990a) claims that this effect was compensated for by allowing a mismatch between the calculated steam and feed flows, this mismatch is more likely to be due to uncertainties in other boundary conditions. Unfortunately, due to data uncertainties and uncertainties over the response times of the reactor inlet and outlet temperature measurements, it is difficult to draw any conclusions regarding the heat transfer modelling from the predicted values of the hot and cold leg temperatures. If anything, the temperatures tend to be under-predicted, which is not inconsistent with an over-compensation of SG heat transfer.

Overall, the primary side conditions during the plant trip transient were generally calculated correctly by RELAP5, although the comparison was rather limited due to the sparsity of reliable data. For the same reason, it was not possible to draw any conclusions regarding the modelling of SG levels.

\subsubsection{Steady-state tests}

As part of the present study, RELAP5 has been applied to analyse a series of steady-state commissioning tests carried out at Wolf Creek over a variety of load conditions. These calculations are described in detail in Section 4, but the errors in HTC are also included in Table 2 and Table 3. Again an under-prediction of SG heat transfer is evident, with the errors in HTC-A and HTC-O tending to reduce with load. Although the reduction is not strictly monotonic, this can probably be explained by the uncertainties in the data.

\subsection{Sizewell B design basis}

Difficulties in calculating correct SG initial conditions with RELAP5/MOD2 have also been encountered when modelling Sizewell ' $B$ '. Hirst and Keevill (1989) for example, report problems in obtaining the design values for both the recirculation ratio and 
inventory, and state that if loss coefficients are adjusted to give the correct recirculation ratio, the inventory is low by $10 \%$. This is not inconsistent with the results for the Wolf Creek load reduction test, where the correct inventory was predicted when the recirculation ratio was over-predicted. It is also consistent with the simple theoretical analysis presented in Section 2.6 and Appendix A.2.

Hirst and Keevill (1990) on the other hand, claim that it is not possible to achieve the design combination of SG pressure and cold leg temperature with the standard Sizewell ' $B$ ' deck. In particular, to obtain the correct cold leg temperature, it is necessary to adopt a lower-than-correct secondary side pressure (by 3.4 bar, although it is not clear whether this corresponds to the calculation of the correct recirculation ratio or inventory). The authors attribute this deficiency to the use of the Chen correlation (albeit modified) to calculate the heat transfer coefficient on the secondary side of the SG tubes. They also note that the value of this heat transfer coefficient may be artificially increased by reducing the equivalent heated diameter on the secondary side, but in order to calculate the correct SG conditions, the diameter must be set equal to the inter-tube gap width divided by approximately 200 (as opposed to the outer diameter of the tubes in the standard deck). As demonstrated in Sactions 2.3 and 2.4, this reflects the fact that the overall primary to secondary heat transfer rate is relatively insensitive to increases in the secondary side heat transfer coefficient, while the Chen correlation only exhibits a strong dependence on diameter at very small diameters (see Fig. 3).

\subsection{KNU \#1 loss of offsite power transient}

Korea Nuclear Unit 1 (KNU \#1) is a two-loop Westinghouse PWR rated at $1724 \mathrm{MWt}$ and commissioned in 1978, for which BECHTEL was the architect/engineer. The SGs are U-type Model 51.

Chung, Kim and Lee (1990) present results from a RELAP5/MOD2 analysis of a loss of offsite power transient that occurred at KNU \#1 in June 1981, following the loss of feedwater in one SG while the plant was operating at $77.5 \%$ reactor power. The analysis was performed for code assessment purposes, and was carried out by the Korea Advanced Energy Research Institute (KAERI) and Seoul National University. The code calculations were made using a two loop model with a nodalisation philosophy based on guide lines given in the code manual.

Before embarking on the transient analysis, the authors applied the code to calculate steady-state values for full power operation. In order to obtain good agreement with design values, it was necessary to artificially increase the total heat transfer area of the SG U-tubes by $9 \%$. This is again indicative of an under-prediction of primary to secondary heat transfer, but as shown in Section 4, the increase in heat transfer area required to compensate for this effect is somewhat less than that found necessary for the Wolf Creek PWR at nominally the same SG conditions (viz. a $28 \%$ increase). Also, the calculated SG inventory for KNU \# 1 showed excellent agreement with the plant value, whereas the Wolf Creek and Sizewell ' $B$ ' calculations reviewed above indicate that the code under-predicts inventory if the SG level and recirculation and feed flows are calculated correctly (as they are in the KNU \#1 analysis).

Examination of the RELAP5 input deck used by Chung et al. (1990) for the KNU calculation reveals a value for the equivalent heated diameter on the secondary side of the SG U-tubes which is consistent with the physical hydraulic diameter. The actual hydraulic diameter however, which is used in the wall and interfacial friction models, is set to be consistent with the total flow area assuming a circular channel, which results in a value of the order of $250 \mathrm{~cm}$. Adopting such a large value will have the effect of artificially reducing the interfacial friction calculated for the slug flow regime, by reducing the interfacial area per unit volume. Evidently, this will tend to depress the average void fraction calculated in the bundle region, which could explain why the inventory was predicted correctly. Furthermore, the lower void fractions will result in greater values of the modified suppression factor $S^{*}$ in the 
modified Chen heat transfer correlation, leading to larger values of the boiling heat transfer coefficient on the secondary side of the SG tubes. This may be the reason why only a modest increase in heat transfer area was needed to obtain the correct primary and secondary side conditions.

With the above modelling. RELAP5/MOD2 provided accurate predictions of most plant param.aters for the KNU \#1 transient. In the base case calculation, the code did not predict the decrease in the affected SG level that occurred while the feedwater flow was decreasing in the loss of feed phase of the transient, and spurious level peaks were calculated at the turbine trip in both SGs. These discrepancies however, were subsequently eliminated by introducing a 'bypass' flow path between the top of the downcomer and steam dome. This type of modelling is standard in UK Sizewell ' $B$ ' SG models.

\subsection{Doel 2 SGTR accident}

Doel 2 is a Westinghouse two-loop 1192 MWt PWR located in East Flanders, Belgium. TRACTEBEL was the architect/engineer for the plant which was commissioned in 1975. The SGs are U-type Model 44.

In June 1979, a steam generator tube rupture accident occurred at Doel 2 while the primary system was in the heat up phase after a 24 hour stop for repair work on the MSIVs. Plant measurements fiom the transient were later made available as OECD/CSNI International Standard Problem (ISP) 20. De Feu. Firnhaber, Pochard and Stubbe (1988) review the results of this exercise, which included the following calculations made using RELAP5/MOD2.

\section{Organisation}

TRACTEBEL (Belgium)

Technical Research Centre of Finland

Joint Research Centre - Ispra

University of Pisa

ENEA (Italy)

\section{Version}

Cycle 36.05

Cycle 36.04

IBM Version

Cycle 36.04

$?$

An earlier calculation performed for ICAP by TRACTEBEL using RELAP5/MOD2 Cycle 36.01 is described in detail by Stubbe (1986)

Unfortunately, due to the rather limited quantity and quality of the available data, and uncertainties in the plant initial and boundary conditions, it is difficult to draw clear conclusions from the ISP-20 analyses regarding SG modelling in RELAP5/MOD2. Nevertheless, two clear shortcomings were identified:

1. RELAP5 over-predicted the water level swell that occurred in the intact SG when cooldown was initiated by opening the SRV, and also when steam was discharged to the turbine driven auxiliary feedwater pumps. This was attributed to the an over-prediction of interphase drag in the riser region, combined with liquid fall back in the separator region - which resulted in excessive mixture level swell in the riser, leading to a hold-up of water in the downcomer and the region located at the narrow range measurement taps.

2. After the affected SG generator had been completely isolated (zero steam and feed flows), the predicted SG pressure remained relatively constant (or decreased slightly), whereas the measured pressure increased. During this period, a large temperature stratification existed in the SG. In addition, water level was high and increasing as the break flow filled the SG. The pressure increase recorded on the plant resulted from the piston effect caused by the rising level on the vapour in the steam dome. The failure to predict this trend 
was traced to the calculation of an excessive vapour condensation rate in the dome, which was believed to be due to the use of constitutive equations appropriate to the slug flow regime under stratified flow conditions. Calculations performed by TRACTEBEL however, showed that an increase in pressure could be calculated if the steam dome was subdivided into several volumes.

\subsection{Doel 4 loss of load test}

Doel 4 is a Westinghouse three-loop 3000 MWt PWR located in East Flanders. TRACTEBEL was the architect/engineer for the plant which was first connected to the Belgium grid in April 1985. The reactor is equipped with U-type Model E (preheater) SGs and benefits from a high quality data acquisition system (DAS).

Stubbe, Vanhoenacker, Moeyaert and De Schutter (1988) present results from a RELAP5/MOD2 analysis of a loss of load test at Doel 4, which was performed to verify that the plant control systems were capable of bringing the reactor power to house load $(\simeq 5 \%)$ without scram. Although an acceptable overall agreement was obtained between measured and calculated data, the following errors were observed in the predicted SG level:

- The rapid fall in the SG level10 that occurred on the plant following the sudden increase in SG pressure when the main steam line valves closed, and which was due to steam collapse in the riser, was under-predicted by RELAP5.

- The level swell that occurred (due to bulk boiling in the SG) when the steam dump valves opened was nver-predicted by the code.

Stubbe et al. (1988) attribute the first level discrepancy to separator modelling deficiencies and the second to excessive interphase drag in the riser region at low void fraction, which caused the calculation of excessive water entrainment into the separator region where the DP level measurement is located. The present authors believe however, that the first discrepancy could also be caused by an over-predictior of interphase drag in the riser. It should be noted that the level errors in the calculation did not persist for very long, as the feedwater control system reacted quickly to restore the SG level. However, due to the strong thermal coupling between feedwater flow rate and cold leg temperature associated with pre-heater SGs, the error in feedwater flow that resulted from the over-prediction of level swell manifested itself in a small over-prediction of the cold leg temperature $\left(\simeq 1 \mathrm{C}^{\circ}\right)$. This strong thermal coupling is a particular feature of preheater type SGs and the same error in cold leg temperature would not be expected for a U-tube SG.

\subsection{Tihange 2 plant trip test}

Tihange 2 is a 2785 MWt, 3 loop PWR designed by Framatome and located in the southern part of Belgium. TRACTEBEL was the architect/engineer for the plant which started commercia! operation in June 1983. The SGs are U-type Series $51 \mathrm{M}$.

As part of a series of commissioning tests, a plant trip test at $100 \%$ power was performed at Tihange 2 in January 1983. Thie test was initiated by manually opening the feedwater control valve in one SG for about $5 \mathrm{~s}$, which resulted in a high water level alarm and a corisequent turbine trip and reactor scrain. Two minutes later, the operator transferred 'he steam dump to manual control to force a cooldown to below the no load reference temperature.

Results from a RELAP5/MOD2 analysis of the transient performed by TRACTEBEL are described by Rouel and Stubbe (1989). Overall, the agreement obtained between calculated and measured parameters was generally good. Although a number of

10 Unless stated otherwise, the term SG level should be interpretted as the downcomer water level, not the bundie mixture (or coll spsed liquid) level. 
anomalies were found, in most cases these did not necessarily point to modelling deficiencies as the errors could be explained by uncertainties in the plant data which despite the presence of a high quality DAS, were relatively large compared with the data uncertainties associated with separate or integral test facilities. This was especially true for the secondary side modelling as, as shown by sensitivity calculations, apparent minor changes in the timing and dynamics of the steam dump could induce relatively large variations in the SG parameters (e.g. water level). Nevertheless, two shortcomings in SG modelling were evident:

1. Prior to the manual operation of the steam dump, the calculated SG pressure reached a final plateau that was very close to the measured pressure. However, in the period immediately following the turbine and reactor trips, during which the SG pressure was increasing rapidly, the calculated pressure was significantly under-predicted. This behaviour was also accompanied by an abnormal rise in the calculated water level. Investigations performed by Rouel and Stubbe (1989) indicated that the incorrect pressure prediction was due to excessive condensation in regions where the feedwater was injected, which had the effect of driving the vapour to saturation and led to a temporary stagnation in the pressure evolution. Since the plant data exhibited a similar pressure plateau but at a higher pressure, the authors deduced that the code's bubbly flow models cannot maintain strong thermal disequilibrium under fast pressurisation conditions, and that due to premature condensation the vapour temperature returns to quasi saturation conditions too quickly.

2. Following the manual opening of the steam dump valves to reduce the SG pressure and force cooldown, a small temporary increase in the SG level was observed on the plant narrow range level recorder, but not in the RELAP5 simulation. This is the opposite effect to that seen in the Doel calculations described above, where an over-prediction of dynamic level swell was evident in a number of situations. However, at the time when the steam dump was changed to manual control in the Tihange test, the residual water levels in the SGs were very low. As noted by Rouel and Stubbe (1989), the failure to predict a level swell could be explained by an under-prediction of the liquid inventory in the SG, resulting in the calculated level being below the level gauge tap, such that the small level swell was not sufficient to enter the measurement range.

\subsection{ROSA-IV 5\% cold leg break test (ISP-26)}

The ROSA-IV Large Scale Test Facility (LSTF) is a $1 / 48$ volumetrically scaled, full height model of a Westinghouse four-loop (3423 MWt) PWR located at the Japan Atomic Energy Research Institute (JAERI). The facility is configured symmetrically with two primary loops, and has an electrically heated core of sufficient power to simulate typical decay heat starting from a few seconds after reactor trip (maximum of $14 \%$ of scaled reference PWR rated power). Each loop, representing two loops in the reference plant, has an active SG which consists of 141 full size U-tubes (the reference single SG having a total of 3382 tubes).

Data from a $5 \%$ " cold leg break experiment with normal pump trip on ROSA-IV have been made available as OECD/CSNI ISP 26. Cooper and Froushan (1990) present results from RELAP5/MOD2 analysis of this problem, which was performed by NE TD and HSD using RELAP5/MOD2 and a two-loop model provided by EG\&G, Idaho. Before calculating initial conditions for the full model, a number of steady-state calculations were performed for a single SG generator that had been isolated from the NSSS by specifying appropriate boundary conditions. These showed, in particular, that there was only a restricted range of values of SG inventory for which satisfactory steady-states could be obtained. Values outside this range either flooded the

11 Based on flow area. 
separator, giving water carryover, or gave conditions whereby steam was present in the liquid return.

The preliminary calculations also demonstrated that it was not possible to obtain a steady-state solution with the correct combination of SG level, collapsed liquid level in the riser (or boiling range) and recirculation ratio. For the full plant model, the authors aciopted a compromise solution in which the SG level was matched to the measured data, but the recirculation ratio was over-predicted and the collapsed liquid level in the riser was under-predicted, resulting in an under-prediction of the SG inventory. Although the recirculation ratio could be reduced slightly by increasing the frictional loss at the junction at the bottom of the downcomer, the authors found that this led to a reduction in the SG inventory. This type of behaviour is consistent with steady-state calculations for Wolf Creek and Sizewell 'B' and the theoretical analysis presented in Section 2.6 and Appendix A.2.

The initial secondary side pressures calculated by RELAP5 for ISP 26 were only slightly lower than the measured values $(0.5$ and 0.8 bar for the two loops). Due to errors in the calculated hot and cold leg temperatures though, the power removed by each SG was also under-predicted. As a result, and as indicated by the errors in HTC-A and HTC-O given in Table 2 and Table 3, the under-prediction of SG heat transfer by the code was more significant than that implied by the pressure error. Note however, that the data uncertainties for the test are quite large, in particular the accuracy of the hot and cold leg temperature measurements were $\pm 3.3^{\circ} \mathrm{C}$.

The transient calculations performed by Cooper and Froushan (1990) gave a reasonable prediction of the system thermal-hydraulic behaviour during the test. $A$ few discrepancies were found, but none of these were attributable directly to deficiencies in SG modelling. However, following loop seal clearance, RELAP5 predicted a period of liquid hold-up in the SG inlet plena which was not observed in the test. Use of a modified version of RELAP5 which allowed for the existence of stratified flow in the inclined section of the hot leg improved the prediction, but the time of draining was still over-predicted - leading to an under-prediction of the core liquid inventory during the period of core boildown.

\subsection{LOFT tests}

LOFT is an integral effects test facility designed to simulate the major cornponents and system response of a commercial four-loop PWR during LOCAs and anticipated transients. The facility has a nuclear core and two primary loops:

1. An 'intact' (active) loop with an active SG, pressuriser, and two primary coolant pumps connected in parallel.

2. A 'broken' (test) loop with resistance and elevation changes designed to simulate the SG and pump resistance, and two quick acting blowdown valve assemblies 12

The scaling philosophy adopted in the design was to reduce the coolant volumes and flow areas for the components by the ratio of the LOFT core power to that of a commercial PWR (viz. 50/3400 = 1/68). This was not completely achieved however, with the result that some of the components were oversized. Also, the vertical scaling was not preserved with several components considerably shorter than their counterparts in the reference plant. In particular, the SG riser section in LOFT is approximately one-third the height of commercial SG riser, with the SG heat transfer area nominally preserved by having six times as many U-tubes (1845 in total).

12 The SG and pump simulators were often disconnected during intact primary circuit fault experiments, and the majority of small break tests were conducted with the break in the 'intact' loop. In both cases, the broken loop pipework acted simply as a fluid storage reservoir. 
Despite the shorter riser, the recirculation ratio is similar in magnitude to that in a commercial PWR.

\subsubsection{Steam generator steady-state heat transfer}

Some analysts have observed an under-prediction of SG pressure when applying RELAP5/MOD2 to calculate initial steady-state conditions for LOFT tests. For example, NE TD found that the initial pressure for test LP-SB-03 $(0.4 \%$ cold leg break) was under-predicted by 1.1 bar (Harwood and Brown, 1990), while for test L3-7 (1" cold leg break) KAERI obtained an under-prediction of 3.3 bar (Lee, Chung and Kim, 1990). Other authors however, have encountered no significant difficulties in obtaining correct initial conditions for LOFT and, as shown in Table 2 and Table 3 , the errors in HTC-A and HTC-O for all calculations reported are fairly well spread. Moreover, in many cases, the errors lie within the experimental uncertainties, although there is a clear bias in the direction of an under-prediction of SG heat transfer.

Trends in the HTC errors shown in Table 2 and Table 3 will be discussed later. For the present purposes, it should be noted that the UK calculations were made with the equivalent heated diameter on the SG secondary side set to the inter-tube gap, whereas the KAERI and Studsvik calculations used the hydraulic diameter ${ }^{13}$. Also the predicted recirculation ratio is not known in most of the calculations considered and the experimental value was not measured. As far as can be ascertained, all calculations were performed using an input deck that originated from EG\&G, Idaho. However, for the UK, KAERI and INER-China analyses, the SG heated riser region was modelled using four fluid nodes, whereas for the Studsvik calculations, it was represented using three nodes. These calculations also used a slightly longer heated length (by $6 \%$ ).

Table 2 and Table 3 include results from two calculations made against LOFT test L2-5 (200\% cold leg break) - one carried out by KAERI (Bang, Lee and Kim, 1990), the other by INER-China (Kao, 1988). Interestingly, the errors in HTC-A and HTC-O are much larger for the latter calculation, despite the fact that the SG nodalisation used in each case is virtually identical. As noted above, the equivalent heated diameter used for the KAERI analysis was equal to the hydraulic diameter, and the SG heat transfer area and tube thermal conductivity were also physically correct. Although the values of these parameters used in INER-China analysis are not known, they are unlikely to have resulted in poorer SG heat transfer (e.g. the analysts are unlikely to have used a heated diameter greater than the hydraulic diameter). The results obtained in the two calculations therefore suggest that there may be factors other than those already identified, which can have an effect on SG heat transfer. Note however, that the results from the INER-China analysis were taken from a presentation given at an ICAP specialists meeting, and a final assessment report has not yet been issued.

Table 2 and Table 3 include details of two calculations performed by Winfrith Technology Centre (WTC) (Birchley, 1988) against LOFT test L9-3 (loss-of-feedwater ATWS). In the second (Revised) calculation, a number of changes were made to the input deck in an attempt to obtain a better prediction of the SG boildown behaviour principally

- The bottom nodes in the SG riser and downcomer were subdivided into two.

- The flow area in the lower part of the SG downcomer was increased in line with engineering data.

- The flow resistance of the SG was reduced to increase the recirculation ratio.

13 The hydraulic diameter was set to $2.34 \mathrm{~cm}$ for the KAERI calculations and $1.92 \mathrm{~cm}$ for the Studsvik calculations. This compares with an inter-tube gap size of $0.64 \mathrm{~cm}$. 
For the initial condition calculation, these changes resulted in a slight reduction in the hot and cold leg temperatures (by $0.4^{\circ} \mathrm{C}$ ) - which, as evident from the tables, had the effect of reducing the errors in HTC-A and HTC-O. It is suspected that this apparent improvement in SG heat transfer was primarily a consequence of the increased recirculation ratio.

The tables also include details of two calculations made by Studsvik against test L3-6 $(2.5 \%$ cold leg break). In the second calculation (Case $B)$, changes were made to the riser geometry to increase the initial inventory (by $140 \mathrm{~kg}$ ). As can be seen, this had the effect of reducing the primary to secondary heat transfer slightly, although the errors in HTC-A and HTC-O are still within the experimental uncertainty. This again shows the sensitivity of these parameters to SG modelling.

\subsubsection{Separator performance}

Several of the UK analyses of LOFT tests have experienced difficulties in achieving satisfactory separator performance in the initial steady-state or during the early part of the transient (viz. from those shown in Table 2 and Table 3, tests LP-SB-03, LP-SB-01, LP-SB-02, LP-FW-01 and L9-4 $\left.{ }^{14}\right)$. The particular problems encountered were the periodic emptying and filling of the separator volume and steam carryunder to the downcomer, which are not inconsistent with the difficulties experienced in the ROSA-IV ISP-26 analysis discussed in Section 3.7. In the LOFT analyses, the various solutions adopted to overcome these problems were

1. Set the SG water level artificially high.

2. Reduce the SG flow resistances.

3. Specify a very small value for the carryunder parameter VUNDER ${ }^{15}$.

It is suggested that the separator problems encountered on LOFT are a consequence of an over-prediction of interphase drag in the tube bundle region, resulting in the calculation of high void fraction in the separator volume and a liquid fraction less than VUNDER. Not only will this lead to an incorrect prediction of carryunder to the downcomer, but the presence of voidage in the downcomer could also be responsible for the periodic emptying and filling of the separator observed in some calculations. (For example, the onset of carryunder results in a surge of two-phase fluid from the downcomer to the steam dome, which could lead to an increase in vapour generation as water flashes to steam.) As discussed in Section 2.6 and Appendix A.2, increasing the SG level or reducing the SG flow resistances has the effect of reducing the vapour fraction entering the separator volume, thereby reducing the potential for carryunder. Both actions however, will tend to increase the SG inventory.

Other apparent deficiencies in the RELAP5 separator model have also been observed in some transient situations:

1. In the RELAP5 analysis of LOFT test LP-SB-03 (0.4\% cold leg break), oscillations in the predicted SG level were present throughout the transient (Harwood and Brown, 1990). Instabilities in SG level behaviour were also observed in the analysis of the Wolf Creek load reduction test reviewed in Section 3.1.1, and can probably be attributed to the non-mechanistic nature of the separator model.

2. Preliminary calculations against test L9-4 (loss of offsite power, ATWS) were found to be sensitive to the calculational time step (Keevill, 1988). This sensitivity was eventually found to be caused by numerical oscillations in SG separator

14 The UK LOFT calculations in Table 2 and Table 3 are shown in the order that they were performed. although the reports were not issued in this order.

15 In the RELAP5 separator model, vapour carryunder to the downcomer cannot occur until the separator liquid fraction falls below VUNDER. 
during the first few seconds of the transient, which were subsequently removed by changing the flow resistance of the liquid fall back junction. When this was done the sensitivity to time step was no longer present.

\subsubsection{LOCA tests LP-SB-01, LP-SB-02, LP-SB-03, L2-5, L3-5, L3-6 and L3-7}

In general, although RELAP5 calculations against LOCA tests on LOFT have revealed some deficiencies in the code, none of these can be attributed specifically to SG modelling. This may be partly due to the fact that, for break sizes typically greater than 5\%, SGs only play a small part in LOCA transients as much of the primary system energy is removed by the break flow, and the fact that errors in the predicted SG behaviour do not have a very large impact on the primary side parameters important for safety analysis. Nevertheless, a number of minor discrepancies have been observed and these may be summarised as follows.

1. In the analysis of test LP-SB-03 $(0.4 \%$ cold leg break), RELAP5 failed to predict continued reflux condensation after the primary pressure fell below the secondary pressure - although the code did go on to predict restoration of the reflux cooling in the SG bleed and feed phase reasonably well. The analysts (Harwood and Brown, 1990) suggested that the inclusions of a small node at the bottom of the riser might have resolved this discrepancy.

2. Throughout the transient phase of test LP-SB-01 (1\% hot leg break with normal pump trip), RELAP5 gave a systematic over-prediction of the secondary side pressure of the order of 2.5 - 5 bar. Hall and Brown (1990) suggested that this may have arisen from a tendency to over-estimate SG heat transfer (which is the opposite effect to that generally observed at steady-state ${ }^{16}$ ), or from errors in modelling heat losses or steam leakage via the main steam control valve. The latter seems the most likely explanation, and for the subsequent analysis of test LP-SB-02 (1\% hot leg break with delayed pump trip). Hall (1987) 'tuned' the leakage flow to obtain reasonable predictions of the secondary side pressure.

3. In the UK analysis of LOFT test L3-6 (2.5\% cold leg break with delayed pump trip), RELAP5 under-predicted the SG liquid level after the reactor had tripped and the secondary side fluid had settled (i.e. when the recirculation flow had ceased and the vapour generation rate had fallen off). As noted by Scriven (1990), this discrepancy could be caused by a number of factors:

- An over-prediction of the voidage in the SG riser at full power conditions (i.e. when initialising the SG).

- An under-prediction of the initial recirculation ratio.

- The incorrect prediction of liquid hold-up in the separator.

- Errors in representing the variation of cross-sectional area with height in the input deck.

4. Scriven (1990) also found that the SG secondary side pressure in L3-6 was progressively under-predicted by RELAP5 from around 1000 s onwards, while the predicted primary side pressure drifted above the measured value between 1000 and 2000 s. Further examination revealed that this occurred because the calculated primary and secondary side pressures did not decouple until nearly 2000 s (at which point the secondary pressure 'held-up' above the primary pressure), whereas in LOFT the pressures decoupled at around $1000 \mathrm{~s}$. In the RELAP5 calculation, the decoupling of the primary and secondary side pressures was associated with the predicted draining of the SG U-tubes, which left the tubes vapour filled and resulted in a large degradation in SG heat transfer. This led

18 As shown in Table 2 and Table 3 , the initial steady-state SG heat transfer is predicted very well. 
Scriven (1990) to conclude that the discrepancies in pressure observed were the consequence of a late prediction of U-tube draining.

5. The SG level and secondary side pressure errors observed in the UK analysis of L3-6 by Scriven (1990) were also seen in a calculation performed by Eriksson (1990) at Studsvik Engineering AB, Sweden. In an attempt to improve the level prediction, the author performed a second calculation in which the boiler geometry was modified to be inore realistic (which had the effect of increasing the initial inventory), and the closure of the feedwater value was delayed. Although this resulted in some improvement in the level prediction at the time of trip, the level error then proceded to increase with time, whereas in both the original and Scriven's calculations it remained relatively constant.

6. In the KAERI analysis of L2-5 (200\% cold leg break), the predicted secondary side pressure started to deviate from the measured value at around $40 \mathrm{~s}$ (which is after the low head safety injection system had been initiated), and by the end of the calculation (115 s) was some 3-4 bar lower. Bang et al. (1990) note this discrepancy but offer no explanation for it. However, the behaviour of the predicted secondary side pressure is similar to that observed in the L3-6 calculation, indicating that it may be explained by a delay in predicting the draining of the SG U-tubes. The results for L2-5 presented by INER-China (Kao, 1988) do not include the secondary side pressure.

It is worth noting that the incorrect prediction of the secondary side behaviour observed in L3-6 calculation was not seen in the analysis of the companion test L3-5, in which the pumps were tripped early. Of the other small break LOCA tests considered which involved a delayed pump trip (LP-SB-03 $-0.4 \%$ cold leg break and LP-SB-02 - 1\% hot leg break), the break size was much smaller and the primary and secondary pressures did not decouple while the pumps were running.

\subsubsection{Intact circuit fault tests LP-FW-01, L9-3 and L9-4}

In general, SG behaviour has a more important role in determining the course of intact circuit fault transients than LOCAs, and thus SG modelling errors can have a more significant effect on code predictions. To date, three LOFT intact circuit fault tests have been analysed with RELAP5/MOD2 in the UK: LP-FW-01 and L9-4 by NE TD and L.9-3 by WTC. The SG modelling deficiencies identified in these studies are discussed below.

\section{LP-FW-01 (complete loss-of-feedwater with recovery by primary side feed-and-bleed)}

This transient was initiated by terminating the main feedwater flow to the SG and disabling the auxiliary feed. The SG inventory then boiled down, eventually emptying at around $90 \mathrm{~s}$. Since the reactor did not trip until $48 \mathrm{~s}$ (on high primary side pressure), most of this boildown occurred under full power conditions.

In the RELAP5/MOD2 analysis of the transient (Croxford, Harwood and Hall, 1988), the SG collapsed liquid level was predicted to fall at a somewhat faster rate than the experimental value. However, since the initial level for the calculation had been set slightly high, the time at which the SG was predicted to empty was approximately correct.

The secondary side pressure calculated by RELAP5 during the boildown phase of the transient indicated a slight delay in the predicted onset of the degradation of primary to secondary heat transfer ${ }^{17}$. Evidently, this behaviour could be explained both by an over-prediction of the mixture level in the riser, and an over-prediction of liquid entrainment above this level. As discussed below, the latter effect was evident in the

17 This delay was believed to be the cause of a small error in the predicted pressuriser level behaviour that was present up to and just after reactor trip. 
RELAP5 analysis of LOFT test L9-3. Interestingly, the secondary side pressures for LP-FW-01 appears to indicate that once SG heat degraded, the rate of degradation was more rapid in the calculation. This behaviour was also seen in the L9-3 analysis.

No other discrepancies between the calculated and measured results for LP-FW-01 were attributed to deficiencies in SG modelling. However, the main phenomenon of interest in the analysis was the primary side behaviour, which was relatively insensitive to SG conditions after the latter had emptied. Nevertheless, the long term secondary side pressure was still well predicted - although this mainly indicates that the steam leakage from the main steam control valve (MSCV) (which was closed at reactor trip) was well modelled.

\section{L9-4 (loss-of-offsite-power ATWS)}

LOFT test L9-4 simulated a loss-of-offsite-power accident without reactor trip. The experiment was initiated from typical commercial PWR operating conditions by tripping the primary coolant and main feedwater pumps, and by closing the SG MSCV. Auxiliary feedwater was initiated after a delay of $10 \mathrm{~s}$ to simulate the start-up time of the diesel generators, and the pressuriser PORV and spray were both inoperative throughout the transient. In the UK RELAP5 analysis of the test (Keevill, 1988), the reactor power was specified using a table of power vs time (as there was insufficient reactor physics data to use the code's point kinetics model), and the pump coastdown was modelled using an input table of pump velocity vs time.

A number of discrepancies between the RELAP5 calculation and the experimental data occurred in the initial SG boildown phase of the transient. In particular, the predicted SG level fell more rapidly than the experimental level, with the SG emptying at $370 \mathrm{~s}$ against $600 \mathrm{~s}$ in the experiment. This resulted in a more rapid heat-up of the primary side while the heat sink was lost (even though the calculated heat-up started slightly later), with 25 pressuriser SRV cycles necessary to control the pressure compared with the 7 cycles that occurred in the test. The early loss of heat sink in the calculation also kept the primary coolant temperature high after the boildown had finished, although the long term primary depressurisation was predicted reasonably well.

In order to investigate whether the rapid boildown in the RELAP5 calculation was due to insufficient water in the SG secondary side, Keevill (1988) performed a second calculation in which the recirculation ratio was increased from 5.1 to 8 . This had the effect of increasing the initial inventory by $8 \%$, but although the level calculation was improved between 50 and $200 \mathrm{~s}$, significant differences still remained at the beginning and end of the boildown. It was also found that the revised inventory did not significantly improve the primary pressure calculation. The author concluded that a very large recirculation ratio would be needed to increase the initial inventory to the value needed to match the experimental boildown behaviour, and suggested that the errors in the initial inventory calculation may have arisen from errors in the void fraction calculation in the riser region. It is interesting to note however, that although increasing the initial inventory had the effect of delaying the time at which the SG emptied by approximately $50 \mathrm{~s}$, it did not have a significant affect of the rate of boildown.

Keevill (1988) also suggested that errors in the input power and pump characteristics, and the rather coarse secondary side nodalisation adopted, may have contributed to the incorrect boildown prediction - noting, in particular, that since reactivity feedback was not modelled explicitly, the calculation was very sensitive to the primary coolant flow rate.

Despite the errors in SG level calculation, the initial $40 \mathrm{~s}$ of the L9-4 transient containing the initial heat-up and first phase of SRV cycling, and when DNB is most likely to occur in the core, was well predicted by RELAP5/MOD2. 


\section{L9-3 (loss-of-feedwater ATWS)}

LOFT test L9-3 was characterised by a rapid boildown of the SG, following the loss-of-feedwater, with the reactor remaining close to its initial power until the SG became sufficiently uncovered for primary to secondary heat transfer to be significantly reduced. One important area where the RELAP5/MOD2 analysis of the transient (Birchley, 1988) differs from that of L9-4, is that the point kinetics model was used to calculate the reactor power, thereby ensuring that calculated reactivity and thermal-hydraulic transients remained in step. Also, since the pumps were running throughout the transient, the primary to secondary heat transfer was essentially controlled by secondary side conditions, whereas in L9-4 SG heat transfer was dominated by the low heat transfer coefficient on the primary side of the tubes until the SG dried out.

For the first $30 \mathrm{~s}$ of L9-3, the SG level calculated by RELAP5 was in excellent agreement with the data. From this point until the MSCV was closed at $67 \mathrm{~s}$ however. the calculated level fell more rapidly than the measured level. In the experiment, the SG level was just above the bottom of the indicating range at $67 \mathrm{~s}$, whereas in the calculation the SG was almost empty. The primary side heat-up that occurred as the SG tubes became progressively uncovered was slightly delayed in the calculation, but once initiated the primary coolant temperatures increased more rapidly.

Examination of the integrated steam flows and SG levels at the time of MSCV closure indicated that the initial SG inventory was too low in the RELAP5 calculation. In addition, a plot of SG heat transfer against level showed that the calculated heat transfer remained almost constant during boildown until the SG was almost empty, whereupon a sudden drop in heat transfer occurred. In contrast, a gradual degradation of SG heat transfer occurred in the experiment as the level fell.

In order to investigate the effects of these discrepancies in more detail. Birchley (1988) performed an additional calculation in which

1. The initial SG inventory was increased by increasing the downcomer flow area (in line with engineering data) and the recirculation ratio.

2. A more gradual degradation of SG heat transfer was sought by subdividing the bottom nodes in the downcomer and riser into two. ${ }^{18}$

Surprisingly, the revised calculation gave results that were qualitatively similar to the original calculation. The increase in initial inventory did cause the SG to boil dry slightly later, and a delay in the onset of heat transfer degradation, but the rate of fall in the SG level was not significantly affected. Also, the finer noding at the bottom of the SG did not result in a smoother degradation in heat transfer as the tubes uncovered. On the primary side, the calculated heat-up was delayed slightly due to the higher initial inventory, but the rapidity of the heat-up was largely unchanged.

The integrated steam flow and SG level in the revised calculation indicated that the initial SG inventory was probably still too small. Since the changes made to the model were as large as was thought sensible. Birchley (1988) deduced that the discrepancies observed were most likely caused by an over-prediction of the void fraction in the riser region.

A detailed examination of the liquid fraction and heat transfer calculated for each node in the riser showed that, prior to the closure of the MSCV, the liquid fractions decreased more or less together, so that instead of a sequential emptying of the nodes, the liquid was smeared along the riser. As a result, the heat transfer remained high in all the nodes until they were nearly all empty (largely simultaneously). whereupon the heat transfer fell sharply in all of them (which explains the rapid, but

18 Some changes to the trip setting were also introduced to match the measured conditions at actuation more closely. 
delayed, primary heat-up). This behaviour is indicative of an over-prediction of liquid entrainment above the riser mixture level - although errors in the calculation of this level could also have an effect.

\subsection{MB-2 tests}

Main Boiler No.2 (MB-2) represents an approximately $0.8 \%$ power scaled, full height model of a Westinghouse Model F SG (the SG used in Sizewell ' $B$ '). which is geometrically and thermal-hydraulically similar in many important areas. In particular, the tube bundle region consists of 52 Inconel $600^{19}$ tubes arranged in a 13 $\times 4$ rectangular array, which have the same $O D$. wall thickness and tube pitch as the tubes in the full size Model F design. Some differences from the reference plant do exist in the separator component, although the design adopted was considered to be more representative than attempting to scale down the Model $F$ assembly in some way. The primary side of MB-2 acts solely as a heat source and consists of a pressurised loop (155 bar) under forced circulation and heated by a $10 \mathrm{MW}$ gas heater - which may be augmented by a further $7 \mathrm{MW}$ if the test specification requires isothermal conditions to be maintained. At 100\% scaled reference power (6.67 MWt), the boiler produces dry, saturated steam at 69 bar, the same as Model F. The facility is heavily instrumented and has been used to study steam generator tube rupture. loss of feedwater and steam line break transients.

\subsubsection{Loss of feedwater tests no. 1 and 2}

MB-2 loss of feedwater (LOF) tests no. 1 and 2 were performed to investigate the preand post-reactor trip periods of a complete LOF. and to provide basic data on SG responses to changes in power and the loss of inventory. Both tests were initiated from $100 \%$ power conditions by shutting off the main feedwater flow. In LOF Test no. 1. the remaining boundary conditions were kept constant, while in Test no. 2 the power was rapidly reduced to $3 \%$.

Wu and Wang (1988) and Wang and Wu (1988) summarise results from a number of RELAP5/MOD2 calculations against LOF tests no. 1 and 2, which were carried out at the Institute of Nuclear Energy Research, Taiwan (INER-Taiwan). Significantly, in order to achieve the correct steady-state initial conditions in the calculations, the SG heat transfer area in the RELAP5 model had to be artificially increased by $21.5 \%$. The authors claim that with this bias, the code did 'reasonably' well in predicting SG behaviour for the two transients, although the only result shown is the downcomer water level response during LOF test no. 1. For the first $50 \mathrm{~s}$ of the transient, the calculated level is seen to be in good agreement with the data. However, the level then falls more rapidly, eventually indicating dryout some $20 \mathrm{~s}$ too early (at around $80 \mathrm{~s})$. Overall, the comparison is not dissimilar to that observed for the Winfrith analysis of LOFT LOF test L9-4 (see Section 3.8.4).

The authors also found that by refining the nodalisation used in the evaporator region, the bias in heat transfer area necessary to achieve the correct steady-state initial conditions could be reduced to $12.6 \%$. However, this did not lead to any significant improvements in the transient predictions for the major SG parameters. Refinements to the nodalisation in other regions (such as the downcomer) and changes to the flow junction between the dryer and drain tube, also resulted in only minor improvements to the calculated results.

Calculations were also performed using a version of RELAP5/MOD2 in which the Thom correlation was applied in place of the Chen correlation, to calculate the boiling heat transfer coefficient on the secondary side of the tubes. With this version of the code and the optimised evaporator nodalisation, the increase in heat transfer area required to calculate correct initial conditions was only $2.7 \%$. As before however,

19 The Sizewell 'B' SG tubes are manufactured from Inconel 690. 
no significant improvements were evident in the predicted transient behaviour, except that the local heat fluxes and heat transfer coefficients were calculated more accurately.

A RELAP5/MOD2 analysis of MB-2 LOF test 1 carried out at Texas A\&M University is briefly described by Kalyanasundaram and Hassan (1988). The only result shown is the bundle collapsed water level, which is systematically under-predicted during the boildown process.

\subsubsection{Steam line break test T-2013}

MB-2 test T-2013 simulated a $100 \%$ steam line break transient initiated from hot zero power conditions, with the initial SG level sef for normal operating conditions. The transient was characterised by the following phases

1. A short period lasting around $5 \mathrm{~s}$ in which single phase steam was discharged through the break leading to fast two-phase level swell.

2. A period lasting from 5 to $33 \mathrm{~s}$ in which there was significant liquid carryover (caused by the level rise flooding the separators and interrupting the separation process), resulting in a two-phase mixture being discharged from the break.

3. A final period in which single phase vapour was again discharged from the break.

During the experiment, the primary side flow was maintained and the hot leg temperature was kept approximately constant by means of gas fired heaters. A RELAP5/MOD2 analysis of the test is described by Rogers (1989b).

No significant difficulties were encountered in setting up initial steady-state conditions for the RELAP5 analysis, despite the existence of a very weak thermal coupling between the primary and secondary sides and very low secondary flows. However, the difference in temperature between the SG inlet and outlet in the calculation was greater than the experiment, indicating an over-prediction of the initial primary to secondary heat transfer rate. Although this is the opposite effect to that generally observed at higher reactor power conditions, due to the very small temperature differences and thus large uncertainties involved, it is not possible to say for certain whether the errors were due to deficiencies in heat transfer modelling. For this reason, the corresponding errors in HTC-A and HTC-O $(267$ and $433 \%$, respectively) have not been included in Table 2 and Table 3 . The apparent over-prediction of initial heat transfer was not expected to have any significant implications for the transient analysis of the test, since after the break had opened the heat transfer rate increased by nearly two orders of magnitude.

The main differences between the RELAP5 prediction and the test measurements in each phase of the blowdown behaviour may be summarised as follows.

\section{Phase 1}

The onset of two-phase flow through the break occurred $3.5 \mathrm{~s}$ earlier in the calculation than the experiment (at $1.5 \mathrm{~s}$ against $5 \mathrm{~s}$ ). As noted by Rogers (1989b), this was indicative of the prediction of too rapid a level swell - a conclusion supported by the comparison of the predicted and calculated SG DP levels. The conclusion is also consistent with the results of plant calculations reviewed in this report, in which RELAP5 has been found to over-predict level swell when steam is discharged from the SG.

\section{Phase 2}

In the RELAP5 calculation, the rate of depressurisation slowed abruptly at the onset of two-phase flow through the break. No such change was observed in the experiment and, as a result, the depressurisation rate was under-predicted during 
this phase. This discrepancy was traced to an uncler-prediction of the steam flow rate at the break, resulting in a under-prediction of the energy removed from the system. As a consequence, the primary to secondary heat transfer rate was under-predicted. causing the cold leg temperature to be over-predicted by up to $8^{\circ} \mathrm{C}$ (i.e. the primary cooldown was under-predicted). Some uncertainty was present in the liquid flow rate at the break but, apart from the beginning of two-phase discharge where the uncertainty was greatest, the calculated flow rate was in excellent agrecment with the data. with the termination of liquid flow predicted to occur only one second after it was observed.

Rogers (1989b) attributed the under-prediction of vapour flow rate to the calculation of too much liquid carryover to the break, and suggested that this may have been caused by an over-estimation of interphase drag by the code. However, Agar (1990) has recently repeated the MB-2 test analysis using RELAP5/MOD2.5, which has improved models for interphase drag in the bubbly and slug flow regimes, including a special model for bundle geometries. Despite performing various sensitivity calculations, no significant improvement over the MOD2 results was obtained.

The only explanation suggested by Agar (1990) for the apparent over-prediction of liquid carryover, is that the steam dryers in the facility, which were not modelled in the RELAP5 calculations, may have impeded the passage of liquid to the steam line. and/or deflected liquid away from it. Although the present authors and their colleagues do not believe that the dryers themselves could have such a significant effect, it is suggested that liquid carryover to the break in the experiment may have been reduced by the accumulation of liquid on other structures in the upper part of the SG, as a result of eddies in the local vapour flow.

The similarity between the RELAP5/MOD2 and RELAP5/MOD2.5 results can probably be explained by the fact that the liquid carryover in the calculations would have been primarily controlled by the interphase drag at and above the two-phase mixture level. The relevant flow regimes are therefore likely to be the annular-mist or post-dryout regimes, for which the interphase drag models are the same in both versions of the code. Alternatively, the flow velocities may have been so high that the carryover was not particularly sensitive to interphase drag.

\section{Phase 3}

At the beginning of the third phase in the experiment (termination of water carryover). water held-up in the top of the downcomer, separator or other structures drained back into the boiler region and caused a temporary increase in the boiler collapsed liquid level. This increase was accompanied by a more rapid fall in cold leg temperature, and the data suggests that some of the water flowed into the top of the boiler and rewetted the entire bundle. This insurge of water was not observed in the calculation, although the termination of carryover did result in the collapsed liquid level in the boiler remaining constant for a while, and caused the cold leg temperature to stop falling.

Rogers (1989b) notes that failure of RELAP5 to predict drain back into the boiler could be due to incorrect modelling of counter current flow limitation (CCFL) in vertical components by RELAP5. However, he goes to suggest that it is more likely to be a result of not modelling the deck plates in the upper separator region, which have the capability to provide a reservoir of trapped water. This sort of explanation ties in with the explanation suggested above for the apparent under-prediction of liquid carryover in phase 2 of the transient. In fact, it is possible that the drain back seen in the experiment corresponds to water accumulated in various structure in the upper SG that was predicted to carryover to the break in the RELAP5 calculation.

The RELAP5 calculation also predicted a spurious return to two-phase discharge during the last phase of the transient. It was subsequently found that the effect could be prevented by specifying a large loss coefficient for the separator drain lines, which 
had been modelled as a junction flowing into the top of the downcomer. However, this caused only a marginal improvement in the calculated results.

\section{Overall agreement}

In general terms, RELAP5/MOD2 calculation gave reasonable agreement with the test data, especially the timing of key events. However, due to the above discrepancies, the primary side cooldown rate was under-predicted.

\subsection{SPES loss of feedwater test (ISP-22)}

The Italian SPES integral test facility is a $1 / 427$ th power-scaled, full height model of a Westinghouse 312 type (2775 MWt) PWR, which forms the basis for the proposed Italian PUN reactor. The facility has an electrically heated core and simulates all three loops of the reference plant explicitly. Each loop has an active SG which consists of 13 full sized U-tubes (implying approximately 5550 tubes per SG at full scale). SPES is well instrumented and is the largest PWR integral test facility currently in operation which is capable of representing full reactor power.

SPES test SP-FW-02, performed in December 1988, simulated a complete loss of feed from full power conditions with delayed auxiliary feed initiation to one SG. The transient, which formed the basis of OECD/CSNI ISP-22, was characterised by the following stages:

1. SG boildown under nominal full power conditions until closure of the MSIV and reactor trip on low SG level.

2. SG boildown through PORVs under decay heat conditions, with associated primary side heat-up, until SGs dry out.

3. Continued primary side heat-up and subsequent boiloff through pressuriser PORV until core incovery.

4. Auxiliary feed initiation to one $S G$ on high heater rod temperature, leading to primary cooldown and core recovery (due to pressuriser draining).

The UK RELAP5/MOD2 submissions for the problem consisted of a pre-test 'double blind' calculation performed jointly by NE TD and HSD, and a post-test calculation carried out by PPG. Comparisons of the results from both calculations with the experimental data are discussed by Willmott (1990). The results illustrate a number of difficulties in modelling SG level and inventory.

In the pre-test calculation, it was not possible to obtain correct initial values for both the SG inventory and downcomer level. Since the inventory was deemed to be the more important parameter, the level was set as high as practically possible $11 \mathrm{~m}$ above the experimental level). This led to an initial inventory that was low by only $6 \%$ $(9.3 \mathrm{~kg})$, but also resulted in a recirculation ratio approximately twice that measured on the SPES facility.

Immediately after the reactor trip however, when the SG secondary side had settled down and the recirculation ratio and riser voidage had reduced considerably, the calculated level was substantially lower than the experimental level. As a result, although the calculation correctly predicted the order and nature of the main phenomena, they all occurred significantly earlier than in the experiment - an effect that was exacerbated by an under-estimation of the pump heat losses. The low level prediction was attributed to a greater loss of inventory being calculated for the pre-trip period, caused by a delay of almost $20 \mathrm{~s}$ in the predicted trip time (on low SG level). The delay itself was a consequence of an over-prediction of the SG level in the pre-trip perind, which was believed to be due to two factors:

1. Setting the initial SG level in the calculation higher than the experimental level. 
2. The fact that the calculated level was derived from the liquid fractions in the downcomer volumes, whereas the experimental value was based on DP measurements - which, due to frictional pressure losses, were likely to indicate a lower level than the static value during the high flow conditions at full power.

For the post-test calculation an attempt was made to rectify the second discrepancy by using the predicted DP values to determine the SG level. However, due to the very high recirculation ratio that had been used in the calculation to increase the initial inventory, this resulted in an initial SG level that was below the experimental level at reactor trip. Thus, since the SG inventory at reactor trip was known to have a significant impact on the rest of the transient, it was decided to trip the post-calculation at the experimental trip time $(44 \mathrm{~s})$, regardless of the calculated SG level. A number of improvements to the modelling of heat losses were also introduced.

As expected, the use of the experimental trip time led to a better representation of the SG level behaviour in the pre-trip period, although the level was still over-predicted due to the reasons noted above. However, following the trip, the level again settled to a lower value than the experimental value, with the level error approximately half that of the pre-test calculation. The measured and experimental levels then fell slowly at a comparable rate, but with the code predicting degradation of SG heat transfer to occur at around $1800 \mathrm{~s}$ rather than $2600 \mathrm{~s}$, and SG dryout at $2330 \mathrm{~s}$ instead of $3355 \mathrm{~s}$. These discrepancies clearly affected the timings of subsequent events.

Heat balance analyses performed by Willmott (1990) show that the early prediction of SG dryout in the post-test calculation could be explained solely by the error in SG inventory at MSIV closure, which had the following contributions:

- An under-prediction of $9.3 \mathrm{~kg}$ in the initial inventory (as noted above).

- An error in the experimental value of the initial inventory, implying that the RELAP5 prediction was low by an additional $6.6 \mathrm{~kg}$.

- Discrepancies in the modelling of the MFIV closure time and drain lines, which had the effect of further reducing the RELAP5 inventory by $4.4 \mathrm{~kg}$ with respect to the experimental inventory.

A significant part of the timing discrepancies may therefore be attributed to the under-prediction of the initial SG inventory, which the authors attribute to an over-prediction of void fraction in the riser region.

It is important to recognise that there are certain features in the SPES LOF transient that exacerbate the under-prediction of the initial inventory - viz.

1. As the SG boildown occurs mostly under decay heat levels, the difference in initial inventory between the calculation and experiment takes a long time to boiloff, leading to significant differences in the timings of events.

2. Since the reactor trip was on low SG level, raising the SG level to increase the initial inventory had the effect of delaying the time of trip, which further reduced the predicted SG inventory at the time of reactor trip.

Other deficiencies in SG modelling noted in the post-test calculation were

- The primary side natural circulation mode $e^{20}$ following core recovery was incorrectly predicted due to shortcomings in the modelling of CCFL in the SG U-tubes.

20 The pumps were tripped during the primary side heat-phase when the subcooling in the pump suction fell to $3.9^{\circ} \mathrm{C}$. 
- When the auxiliary feedwater was initiated (which occurred at different times in the calculation and experiment), the SG level increased at a more rapid rate in the calculation than in the experiment. The author attributes this to an over-prediction of voidage in the riser, causing more water to accumulate in the downcomer.

Finally, no difficulties were encountered in the post-test calculation in obtaining an acceptable steady-state prediction for the initial SG heat transfer. As shown in Table 2 and Table 3. the errors in HTC-A and HTC-O are both within the experimental uncertainties, although they do indicate a slight over-prediction in heat transfer. As noted above however, the recirculation ratio in the calculation was high by a factor of two, and this would have had the effect of enhancing the heat transfer. It is also worth noting that initial secondary side conditions were slightly unstable in the test. and oscillations were present in the SG level and pressure. Consequently, appropriate average values were used for the RELAP5 analysis.

\subsection{LOBI-MOD2 tests}

The LOBI-MOD2 facility, which is located at the Joint European Research Centre at Ispra in Italy, is a $1 / 712$ th scale, full height model of the German Biblis $(\simeq 3760 \mathrm{MWt})$ PWR. The primary circuit consists of a reactor vessel with an electrically heated core and two loops: an 'intact' loop which simulates three loops in the reference plant, and a 'broken' loop with pressuriser representing a single loop on the plant. Each loop has a single active SG - the intact loop SG contains 24 inverted L'-tubes and the broken loop SG has eight tubes.

\subsubsection{Steam generator steady-state heat transfer}

No difficulties in obtaining acceptable SG initial conditions for LOBI tests have been reported for RELAP5/MOD2 calculations carried out in the UK - although some analysts have had to overcome problems associated with nonsteady experimental conditions and data uncertainties. Scriven (1988) notes however, that in order to achieve the correct steady-state primary to secondary temperature difference, the UK deck was 'tuned' slightly by reducing the U-tube wall thickness and setting the equivalent heaied diameter equal of the secondary side equal to the inter-tube gap. As explained earlier, both actions have the effect of enhancing primary to secondary heat transfer.

The only analyses which included a comparison of predicted and measured initial conditions were those performed by WTC for BT-12 and A2-90. The former simulated a steam line break test from typical hot stand-by conditions ( $\simeq 3 \%$ power), and was therefore characterised by very low temperature differences between both the SG inlet and outlet plena $\left(1^{\circ} \mathrm{C}\right)$, and the primary and secondary sides. Consequently, it does not provide reliable data for assessing SG heat transfer modelling.

In the case of A2-90, which involved a loss of offsite and normal on site electrical power from full load conditions, the estimated errors in HTC-A and HTC-O are shown in Table 2 and Table 3. Both parameters indicate an over-prediction of SG heat transfer in the intact loop and a slight under-prediction in the broken loop. However, although the uncertainties in the test measurements are not known, the errors indicated are not thought to be significant.

\subsubsection{LOCA test BL-02}

LOBI test BL-02 simulated a $3 \%$ cold leg break with normal pump trip. As seen in other LOCA test analyses, the RELAP5/MOD2 calculation of the transient (Scriven, 1987) did not reveal any significant shortcomings in SG modelling, primarily because the SG itself did not play a very important part in controlling the transient. Nevertheless, the secondary side pressure response was reasonably well predicted, although this was only achieved after particular attention had been given to the 
modelling of the relief valve, steam leak and auxlliary feed flow actuation. The decoupling of the primary and secondary side pressures was also well predicted. although this discrepancy in the equivalent LOFT test was only observed when the pump trip was delayed (i.e. L3-6, 2.5\% cold leg break). There was some evidence that the code was calculating excessive draining from the SG inlet plena, but further investigations indicated that this was due to poor modelling of CCFL along the horizonal part of the hot leg.

\subsubsection{Intact circuit fault tests ST-02 and A2-90}

\section{ST-02 loss of feed water test}

LOBI test ST-02 (subsequently renamed BT-00) simulated a loss of main feedwater transient leading via SG dryout to a long term cooldown using bleed and feed. $A$ RELAP5/MOD2 analysis of the test is described by Scriven (1988).

Unfortunately, due to numerous uncertainties in the boundary conditions and operator actions, the test did not prove to be particularly suitable from the point of code assessment. However, two shortcomings in the area of SG modelling were identified:

1. During the period when the SG was boiling down after reactor scram, and before the auxiliary feedwater was tripped when the downcomer level reached $1 \mathrm{~m}$, the primary to secondary side temperature difference was over-predicted. Further investigation into this effect revealed that the SG heat transfer coefficient was being over-predicted by roughly a factor of 2 . Scriven (1988) notes that this could be partly due to the use of a relatively coarse noding on the secondary side, and the fact that the code does not recognise the presence of a mixture level in a node, sc that the wall is assumed to be wet until the node is virtually empty. He also points out however, that even when this effect is allowed for, the RELAP5 calculation still appears to over-predict the heat transfer to the secondary side, and suggests that this might be due to the fact that the LOBI deck had been tuned to obtain the correct primary to secondary temperature difference under steady-state full power conditions. As noted above the modelling adopted had the effect of enhancing heat transfer, and it is possible that this could have resulted in an over-compensation of heat transfer for the low power, low flow conditions prevalent during boildown.

The present authors believe that another factor contributing to the over-prediction of heat transfer could be the calculation of excessive entrainment above the riser mixture level, which would have had the effect of keeping the tubes wet until the the SG was almost empty. As discussed in Section 3.8.4, this behaviour was observed in the RELAP5 analysis of LOFT test L9-3 and possibly LP-FW-01, although it is recognised that in these cases the boildown took place under essentially full power conditions. However, the possibility of an over-prediction of entrainment in ST-02 is supported by a graph presented by Scriven (1988), which shows that the primary side temperature continues to fall gradually as the SG mixture level crosses the top of the second lowest node - since in the absence of entrainment and any vertical stratification modelling. RELAP5 would be expected to predict a step rise in temperature at this point.

2. After reactor trip, the SG downcomer levels were lower in the RELAP5 calculation than the experiment, despite initially being set higher. (Although, in the broken loop, the initial level in the experiment was rather low and not well known due to an instrument failure.)

\section{A2-90 LONOP-ATWE}

Whittall (1990) presents results from a RELAP5 analysis of LOBI test A2-90, which represented a loss of offsite and normal onsite electrical power without scram. Unfortunately, the SG boildown phase of the iransient was not anaiysed in very much detail, and the results shown are complicated by the fact that the initial downcomer 
levels were incorrectly set. Consequently, the calculation does not provide suitable information for assessing RELAPS SG modelling, apart from the modelling of steady-state heat transfer at full power conditions (see above).

\subsubsection{Steam generator tube rupture test BL-21}

LOBI test BL-21 simulated a $0.4 \%$ steam generator tube rupture with failure of both the ma', and auxiliary feedwater systems and the high head safety injection system. This led to core uncovery at high pressure, after which the operator opened the pressuriser PORV to reduce the primary pressure to the accumulator set point and so restore adequate cooling.

Results from a RELAP5 analysis of the transient are discussed by Willmott (1989). The following shortcomings in SG modelling were noted.

1. The downcomer level in the intact SG boiled down more rapidly in the RELAP5 calculation than the experiment. (In the broken SG of course, the level soon rose above the measurement range as the SG filled up.) Willmott (1989) suggests two possible reasons for this discrepancy. Firstly, as was found in the ST-02 analysis discussed above, the heat transfer to the secondary side may have been over-predicted during the boildown process. Secondly, the set pressure of the broken loop SG PORV during the experiment was apparently 81 bar, rather than 80 bar as was specified and used in the deck. Evidently, both effects could have resulted in a greater proportion of the decay heat being calculated to be transferred to the intact SG. Although errors in the riser void fraction prediction could also have contributed to the level discrepancy, it is not possible to prove this conclusively.

2. The calculation provided examples of situations where the code failed to model CCFL correctly in the SG U-tubes (as for the SPES loss feedwater test), and where excessive liquid hold-up was calculated for the U-tubes. Willmott (1989) attributes the latter to an over-prediction of interphase drag in the vertical section of the hot leg preventing liquid from draining back (but gives no evidence to support this view).

\subsubsection{Steam line break test BT-12}

LOBI test BT-12 simulated a 100\% steam line break transient initiated from hot shutdown conditions, with the break downstream of the flow restrictor. Isolation of the intact loop SG occurred after $4 \mathrm{~s}$, and thus the blowdown of this SG had little effect on the transient. Smethurst (1990) presents results from a RELAP5/MOD2 analysis of the test in which sensitivity calculations were used to examine the effects of heat losses on the intact loop SG, break discharge coefficient, water in the steam lines and the code's nearly implicit numerics scheme.

In contrast to the analysis of MB-2 steam line break test T-2013, which was initiated from similar power conditions, the initial conditions calculated by RELAP5 for BT-12 indicated an under-prediction of SG heat transfer (the primary side temperature difference across the $S G$ being calculated as $0.41^{\circ} \mathrm{C}$ compared with a measured value of $1^{\circ} \mathrm{C}$ ). Again however, due to the relatively large uncertainty associated with such small temperature differences, these results are not believed to provide a reliable indicator of SG heat transfer modelling in RELAP5. Consequently, the corresponding values of HTC-A and HTC-O (-23 and $-30 \%$, respectively) have not been included Table 2 and Table 3.

It is interesting to note that in order to obtain the correct initial inventory in the broken loop SG for the RELAP5 calculation, the SG level had to be set artificially high (at 8.68 $\mathrm{m}$ instead of $8.23 \mathrm{~m}$ ). Although this problem has been encountered during the analysis of other test and plant transients, due to the very low power conditions in BT-12, it is unlikely to be a consequence of an incorrect prediction of the riser void 
fraction distribution. The most probable explanation are errors in representing the SG geometry.

Qualitatively, the general trends of BT-12 transient were well predicted by RELAP5 and, in particular, the timing of key events was fairly accurate. However, the code always over-predicted the cooldown of the primary side. which was the opposite effect to that seen with the MB-2 steam line break analysis. For the broken loop. the error in cold leg temperature was up to $13^{\circ} \mathrm{C}$ in the broken loop cold leg, although by the end of the transient the difference had been reduced to $7^{\circ} \mathrm{C}$. compared to an overall experimental cooldown of $24^{\circ} \mathrm{C}$.

Possible reasons for the $7^{\circ} \mathrm{C}$ discrepancy in the overall cooldown are discussed by Smethurst (1990). The possibility that this could be due to an under-prediction of the liquid entrained in the break flow is ruled out because, as for the MB-2 analysis, the available evidence indicates that RELAP5 over-predicted this quantity. A possible contribution of $1.3^{\circ} \mathrm{C}$ from temporary variations in the auxiliary feedwater temperature was identified, but this was clearly not enough to explain the discrepancy. The most plausible explanation was that the metalwork in the broken lvop SG contributed more heat to the fluid than predicted, resulting in liquid being calculated to return to the boiler and remove primary side heat, rather than being evaporated by metalwork heat in the upper regions of the SG. The information available indicated that the mass of SG metal in the model was under-estimated by about $15 \%$, and the author calculated that the corrected metalwork mass would remove the final $7^{\circ} \mathrm{C}$ discrepancy.

In the broken loop SG, the secondary side pressure calculated by RELAP5 agreed reasonably well with the data for the first $100 \mathrm{~s}$ of the blowdown transient. After this point however, the predicted pressure fell more slowly than the measured pressure, until $160 \mathrm{~s}$ when a very rapid fall in pressure occurred as the SG dried out. This temporary hold-up in pressure was accompanied by an over-prediction in the primary side cooldown, and was responsible for the peak difference of $13^{\circ} \mathrm{C}$ between the predicted and measured cold leg temperature. The reasons for this discrepancy are not discussed by Smethurst (1990). However, the effects observed are similar to those seen in some boildown transients, where the code has apparently over-predicted the liquid entrainment above the mixture level, causing the tubes to remain wet and provide good heat transfer until the SG has virtually emptied.

\subsection{Steady-state analysis for Once-Through Integral System}

The Once-Through Integral System (OTIS) test facility was designed to simulate conditions in the reactor coolant system and stearn generator of a raised-loop B\&W PWR, during the natural circulation phases of a sinall break LOCA. It consists of a one-by-one (one hot leg, one cold leg) electrically heated loop in which key components of the reference plant are represented at 1/1632 scale, and is capable of supplying scaled powers ranging from 1 to $5 \%$ of full power. The loop has a single 19-tube once-through steam generator (OTSG).

Note that all other plant and facilities examined in the present review have $U$-tube $S G s$, as does sizewell ' $B$ '. The reason for including results from the OTIS facility is to allow a comparison to be made of steady-state heat transfer characteristics of $U$-tube and once-through SGs, so that the modelling requirements for each design may be established.

Dimenna, Hall, Kullberg, Larson, Larson and Watkins (1989) present results from a RELAP5 analysis of a loss of feedwater transient performed on the OTIS, in which the initial conditions corresponded to plant conditions at approximately 1.5 minutes after reactor trip and pump coastdown, with auxiliary feedwater activated. In the RELAP5 calculation, the initial SG pressure was under-predicted by 3 bar (from 80 bar), and the initial core $\Delta T$ was over-predicted by $2^{\circ} \mathrm{C}$. As shown in Table 2 and Table 3 , the corresponding errors in HTC-A and $\mathrm{HTC}-\mathrm{O}$ are -10 and $-52.5 \%$ respectively, indicating an under-prediction of SG heat transfer, although the uncertainties in the test measurements are not known. 
It is pertinent to note that difference between the hot and cold leg temperatures in the OTIS test was $22^{\circ} \mathrm{C}$, whereas the measured SG heat flux was only $0.5 \mathrm{~W} \mathrm{~cm}^{-2}$. This temperature difference is significantly greater than that seen in experiments carried out in U-tube SGs at similar heat fluxes (viz. the steam line break tests review in this report). For example, for LOBI test BT-12, the initial SG heat flux was also 0.5 $W \mathrm{~cm}^{2}$ but the difference between the hot and cold leg temperatures was only $1^{\circ} \mathrm{C}$. Also, in MB-2 test T-2013 and Semiscale test S-FS-1, the initial heat flux was 0.3 $\mathrm{W} \mathrm{cm}{ }^{-2}$ and the temperature differences were 0.6 and $0.7^{\circ} \mathrm{C}$, respectively." Although this could indicate that SG heat transfer is better in a U-tube SG than in a OTSG, implying that different models may be needed in each case, it should be remembered that the mixture level is above the tube bundle in a U-tube $S G$ but approximately half way up in a OTSG. Consequently, the actual heat flux to the mixture region is greater than that quoted in the tables by roughly a factor of $2^{22}$. In addition, the mass flux is somewhat less in a $U$-tube SG and the mixture quality is unlikely to rise above $30 \%$ or less, whereas in a OTSG the quality reaches $100 \%$ at the mixture level. The thermal-hydraulic conditions are therefore quite different in the two types of SG, implying that the apparent difference in heat transfer characteristics may not necessarily be due to geometric features alone.

\subsection{Semiscale tests}

The Semiscale Mod-2C facility represents a $1 / 1706$ th scale, full height model of a four-loop (3411 MWt) PWR. It consists of a reactor vessel with an electrically heated core and two primary loops, identified as the intact loop and the broken loop. The intact loop is scaled to represent three loops of the reference plant and the broken loop represents the remaining PWR loop. Each loop has an active U-tube SG in which the component flow areas, volumes, lengths and pressure drops are sized to simulate a Westinghouse Model 51 SG, although both SGs incorporate an external downcomer and have a separator which is not typical of any PWR plant. The broken loop SG has only two U-tubes and the iniact loop SG has six.

\subsubsection{LOCA tests S-LH-1 and S-LH-2}

Semiscale tests S-LH-1 and S-LH-2 both simulated a $5 \%$ cold leg break transient with a normal pump trip. The only difference between the tests was the presence of a large core bypass flow in S-LH-2. As a result, the core level depression prior to loop seal clearance was less severe in S-LH-2 and, unlike S-LH-1, did not lead to core uncovery. Following loop seal clearance however. both tests experienced a period of core uncovery due to coolant boiloff.

Results from RELAP5/MOD2 calculation of S-LH-1 and S-LH-2 are described by Hall and Bull (1989) and Brodie (1989). Like other RELAP5 LOCA test analyses, no significant deficiencies in SG modelling were identified (as the SG played only a minor role in the overall primary system energy removal). However, the following points are worth noting.

1. When calculating the initial steady-state conditions for the tests, the SG level for the intact loop had to be set artificially low to allow RELAP5 to simulate stabie operation of the SG. As a result, the SG liquid inventory was under-predicted by some $20 \%$. It is possible that errors in the void fraction modelling in the riser could have contributed to this discrepancy (as seen in other calculations) -

21 In fact, in all ihese tests, the temperature differences were too low to allow reliable estimates to be made of HTC-A and HTC-O, which is not the case for the OTIS experiment.

22 It should also be noted however, the Dimenna et al. (1989) do not quote the tube diameter and heated length for the OTIS SG, and the dimensions used in this study for estimating the average heat flux were those given by Hassan (1988) for an unspecified 19-tube OTSG model. 
although, in the broken loop SG, the inventory was predicted to within the experimental uncertainty. ${ }^{23}$

2. No difficulties were encountered in obtaining satisfactory steady-state predictions for the SG pressures and primary side temperatures. As shown in Table 2 and Table 3, the errors in HTC-A and HTC-O are relatively small. Although some errors are a little larger than the uncertainty estimates (particularly those associated with the broken loop SG in test S-LH-2), these are not thought to be significant.

3. In the transient calculations, the SG pressures were systematically over-predicted at all times after closure of the MSIVs, but the errors appeared to have only a minor influence on the test predictions. For $S-L H-1$, some sensitivity calculations were performed which indicated that the discrepancies observed later in the test could be accounted for by assuming a MSIV leakage of less than $0.16 \%$.

4. Errors were present in the RELAP5 predictions of the liquid hold-up in the SG tubes. However, no clear systematic trend was evident and the core level depression prior to loop seal clearance was reasonably well predicted for both tests.

\subsubsection{Steam line break test S-FS-1}

Semiscale test S-FS-1 simulated a $100 \%$ steam line break transient initiated from hot shutdown conditions, with the break downstream of the flow restrictor. The intact loop SG blew down through a separate break assembly but was isolated after $20 \mathrm{~s}$, when a safety injection (SI) signal was generated on low SG pressure. A loss of offsite power was assumed coincident with the SI signal, causing the primary pumps to trip and delaying the operation of the high head safety injection and auxiliary feedwater systems. Results from a RELAP5/MOD2 analysis of the test are presented by Rogers (1989a). For this analysis, the measured secondary side pressure behaviour in the intact SG was imposed as a boundary condition.

Some difficulties were encountered in the RELAP5 analysis in calculating initial steady-state conditions for the SGs. These difficulties were really a consequence of the hot standby conditions - in particular the almost stagnant liquid conditions present on the secondary side and the small heat transfer across the tubes ${ }^{24}$. The difficulties were eventually overcome by modifying the control systems used to adjust the feedwater and steam valves and achieve the desired SG mass. The values of HTC-A and HTC-O corresponding to the calculated and measured initial conditions indicate a large over-prediction of SG heat transfer. However, as noled for the other steam line break tests, due to the large uncertainty in these parameters at very low power conditions, they do not provide a reliable indicator of heat transfer modelling.

Overall, the RELAP5 predictions for the transient phase of the test gave acceptable agreement with the experimental results. A number of differences were apparent however, and these are discussed below.

1. For the short period while single phase steam was being discharged from the break (0-3 s), the predicted SG depressurisation matched the experimental behaviour almost exactly. When the break flow became two-phase however, the

23 Note that for both tests, the analysts do not quote the calculated and measured SG levels, only the inventories. It is possible that the experimental levels were not known and that the calculations attempted to match the experimental inventories. If this was the case, the low inventory required for stable operation of the intact SG could be explained by an under-prediction of void fraction in the riser, and the correct prediction for the broken loop SG would not necessarily indicate correct void fraction modelling in its riser.

24 It is likely that similar problems were encountered when sefting up initial conditions for the experiment. 
predicted pressure and cold leg temperature fell less rapidly. This indicates that the liquid carryover to the break was greater in the calculation than the experiment, a conclusion supported by the predicted and measured break flow densities. A similar effect was observed in the RELAP5 analysis of the MB-2 and LOBI steam line break tests. In the Semiscale calculation, the carryover appeared to correct itself by about $15 \mathrm{~s}$, with the subsequent depressurisation being over-predicted.

2. The SG tubes dried out somewhat earlier in the RELAP5 calculation than they did in the experiment (at approximately $40 \mathrm{~s}$ as opposed to $70 \mathrm{~s}$ ) and this, together with the lower initial depressurisation, resulted in an under-prediction of the overall primary side cooldown (by around $20^{\circ} \mathrm{C}$ ). The later dryout in the experiment could be explained by liquid that had accumulated in structures in the upper SG during the early period of the blowdown, which was not modelled in the calculation, draining back into the top of the riser. This type of effect was apparent in the RELAP5 analysis of the MB-2 steam line break test, and it was also suggested that accumulation of liquid in the experiment could explain the over-prediction of carryover in the RELAP5 calculation. Although the opposite behaviour was evident in the analysis of the LOBI steam line break test, with the predicted dryout occurring late, much of the liquid carried into the upper SG in the experiment was believed to have been boiled off by the release of metal work heat.

3. When the SG dried out in the RELAP5 calculation, the heat transfer reduced in a step-wise manner as each node progressively changed heat transfer mode (even though the SG was relatively finely noded in the U-tube region). In contrast, the experimental data indicated a rapid drop in primary to secondary heat transfer when dryout occurred. This step effect is clearly a consequence of the absence of any partitioning of heat transfer in a node between the regions above and below a mixture level.

\subsection{Studies performed at Texas A\&M University}

A number of studies of SG modelling in RELAP5/MOD2 have been carried out by Prof. $Y$ A Hassan and his co-workers at Texas A\&M University. The results of these studies are summarised below.

\subsubsection{Steady-state heat transfer in a OTSG}

Hassan and Blanchat (1990) describe a series of steady-state RELAP5 calculations for a full sized model of a OTSG, that were carried out using modified versions of RELAP5/MOD2. At $100 \%$ load conditions, the standard version of the code was found to predict an outlet superheat of only $11^{\circ} \mathrm{C}$, compared to a $22-33^{\circ} \mathrm{C}$ superheat suggested by plant test data ${ }^{25}$. The authors attributed this discrepancy to the use of correlations derived from tube data to represent thermal-hydraulic phenomena in the bundle region. Following a review of the literature, the code was therefore modified to apply more appropriate criteria for the bubbly to slug and slug to annular flow regime transitions. These changes however, made little difference to the predicted temperature profile - although fixing the slug to annular transition in the downcomer to occur at a void fraction of 0.75 did result in near saturation conditions at the tube bundle inlet (as would be expected), whereas the standard version of the code predicted subcooled conditions.

25 In a OTSG, the primary fluid enters the SG through a nozzle at the top, flows down through more than 15000 straight tubes and exits at the bottom head through two outlet nozzles. On the secondary side, subcooled feedwater is sprayed downwards into an annulus between the SG shell and tube bundle shroud, where it is heated to saturation by direct contact with steam aspirated from the bundle. It then enters the bottom of the tube bundle where nucleate boiling begins. After reaching $100 \%$ quality at about the mid-bundle elevation, the steam is superheated in the upper half of the bundle, flows down through the steam annulus and exits through iwo steam outlel nozzies. 
The authors then turned their attention to the heat transfer correlations applied in the bundle region. The first modification introduced was to change the constant in the Dittus-Boelter equation, which is used in the code to model convective heat transfer to single phase liquid (and vapour), to be consistent with the results of Weisman (1959), who correlated available heat transfer data for water flowing parallel to tube bundles. This resulted in an increase in the value of the constant from 0.023 to 0.0304 , but since single phase forced convection to liquid was never predicted in the OTSG bundle, the modification had no effect on the temperature profile (even though it was presumably applied in the single phase vapour region). However, introducing the same modification to $H_{\text {mac }}$ in the code's Chen correlation (see Section 2.4) resulted in an increase in the predicted superheat of $1.1^{\circ} \mathrm{C}$.

Based partly on an equation for the liquid-only two-phase friction factor developed by Ishihara. Paleo and Taborek (1980) using data from a variety of tube banks, the authors then performed a number of investigations in which the factor $F$ in the Chen correlation was modified in various ways to increase the heat transfer coefficient to the range determined experimentally by Boucher (1987b) for the Semiscale SG. The expression ultimately adopted was

$$
F=\left[1+\frac{20}{x_{t t}}+\frac{1}{x_{t t}^{2}}\right]^{0.75}
$$

which, together with the other modifications, produced an increase in the predicted superheat for the OTSG model of $8^{\circ} \mathrm{C}$ The combined modifications also resulted in better predictions of the primary and secondary side temperature profiles for a 19-tube integral economiser OTSG test facility, although the outlet superheat was still under-predicted.

In a subsequent study, Blanchat and Hassan (1989) examined the application of different CHF correlations for the secondary side of a OTSG, and recommended the use of the lookup table developed by Groeneveld, Cheng and Doan (1986) - although this had no effect on the steady-state predictions. Rais and Hassan (1990) later showed that with the proposed bundle forms of the boiling heat transfer and CHF correlations, and if the interphase drag in the bundle was also determined using the EPRI drift flux correlation, RELAP5/MOD2 correctly predicted the degree of superheat for a 30-tube OTSG facility at 65,75 and $100 \%$ load conditions. The authors evidently attribute the improved agreement over the earlier comparisons to the new interphase drag model. The present authors believe that this is due to a lower void fraction being calculated in the mixture region, resulting in an increase in the modified suppression factor used in the Chen correlation.

\subsubsection{Steady-state heat transfer in a U-tube SG}

Hassan and Salim (1990) describe the development of a boiling heat transfer correlation for RELAP5/MOD2 for application in a U-tube SG. The work was performed using a two-loop model of a full size PWR with pre-heated type SGs. During the steady-state initialisation of the model, it was found that the code under-predicted the primary to secondary heat transfer. In particular, RELAP5 calculated a cold leg temperature of 299.45 degreeC, which was significantly higher than the design temperature of $293.35^{\circ} \mathrm{C}$.

In an attempt to rectify this effect, the bundle heat transfer and critical heat flux correlations developed for the OTSG case were implemented in the code. As a result, the predicted cold leg temperature was reduced to $296.65^{\circ} \mathrm{C}$, which was still $3.3^{\circ} \mathrm{C}$ too high, indicating that a further improvement in heat transfer was required. A short investigation was then carried out using different expressions for the factor $F$ in the Chen correlation, from which the following equation was recommended

$$
F=\left[1+\frac{40}{x_{t t}}+\frac{5}{x_{t t}^{2}}\right]^{0.75}, \quad x_{t t}^{-1} \leq 5
$$


This particular equation produced a cold leg temperature of $294.95^{\circ} \mathrm{C}$ (which was only $1.6^{\circ} \mathrm{C}$ too high) and also gave good agreement with experimental data obtained from the Semiscale SG. In particular, both tne data and modified correlation exhibited a convex variation of heat transfer coefficient along the U-tubes, whereas the standard RELAP5/MOD2 correlation shows a slightly concave variation.

Note that the expressions for $F$ developed at Texas A\&M for the OTSG and U-tube SG situations (i.e. equations (21) and (22)) have a very similar form, except that the equation for a $U$-tube $S G$ produces a more rapid increase in $F$ with $X_{F}^{-1}$ and thus quality. This may reflect the fact that the quality in the boiling region of a U-tube SG is not as high as in a OTSG. In particular. $X_{i}^{-1}$ varies from 0.2 to 50 in the nucleate boiling regime of a typical OTSG (Hassan and Blanchat, 1990), but for a U-tube SG. does not normally exceed a value of 5 (Hassan and Salim, 1990).

It is also worth noting that equation (21) (and (22)) predict a much stronger dependence of $F$ on quality than the standard expression, viz.

$$
F=2.35\left(X_{t t}^{-2}+0.213\right)^{0.736}
$$

and this dependence seems to be supported for U-tube SGs by measurements of the boiling heat transfer coefficient from Semiscale. However, it should not be forgotten that the calculations performed by Hassan and Salim (1990) using their modified form of RELAP5/MOD2 also (presumably) made use of the modified suppression factor $S$ :. As noted in Section 2.4, this tends to enhance the heat transfer coefficient as the void fraction (and thus quality) reduces, which is the opposite trend to that observed in the Semiscale data.

In a separate study using the Texas A\&M RELAP5/MOD2 U-tube PWR model, Salim and Hassan (1990) found that the desired heat transfer between the primary and secondary sides could be achieved by reducing the hydraulic diameter of the SG U-tubes. The specific value used is not quoted, but it is evident from the values of the heat transfer coefficients shown that a reduced hydraulic diameter was used on both the primary and secondary sides. The authors also claim that the use of a smaller hydraulic diameter did not significantly affect the predicted transient behaviour for a small break LOCA calculation.

\section{ANALYSIS OF WOLF CREEK STEADY-STATE COMMISSIONING TESTS}

This section describes a RELAP5/MOD2 analysis of SG behaviour recorded during a series of steady state commissioning tests carried out on the Wolf Creek PWR over a range of load conditions. The results are used to provide information on SG heat transfer modelling in the code, which is directly relevant to Sizewell ' $B$ ' plant calculations. Sensitivity studies are performed to ascertain the adjustments required to selected heat transfer parameters in order to achieve agreement with the test data.

A brief description of the Wolf Creek PWR is given at the beginning of Section 3.1 and in Table 1.

\subsection{Description of tests}

In 1978 Westinghouse and the SNUPPS utilities agreed to sponsor a joint test programme to provide detailed measurements of the thermal-hydraulic performance characteristics of one of the first Model ' $F$ ' SGs to go into commercial service. The Wolf Creek generating station, a four loop system with a rated thermal output of 3425 $\mathrm{MW}$, was chosen to be the site of this test programme. 
During the commissioning tests ineasurements were concentrated on a single steam generator which had been constructed with 13 additional ports to take special instrumentation for internal secondary side measurements. The data recorded (Curlee and Preece, 1987) for each test condition represent plant measurements averaged over 10 minutes when the plant was operating under nominal steady-state conditions. This covers loads from $23 \%$ to full load, together with a number of loads below $10 \%$. Unfortunately, due to feed flow instability problems, it was not possible to achieve steady state conditions in the load range $10 \%$ to $23 \%$.

Internal SG measurements relevant to the present study are:

1. Downcomer flow velocity.

2. Downcomer fluid temperature.

3. Component pressure drop.

The main reason for measuring fluid velocity and temperature within the downcomer is to enable the circulation ratio to be evaluated. Location of static pressure tapping points throughout the steam generator are shown in Fig. 6. Pressure drop measurements of special interest are summarised in the following table.

\begin{tabular}{|c|c|c|}
\hline $\begin{array}{c}\text { Differential } \\
\text { pressure }\end{array}$ & Component & $\begin{array}{c}\text { Pressure measurement } \\
\text { location }\end{array}$ \\
\hline PT7-PT8 & Mid-deck plate & Across mid-deck plate \\
\hline PT9-PT8 & $\begin{array}{c}\text { Tube bundle primary } \\
\text { separator and mid } \\
\text {-deck plate }\end{array}$ & $\begin{array}{c}\text { From low in the downcomer } \\
\text { to the steam dome }\end{array}$ \\
\hline PT8-Pi & $\begin{array}{c}\text { Primary and } \\
\text { secondary dryer }\end{array}$ & $\begin{array}{c}\text { From mid-deck plate } \\
\text { to steam dome exit }\end{array}$ \\
\hline
\end{tabular}

A full description of the special instrumentation used and location details can be found in Curlee and Preece (1987).

In addition to the special instrumentation, measurements were supplemented by general plant data from permanent process and control instrumentation which form part of the nuclear steam supply system (NSSS). These data include:

1. Primary circuit - pressuriser pressure

- hot and cold leg temperature

- reactor power

2. Secondary circuit - steam flow, temperature and pressure

- feed flow

- feedwater inlet temperature

- downcomer water level

The steam pressure measurements, which provide an important quantity for assessing SG heat transfer modelling in RELAP5, were normally made using three pressure transducers equi-spaced around the steam main at the containment boundary. However, for some of the earlier tests, these were supplemented with a Heise direct-reading gauge mounted on the steam main close to the pressure transducers. The Heise gauge values are the preferred ones because of the relatively high precision achievable, $\pm 0.1 \mathrm{bar}$, compared with $\pm 0.45 \mathrm{bar}$ for the pressure transducer. 
In addition to this other relevant parameters are derived from plant measurements. For example the primary fluid flow is deduced from measurements of the cold and hot leg temperatures and thermal power (NSSS trend block data). However, because the cold leg temperature is measured downstream of the recirculation pump. son:e temperature correction is initially required to allow for the heat input. $Q_{p}$. fron: pumping. Thus, the corrected cold leg temperature. $T^{\prime}{ }_{c}$, is found from:

$$
T^{\prime}{ }_{c}=T_{c}-\frac{Q_{p}}{C_{p} \dot{m}_{p}^{\prime}}
$$

where $Q_{0}=4954.25 \mathrm{~kW}$, (Davis, 1984) and $\mathrm{m}_{\mathrm{p}}$ is an initial guessed value for the primary fluid flow. Since enthalpy on the cold leg side, $H_{c}$, is found from $H_{c}=H_{c}\left(T^{\prime}{ }_{C}, P_{D}\right)$, then

$$
\dot{m}_{p}=\frac{Q}{\left(H_{h}-H_{G}^{\prime}\right)}
$$

The calculation is concluded when $\mathrm{m}_{\mathrm{p}}^{\prime}=\mathrm{m}_{\mathrm{p}}$

The effective values of the downcomer flow and feed flow are the plant values minus the blowdown flow. Thus the circulation ratio, on a mass flow basis, is given by:

$$
\frac{\left(\dot{m}_{d}-\dot{m}_{b}\right)}{\left(\dot{m}_{f}-\dot{m}_{b}\right)}
$$

Before describing the way in which the Wolf Creek plant data are used in RELAP5/MOD2 it is important to understand the limitations in the plant measurements and then to quantify these. This is all the more important since in practice the steam pressure is not measured in the area of interest in the inlet plane of the steam generator flow restrictor nozzle, but at some considerable distance downstream in the steam main at the containment boundary. Careful account then has to be taken of the static and dynamic pressure head loss in order to deduce an accurate value of the steam pressure in the plane of interest. The problem with this method is that it can introduce errors in addition to the basic pressure measurement error and this needs to be addressed. The standard method employed to quantify compound errors of this type is outlined in Appendix B. The results of this are summarised in the following table in terms of uncertainties about the mean value for a given steam generator duty.

\begin{tabular}{|c|c|c|}
\hline Load, \% & $\mathbf{3 6 . 1}$ & $\mathbf{9 8 . 9}$ \\
\hline $\begin{array}{c}\text { Mean } \\
\text { pressure, bar }\end{array}$ & 72.400 & 70.738 \\
\hline Uncertainty, \% & \pm 0.143 & \pm 0.147 \\
\hline
\end{tabular}

\subsection{Tests analysed}

From the datasets recorded by Curlee and Preece (1987), five cases were chosen for detailed analysis using the RELAP5 code. The SG conditions covered by these tests are summarised in Table 4. The data selected concentrate on representative tests which encompass a wide range of load conditions $(36 \%$ to $99 \%$ of the full thermal output of $856 \mathrm{MW}$ from a single steam generator). The selection makes use of the most accurate measurements of steam pressure, based on the Heise gauge values, whilst avoiding the low load cases which may suffer from some form of control system instability. 


\subsection{RELAP5/MOD2 model}

For each of the tests selected, RELAP5/MOD2 was applied to simulate the thermal-hydraulic performance of a single SG. The input deck used for these calculations was derived from the two-loop Sizewell ' $B$ ' whole plant deck described by Harwood (1986). This was felt to be an acceptable approach as the geometric and material characteristics of the Wolf Creek and Sizewell B SGs are essentially identical for simulation purposes. The deck was created by extracting the data cards for the broken loop SG and introducing appropriate boundary conditions to represent the rest of the NSSS.

The nodalisation scheme used for the calculations is shown in Fig. 7 and encompasses the primary side pump suction leg and hot leg elements, the secondary side main feed and the steam generator steam main element. Excluded from the present model are the main steam inlet valve. steam relief valves and the power operated relief valve. The auxiliary feed is also omitted as is the primary side recirculation pump.

In the model, the primary side flow and hot leg temperature are represented by a time dependent junction, TDJ and a time dependent volume.TDV, connected to the steam generator inlet plenum. Pressure within the TDV is set equal to that in the inlet plenum. The pump suction pressure is represented by a TDV connected to the steam generator outlet plenum.

On the secondary side, the main feedwater flowrate and temperature are represented by a TDJ and TDV ${ }^{26}$. The main feed flow through the TDJ is varied to achieve the desired water level in the steam generator. To do this the adjusted flow is set equal to the specified flow in addition to a term based on the level error. The steady state steam outlet flow is represented by a TDJ connecting the top of the steam dome to a dummy steam main TDV, with steam flow set equal to the specified main feed flow. With this arrangement the dummy steam main pressure has no effect on the steam generator performance.

The required circulation ratio is achieved by adjusting the downcomer flow. The downcomer flow is itself controlled by adjusting the friction losses at the junction between the downcomer and riser by varying the junction flow area.

The boundary conditions for the steam generator model are, therefore, specified as follows:

1. Hot leg temperature.

2. Primary flow.

3. Cold leg pressure.

4. Feed water temperatu,e.

5. Feed water flow.

6. Desired SG narrow range water level.

7. Desired downcomer flow.

These may be obtained from Table 4

The calculations were performed using an IBM version of RELAP5/MOD2 cycle 36.04 operating on the NP TEC VM system. Some of the calculations were also repeated using the PWR-Project version (P01) of the code.

26 The feedwater pressure is set to a nominal value, which was felt to be adequate, as this pressure only affects the local fluid properties. 
The calculated values of the secondary side pressure and pump suction leg temperature were used to assess SG heat transfer and vapour generation rate modelling in the code. As discussed in Section 2.2. for the boundary conditions imposed, an error in the secondary side pressure may be attributed to errors in the primary to secondary heat transfer and vapour generation rate models. An error in the pump suction leg temperature on the other hand, may be attributed solely to errors in the vapour generation rate models.

\subsection{Base case calculations}

The difference between the calculated value of steam pressure in the steam generator dome and that deduced from plant measurements at Wolf Creek is indicated in Fig. 8 over a range of reactor power. The calculated steam pressure in this case is that evaluated at the nodal element 612-03 (see Fig. 7), which is compared with the plant value corresponding to the inlet to the steam flow restrictor nozzle (see Fig. 6). The difference between the measured and calculated values are shown to increase monotonically with load, leading to a maximum discrepancy of about 3.5 bar at full load. The initial question raised is whether or not this could be the result of inadequate modelling of the pressure loss components throughout the height of the steam generator.

In practice the main pressure drop component measured on plant is that between the bottom of the downcomer to a point just above the mid-deck plate. Comparison of the calculated and measured values are shown in Fig. 9. Since agreement is to within about $4 \%$ over a substantial load range, this tends to confirm the adequacy of the component pressure loss modelling up to this level. Individual, although small component pressure losses, however, might not be necessarily well modelled as shown for example in Fig. 10, concerning the pressure loss across the mid-deck plate. Better modelled is the pressure loss component between the mid-deck plate and inlet to the steam restrictor nozzle shown in Fig. 11, but again this component is relatively small. Since, therefore, the overall component pressure drop appears to be reasonably well modelled, this leads to the conclusion that the bulk of the discrepancy lies in the calculation of the absolute value of the steam pressure as indicated in Fig. 8.

To investigate this, a comparison between the measured and calculated temperature at the SG outlet plenum (pump suction leg) has been carried out over the load range $36 \%$ to $99 \%$. The measured temperature used in this case incorporates a correction to allow for the heat input from pumping as described in Section 4.1. The calculated temperature corresponds to that in the nodal element 330-01 (see Fig. 7).

The comparison in fact indicates very close agreement with the measured data to within +0.3 to $-0.04 \mathrm{deg}$.C. This effectively validates the vapour generation rate model and as such eliminates it as a prime cause of the error in the calculation of the steam outlet pressure. This error may therefore be attributed to inaccuracies in the modelling of primary to secondary side heat transfer.

\subsection{Sensitivity calculations}

As discussed in Section 2, it is possible to compensate for an under-prediction of SG heat transfer in RELAP5/MOD2 by:

1. increasing the SG tube thermal conductivity,

2. increasing the total heated length of the SG tube, or

3. reducing the heated diameter on the secondary side of the tube bundle, to increase the local heat transfer coefficient.

These changes can be achieved by modifying the RELAP5/MOD2 input deck. 
A series of sensitivity calculations, therefore, was carried out to determine the parameter adjustments required to force the code to calculate the correct secondary side steam outlet pressure for the Wolf Creek tests at $36 \%$ and $99 \%$ load. The results are summarised in Table 5. Bearing in mind that there is a degree of uncertainty associated with the plant measurements, the effect of this, expressed in terms of upper and lower bounds on the adjustment factors, is also indicated.

In all cases the adjustment factor increases with the power level. Of the heat transfer parameters examined, the heated tube length appears to be the most sensitive, with an adjustment of only 8 to $28 \%$ required over the power range examined. Even allowing for plant measurement uncertainties the range of adjustment extends only to 6 to 29\%. The heat transfer appears also to be fairly sensitive to the tube thermal conductivity. In contrast to this the factor applying to the heated-tube diameter has considerably less impact. In this case the heated diameter (expressed as a fraction of the inter- tube gap) ranges from 1/8.3 to 1/164. With plant measurement uncertainties taken into account the factor range extends from $1 / 5.7$ to $1 / 179$. These results are consistent with the theoretical analysis discussed in Sections 2.4 and 2.6.

A further example of the way in which the heat transfer is affected as a result of a forced parameter change in order to achieve the correct steam outlet pressure is illustrated in Fig. 12, for the heated tube diameter. This shows the variation of the heat transfer coefficient, at $99 \%$ load, with the developed SG tube length, in a comparison between the enhanced value and the base case value. The enhancement, shown as a ratio in the inset figure, indicates over a three-fold increase in heat transfer in the upper region of the tube bundle. Most of the gain in the heat transfer occurs on the cold leg side, although on this side the heat transfer coefficient is clearly less.

The load dependence of the effect of heated tube diameter on heat transfer is further illustrated in Fig. 13, for the 36\% load case. As expected, a much smaller change is required as suggested by a maximum increase in the heat transfer of only about $30 \%$, again in the upper region of the tube bundle.

\section{ASSESSMENT OF STEAM GENERATOR MODELLING DEFICIENCIES}

The Sections 3 and 4 have discussed and investigated various deficiencies in SG modelling that have come to light during RELAP5/MOD2 analyses of plant and rig data. The principal phenomena involved may be summarised as follows.

1. Primary to secondary heat transfer under steady-state, normal operating and start-up conditions.

2. Secondary side liquid inventory under steady-state conditions.

3. Downcomer level trajectories under fast boildown conditions (e.g. at full power).

4. Wall heat transfer above the mixture level during boildown and blowdown transients.

5. Dynamic level swell in response to steam discharge from the SG.

6. Liquid carryover to break during steam line break transients.

7. Separator performance.

8. CCFL and liquid hold-up on primary side.

9. Secondary side condensation effects during repressurisation transients. 
This section presents an assessment of RELAP5/MOD2 in the above areas. In each case, the principal code deficiencies are identified together with the specific models responsible. Where appropriate, the errors involved are quantified and the underlying parametric trends are noted. The implications for PWR safety analysis are also assessed and methods for compensating for the deficiencies through changes to the input deck. which may be used in sensitivity studies, are discussed. Consideration is also given as to whether the deficiencies identified will still be present in RELAP5/MOD3 and recommendations for future code development and assessment studies are made. These may be addressed in a subsequent study aimed at assessing SG modelling in RELAP5/MOOO3.

At this stage however, it is worth noting that although the list of deficiencies may appear long, in most cases the implications for PWR safety analysis are not serious.

\subsection{Primarv to secondary heat transfer under normal operating conditions}

\subsubsection{Code deficiencies}

In the review of code assessment calculations presented in Section 3, numerous examples were noted in which RELAP5/MOD2 had under-predicted the total primary to secondary heat transfer under steady-state normal operating conditions. The Wolf Creek analyses described in Section 4 confirmed this effect and also showed that it was not restricted to full load conditions.

As discussed in Section 2.7, a convenient way of quantifying modelling errors in this area is to compare predicted and measured values of the overall primary to secondary heat transfer coefficient. Two definitions of this parameter were considers. (HTC-A and HTC-O) and, as part of the review. the \% errors in the predicted values of both parameters were evaluated for all RELAP5/MOD2 calculations considered, for which sufficient information had been reported. The results of this exercise are summarised Table 2 and Table 3.

In order to obtain an overall picture of SG modelling in RELAP5/MOD2 and to ascertain whether the deficiencies observed depend on SG conditions and scale, the errors in HTC-A and HTC-O have been plotted in Fig. 18 and Fig. 19 against the measured value of the average SG heat flux. Additionally, Fig. 20 shows the errors in HTC.A plotted against the average primary to secondary temperature difference Dr-A. In each case, where the error in HTC lies within the experimental uncertainty, the uncertainty is shown as a vertical line (altrough the uncertainties in the LOBI and OTIS data are not known).

Before considering the results presented it is important to recognise that the uncertainty in HTC can be relatively large. In addition, as discussed in Section 2.6, the predicted primary to secondary heat transfer is dependent on the definition used for the secondary side heated diameter and the calculated value of the recirculation ratio, both of which are not always known. The review of RELAP5 analyses also found that othe. modelling parameters could affect calculated SG heat transfer - e.g. nodalisation. All these factors tend to obscure the trềnds exhibited in the figures, making it difficult to formulate precise conclusions regarding the underlying modelling deficiencies. Nevertheless, the following statements may be made.

- The figures provide substantial evidence that RELAP.5/MOD2 under-predicts SG heat transfer under steady-siate conditions and over a wide range of load conditions. Although many of the error points lie within the experimental uncertainty, there is a clear bias in the direction of an under-prediction of heat transfer. 
- The Wolf Creek results obtained at NP TEC with the secondary side heated diameter set equal to the tube $O D$, and for which the recirculation ratio was calculated correctly, show that the errors in HTC tend to reduce with decreasing reactor power - which may be interpreted as a reduction with decreasing heat flux or decreasing primary 10 secondary temperature difference. The deviation from a strictly monotonic tiand possibly results from data uncertainties.

A reduction in the error in SG heat transfer modelling with reactor power was also apparent in the Wolf Creek sensitivity calculations described in Section 4.5. In particular, the parameter adjustments needed to achieve agreement with the data at $99 \%$ load were significantly greater than those required at $36 \%$ load.

- Of the two Wolf Creek calculations performed at NE TD (which were also made with the secondary side heated diameter set equal to the lube OD), the calculation providing the smailer errors in HTC corresponds to the plant trip test. As discussed in Section 3.1.2, the data for this test may not be very reliable. The results for other calculation are similar to the NP TEC results, and the slightly lower errors in HTC are consistent with a higher prediction for the recirculation ratio.

- For the smallest scale facilities incorporating U-tube SGs - viz. SPES at $1 / 427$ th scale, LOBI at 1/712th and Semiscale at 1/1706th - the tendency for RELAP5/MOD2 to under-predict SG heat transfer is less noticeable (if anything, the results indicate a slight tendency to over-predict heat transfer). This implies that the erriors in heat transfer may reduce with scale. Note however, that the $L O B \mid r \in$ sults were obtained using a secondary side heated diameter equal to the inter-tube gr.p (and a reduced wall thickness), and the recirculation ratio for the SPES calculation was high by a factor of two. (The values of these parameters for the Semiscale calculations are not known.) Both effects would tend to enhance the predicted SG heat transfer with respect to the Wolf Creek results, although it is unlikely that they would compensate for the errors seen completely. This view is supported by the results from an analysis of Wolf Creek at full load, performed with the secondary side heated diameter equal to the inter-tube gap instead of the OD. As evident in the figures, the errors in HTC are still greater than those associated with the LOBI calculation. It should also be noted that although the SPES calculation used a high recirculation ratio, the secondary side heated diameter was set equal to the hydraulic diameter which is greater than the tube $O D$. In addition, the SPES, LOBI and Semiscale results correspond to a higher SG heat flux and primary to secondary temperature difference than the Wolf Creek results, and thus the tendency to under-predict heat transfer would be expected to be greater.

- The results from the LOFT calculations (1/68th scale) show considerable scatter, although a tendency to under-predict SG heat transfer is still evident. In general, the errors corresponding to the UK calculations tend to be smaller than those associated with the Non-UK calculations, reflecting the fact that most (if not all) of the UK calculations were made with the secondary side heated diameter set equal to the inter-tube gap, whereas the others probably used the hydraulic diameter. ${ }^{27}$ Overall, the results indicate that the errors in heat transfer modelling are greater than those corresponding to the smallest facilities, and perhaps slightly less than those associated with Wolf Creek ${ }^{28}$. This trend is more evident when the errors in HTC are plotted against the primary to secondary temperature difference.

27 It is apparent in the figures that one UK calculation gave an error in HTC somewhat larger than the others. This calculation was the first LOFT calculation performed using RELAP5/MOD2 in the UK (LP-SB-03), and it is possible that the secondary side heated diameter was set equal to the hydraulic diameter

28 Note however, that unlike the other facilities, the LOFT SG does not provide a full height representation of a PWR U-tube SG. 
- The ROSA-IV results (1/48th) appear inconsistent with the results from other facilities having U-tube SGs. However, the uncertainty in the experimental value of HTC is very large, and the errors in HTC-A are broadly consistent with those for Wolf Creek and LOFT when they are plotted against the primary to secondary temperature difference.

- The results for the OTIS OTSG facility (1/1632th scale) indicate a much larger error in SG heat transfer modelling than would be expected for a U-tube SG of similar scale and reactor power. However, as noted in Sections 3.12 and 3.14, the thermal-hydraulic conditions in the two types of SG are quite different. Also, the average SG heat flux considered in the figures is not very representative of the actual heat flux below the mixture level in a OTSG (and in fact the errors in HTC-A are slightly more consistent if the errors are plotted against the primary to secondary temperature difference). Thus, the differences seen may not necessarily be due to geometric differences between the two designs.

It is appreciated that due to data and modelling uncertainties, the above type of analysis can only really provide a guide as to how the errors in SG heat transfer modelling in RELAP5/MOD2 vary with thermal-hydraulic conditions and geometry. Nevertheless, there is clear evidence that the tendency to under-predict heat transfer reduces with reactor power, and some evidence that it also reduces with the scale of the facility.

The errors in the HTC-A and HTC-O shown Table 2 and Table 3 and Fig. 18 to Fig. 20 provide some means of quantifying the errors inherent in RELAP5/MOD2's modelling of SG heat transfer. Other measures appropriate to Sizewell ' $B$ ' are provided by the secondary side pressure errors for the Wolf Creek analyses (Fig. 8), and the parameter adjustments required to achieve agreement with the data (Table 5).

\subsubsection{Models at fault}

Section 2.3 and, in particular, equation (1) show how various SG parameters affect the calculation of SG heat transfer in RELAP5/MOD2. From this, it is clear that an accurate representation of primary to secondary heat transfer requires the appropriate modelling of the following features

1. Primary side heat transfer coefficient.

2. Heat conduction through tube wall.

3. Secondary side heat transfer coefficient.

4. Total heat transfer area.

From the Wolf Creek calculations described in Section 4, and the parameter adjustments required to obtain agreement with the data, it would appear that the tendency of the code to under-predict the overall SG heat transfer is unlikely to be due to an inaccurate calculation of the heat conduction effect or heat transfer area. In particular

- As shown in Table 5, the increase in tube ihermal conductivity necessary to obtain the correct primary to secondary heat transfer at full load conditions was $74 \%$. Alternatively, as evident from equation (1), the same effect could have been achieved by increasing $1 / t$ by at least this amount. These levels of adjustment are significantly greater than the data uncertainties associated with these parameters.

- The increase in heated length and thus heat transfer area required to calculate the total heat transfer correctly at full load conditions was $28 \%$, which is again significantly greater than the uncertainty in this parameter. 
Table 5 also shows that RELAP5/MOD2 was able to calculate the total SG heat transfer correctly at full load conditions when the secondary side heated diameter was set equal to the inter-tube gap divided by 167. As shown in Fig. 12, this resulted in an increase in the secondary side heat transfer coefficient over the normal value by up to a factor of more than 3. From the discussion in Section 2.3, it is apparent that the same effect on SG heat transfer could have been achieved by increasing the primary side heat transfer coefficient by a similar amount. For this calculation, RELAP5/MOD2 used the standard Dittus-Boelter correlation, which for the case of water flowing in straight tube at thermal-hydraulic conditions typical of those present on the primary side of a SG, is generally quoted with an accuracy of $\pm 25 \%$ (Dimenna et al., 1988). Thus, even allowing for some enhancement in heat transfer due to entrance and bend effects and the presence of fouling deposits on the inside of the tubes, the tendency to under-predict SG heat transfer cannot be associated with the application of the Dittus-Boelter correlation to determine the primary side heat transfer coefficient. This effect must therefore be attributed to errors in the calculation of the secondary side heat transfer coefficient.

The heat transfer behaviour of the secondary side of the U-tube bundle is controlled by subcooled and saturated boiling, with the latter being the dominant mechanism ${ }^{29}$. As discussed in Section 2.4, for both regimes, RELAP5/MOD2 uses a modified form of the standard Chen heat transfer correlation, in which the modification provides an enhancement to heat transfer as the void fraction reduces.

For the case of boiling heat transfer to water flowing in tubes and annuli, Gungor and Winterton (1987) have compared the standard form of the Chen correlation against a large databank of experimental measurements. The results of this comparison are summarised below.

29 Heat transfer to single phase liquid is rarely present on the SG secondary side in RELAP5/MOD2 calculations at full load conditions. 


\begin{tabular}{|c|c|c|c|}
\hline & $\begin{array}{l}\text { Saturated Boiling } \\
\text { in a Tube }\end{array}$ & $\begin{array}{l}\text { Saturated Boiling } \\
\text { in an Annulus }\end{array}$ & $\begin{array}{l}\text { Subcooled B } \\
\text { in a Tube }\end{array}$ \\
\hline $\begin{array}{l}\text { Pressure } \\
\text { (bar) }\end{array}$ & $0.7-70$ & $1-198$ & $1-203$ \\
\hline $\begin{array}{l}\text { Mass Flux } \\
\left(\mathrm{kg} \mathrm{m}^{-2} \mathrm{~s}^{-1}\right)\end{array}$ & $59-8179$ & $70-5700$ & $1120-61518$ \\
\hline $\begin{array}{l}\text { Quality (\%) } \\
\text { Subcooling }\left({ }^{\circ} \mathrm{C}\right)\end{array}$ & $0-70$ & $0.2-66$ & $0.5-174$ \\
\hline $\begin{array}{l}\text { Heat Flux } \\
\left(W \mathrm{~cm}^{-2}\right)\end{array}$ & $0.5-228$ & $3-262$ & $12-9153$ \\
\hline $\begin{array}{l}\text { Wall Superheat } \\
\left({ }^{\circ} \mathrm{C}\right)\end{array}$ & $0-49$ & $1-78$ & $1.7-107$ \\
\hline $\begin{array}{l}\text { Heated Diameter }{ }^{30} \\
\text { (cm) }\end{array}$ & $0.3-3.2$ & $0.5-2.2$ & $0.3-1.5$ \\
\hline No. Data Points & 1454 & 758 & 546 \\
\hline $\begin{array}{l}\text { Average Error } \\
(\%)\end{array}$ & -21.4 & -3.5 & -4.5 to 15.5 \\
\hline $\begin{array}{l}\text { Mean Absolute } \\
\text { Error }(\%)\end{array}$ & 25.8 & 22.5 & 8.1 to $28.9^{*}$ \\
\hline
\end{tabular}

Measurements made during the Wolf Creek commissioning tests considered in this report, show that for operation in the range of 27 to $99 \%$ load, the pressure on the SG secondary side varies between 69 and 72 bar and the mass flux in bundle region varies from 295 to $460 \mathrm{~kg} \mathrm{~m}^{-2} \mathrm{~s}^{-1}$ (Curlee and Preece, 1987). In addition, the base case RELAP5/MOD2 analysis of the $99 \%$ load case described in Section 4.4 , predicted minimum subcooling of $4.2^{\circ} \mathrm{C}$, a maximum bundle quality of $30 \%$, a wall heat flux in the range 9 to $40 \mathrm{~W} \mathrm{~cm}^{-2}$, and a wall superheat between 3.6 and $10.3^{\circ} \mathrm{C}$. Gungor and Winterton (1987)'s comparisons therefore suggest that for saturated and subcooled boiling in tubular and annular geometries, the standard form of the Chen correlation provides a reasonably accurate prediction of heat transfer coefficient for the thermal-hydraulic conditions typical of those present in a PWR U-tube SG.

It must therefore be concluded that boiling heat transfer in a full size SG tube bundle at full load conditions, is much greater than that in a tube having an equivalent heated diameter. As a result, even though the Chen correlation in RELAP5/MOD2 is modified to enhance heat transfer, a significant under-prediction of the heat transfer coefficient still results.

The above conclusion is also supported by experirnental data on local heat transfer in tube/rod bundles. In particular

1. Data obtained by Boucher (1987b) for the Semiscale Mod-2C broken loop SG (type III) operating at full power conditions, show that the standard form of the Chen correlation under-predicts the secondary side heat transfer coefficient by a factor of typically 2 to 5 . As evident from Table 1, this SG consists of two inverted

30 Defined as $4 \times$ flow area divided by heated perimeter 
U-tubes (giving a four tube bundle) and represents a 1/1706th scale full height model of a Westinghouse Model 51 SG. The experimental heat transfer coefficients were derived from local temperature measurements for the primary and secondary side fluid and tube outer wall, obtained from thermocouple triplets located at various elevations. To minimise the uncertainties associated with measuring small temperature differences, the results were calibrated against data obtained under zero heat transfer conditions.

2. Heat transfer measurements made by Kumamaru, Koizumi, and Tasaka (1987) in a $5 \times 5$ electrically heated fuel bundle also indicate that the Chen correlation under-predicts the local boiling heat transfer coefficient by a considerable amount. The experiments were performed in the JAERI two-phase test facility (TPTF) and the results presented correspond to a pressure of 30 bar, mass fluxes around $300 \mathrm{~kg} \mathrm{~m}^{-2} \mathrm{~s}^{-1}$, heat fluxes in the range 4.9 and $25 \mathrm{~W} \mathrm{~cm}{ }^{2}$, and inlet qualities between 12 and $57 \%$. The authors note that due to the very small temperature differences involved, the uncertainties in the experimental heat transfer coefficients were quite high - varying from $-36 \%$ to $+125 \%$ at $3 \times 10^{\prime}$ $\mathrm{W} \mathrm{cm}^{-2}{ }^{\circ} \mathrm{C}^{-1}$, to $-63 \%$ to $+\infty \%$ at $9 \times 10^{4} \mathrm{~W} \mathrm{~cm}^{2}{ }^{\circ} \mathrm{C}^{1}$. Nevertheless, all results imply an under-prediction of heat transfer and in many cases the errors are outside the uncertainty in the data.

Although the Semiscale $S G$ is very small scale, the heat transfer date obtained by Boucher (1987b) is particularly relevant to the present study. As shown in Fig. 14, the local heat transfer coefficients derived from the data generally increase with bundle elevation ${ }^{31}$, which may be interpreted for example as an increase with increasing void fraction. In contrast, the standard form of the Chen correlation provides a heat transfer coefficient that reduces slightly with elevation, in addition to under-predicting the data by a large amount.

As noted earlier, RELAP5/MOD2 applies a modified form of the Chen correlation in which the heat transfer coefficient is enhanced as the void fraction reduces. This modification however, achieves the opposite effect to that observed in the Semiscale data. This has been illustrated in Fig. 14 by showing (from Fig. 12) the secondary side heat transfer coefficient predicted by RELAP5/MOD2 for the Wolf Creek SG at full load conditions (base case calculation) - which is representative of what the code would calculate for the Semiscale SG. Although the RELAP5 modification clearly enhances the heat transfer coefficient, it exacerbates the incorrect trend inherent in the standard form of the Chen correlation. Interestingly however, the average heat transfer coefficient for the bundle in the RELAP5 calculation is not very different from that implied by the data, which explains why the code did not do too badly when calculating initial conditions for the Semiscale tests considered in Table 1 . By comparing Fig. 14 with Fig. 12 though, it is apparent that the level of heat transfer coefficient necessary to achieve agreement with the Wolf Creek data is somewhat higher than that measured on Semiscale, giving further evidence that the boiling heat transfer coefficient for a SG bundle depends on scale.

\subsubsection{Implications for PWR safety analysis}

For steady-state PWR analysis, the deficiencies in RELAP5/MOD2's modelling of SG heat transfer will result in an under-prediction of either the power dissipated in the SG (and thus the core power), the primary to secondary temperature difference, or some combination of the two. It is likely, however, that the code would be initialised with the correct core power and primary side temperatures, and thus the deficiencies

31 Boucher (1987b) suggests that the reduction in the experimental heat transfer coefficient at an elevation of $8.86 \mathrm{~m}$ is probably due to the increase in flow area and consequent reduction in mass flux at this elevation. He also argues that the apparenlly anomalous reduction at $5.64 \mathrm{~m}$ is possibly caused by a flow perturbation or how regime transition nearby, resulting in some multidimensional effects which significantly reduce the local flow rate. This effect is not evident in the data for the short tube hot side. 
would manifest themselves primarily in an under-prediction of the secondary side pressure. For the Sizewell ' $B$ ' $S G$, the magnitude of this will be similar to that seen in the Wolf Creek calculations (see Fig. 8). Note that the pressure errors reduce with load because the modelling errors (i.e. errors in HTC) and the primary to secondary temperature difference both reduce with reactor power.

Before discussing the implications for transient analysis, it is important to note that while the primary and secondary sides of the NSSS are well coupled, i.e. wet wall conditions exist on both sides of the SG tubes, virtually all the power generated in the core will be removed by the SGs. Thus, any errors in SG heat transfer modelling will chiefly be seen as an error in the primary to secondary temperature difference, and should have little effect on the predicted SG heat transfer rate.

As explained above, at the beginning of a transient calculation, the deficiencies in SG modelling will be reflected by an under-prediction of the secondary side pressure. It is possible of course, that as the transient evolves this error could be transformed into an over-prediction of the primary side temperature, and this might result for example, in the early calculation of two-phase conditions. For a transient involving a reduction in reactor power though, it is more likely that the initially low SG pressure will eventually over-compensate for the deficiency in heat transfer modelling. Evidently, this could manifest itself in an under-prediction of the primary side temperature and perhaps a late prediction of two-phase conditions. In both cases however, the error in the primary side temperature is unlikely to be more than a few degrees $C$, and thus should not have a significant impact on the predicted primary side behaviour. This is particularly true for LOCA analyses, as the SGs do not have a very large effect on the primary system energy removal.

On the secondary side, the main consequence of an incorrect pressure calculation are errors in the predicted timings for the operation of the automatic safety and control systems, and postulated operator actions. In a SGTR transient, the time of break flow isolation could also be affected. Given that the maximum error in the initial pressure is only around 3.5 bar however, it is difficult to believe that the modelling deficiencies would have a serious impact on the results of a safety analysis. A possible exception though, is the predicted behaviour of the SG safety relief valves, as the PORV set point is only around 8 to 10 bar above the SG normal operating pressure, so that an under-prediction of 3.5 bar in the initial pressure may not be insignificant. In the worst case scenario, this error could result in the code failing to predict the opening of the PORV at all, for a transient in which the valve does open and is postulated to stick open. Even so, provided that this possibility is recognised, it should not diminish the value of the code for safety assessment studies.

It is also worth noting that, following a reactor trip and the closure of the MSIV, the secondary side pressure is quite sensitive to the small leakage through the valve (and the heat losses to the environment). This leakage is not generally well known, and thus the corresponding errors in SG pressure could obscure those arising from deficiencies in SG heat transfer modelling.

The discussion up to now has been restricted to situations in which the primary and secondary sides are well coupled. If this coupling is lost, as a result of dryout on either side of the U-tubes, an error in SG heat transfer modelling could lead to an error in the predicted SG heat transfer rate and thus the primary (or secondary) side cooldown. Once dryout occurs however, the heat transfer calculation will no longer be controlled by boiling heat transfer on the secondary side, where the deficiencies occur. Thus, the only consequences of inaccuracies in the modelling of this phenomenon, will be those arising from an error in primary to secondary temperature difference at the beginning of dryout. Again, these may be expected to be relatively minor.

If may be concluded, therefore, that the deficiencies in RELAP5/MOD2's modelling of SG heat transfer at normal operating conditions, which are most severe at full 
power and for full scale facilities, and may be attributed to an under-prediction of the boiling heat transfer coefficient on the secondary side, should not have a serious impact on the use of the code for PWR safety studies. The deficiencies are more an inconvenience as they introduce errors into the calculation before the transient begins, and although the implications of these errors are relatively minor, they must still be taken into account when interpreting the results. This task is quite feasible given the large body of information available from assessment calculations against separate and integral test facilities, although it obviously complicates the arguments that must be put together when making a safety case.

\subsubsection{Techniques for compensafing for deficiencies}

Several approaches may be used to compensate for the deficiencies in RELAP5/MOD2's modelling of SG heat transfer without introducing changes to the code. These may be applied when carrying out sensitivity type calculations as part of a safety case analysis.

The various techniques available for enhancing SG heat transfer through changes to a RELAP5/MOD2 input deck are discussed in Section 2. Those recommended for consideration are as follows.

- Increase the thermal conductivity of the SG U-tubes.

- Increase the total heated length of the tubes.

- Use a very small heated diameter on the SG secondary side.

None of these approaches of course have any physical basis, they are merely artificial ways of increasing primary to secondary heat transfer. The approximate changes necessary to obtain the correct SG heat transfer for Sizewell ' $B$ ' should be similar to those required for the Wolf Creek SG. which are detailed in Table 5. Note that an enhancement in heat transfer could also be achieved by reducing the $U$-tube wall thickness, but since the key parameter is tube conductivity divided by thickness, it seems sensible to restrict the changes to the conductivity component and keep the $U$-tube geometry correct (particularly as reducing the tube thickness will also reduce the secondary side heat transfer area slightly if the internal diameter is kept constant). An enhancement in heat transfer could also be obtained by using a very small heated diameter on the primary side of the tubes. However, since the modelling deficiencies are associated with the calculation of the secondary side heat transfer coefficient, it seems sensible to restrict any artificial changes made to the heat transfer coefficient to this side.

The most appropriate way of enhancing SG heat transfer in RELAP5/MOD2 obviously depends on the transient being analysed, and which ever technique applied must of course be justified. The principal difficulty will lie in establishing the consequences that the changes have when the SG conditions differ from those in the initial steady-state. The following comments may help the reader in making a suitable choice.

\section{Secondary side heated diameter}

One of the disadvantages of setting a very small heated diameter on the secondary side, is that it is difficult to judge how this affects the Chen correlation over the full range of thermal-hydraulic condition that might be encountered. This problem is made worse by the fact that, as shown in Fig. 3, the size of diameter required forces the correlation into a region where it becomes particularly sensitive to changes in diameter.

A more important consideration however, is the effect that the small diameter will have on SG heat transfer if the flow regime on the secondary side of the bundle changes to one in which a different heat transfer coefficient correlation is applied. In particular, as discussed in Section 2.3, the reason why SG heat 
transfer under normal operating conditions is not very sensitive to small changes in the secondary side heat transfer coefficient, is that the primary and secondary side heat transfer coefficients and wall conductance all have similar magnitudes. If the secondary side dries out however, the SG heat transfer will be dominated by the local heat transfer coefficient. Consequently, an inappropriate value of the heated diameter could have a dramatic effect on SG heat transfer and, since the primary and secondary sides would no longer be coupled thermally, this could have a significant effect on the primary side cooldown.

The present authors would not therefore recommend that this approach be adopted.

\section{Bundle heated length}

As discussed in Section 2.3. SG heat transfer is directly proportional to the total heated length of the U-tube bundle, and thus an increase in this parameter should have a similar effect on heat transfer for all thermal-hydraulic conditions encountered. Evidently, this could result in an over-prediction of SG heat transfer if the reactor power falls, but the error involved should be less than that associated with adopting a low secondary side pressure.

\section{Tube thermal conductivity}

Similar comments regarding an over-prediction of heat transfer with reducing reactor power, apply if the initial SG heat transfer is enhanced by increasing the thermal conductivity of the U-tubes. However, an increase in conductivity has the advantage that its influence reduces if the heat transfer coefficient on either side of the SG decreases. In particular, its effect becomes negligible if a significant degradation in heat transfer occurs. For this reason, the present authors believe that this technique would be the preferred approach in most situations.

\subsubsection{RELAP5/MOD3 considerations}

In RELAP5/MOD3, the Chen correlation has been returned to its standard form and thus the tendency to under-predict SG heat can be expected to be greater than that associated with RELAP5/MOD2. This has already been observed in early RELAP5/MOD3 calculations (Coney, 1990).

Despite the comments made in Section 5.1 .3 regarding implications for PWR safety analysis, it is suggested that a study be undertaken with the objective of developing an improved correlation for RELAP5/MOD3 for boiling heat transfer in bundle geometries. This work should clearly take account of the experimental data on local heat transfer obtairied for the Semiscale SG, for which a more detailed description is given by Boucher (1987a). Some of the experiments carried out on the LOBI facility may also provide data on local heat transfer. There are also a wealth of data relevant to total SG heat transfer from a whole range of PWR plants and facilities, and these may be used to characterise the scale effect.

The work on SG heat transfer carried out at Texas A\&M by Prof $F$ issan and his colleagues (Section 3.14) would clearly provide a good starting poin; ior the study. The modification to the Chen enhancement factor $F$ derived for a U-tub ? bundle has some physical basis and also makes use of the Semiscale data. However, it would appear that the complete correlation still uses the RELAP5/MOD2 modified suppression factor, which introduces an unphysical dependence on void fraction. In addition, the correlation does not account for any scale effects.

The study should also take account of work performed at MEL in which various boiling heat transfer correlations were compared against the complete series of Wolf Creek commissioning tests using the NUMAC-PWR code. In particular, Atthey (1989) found that the standard form of the Chen correlation significantly under-predicted the total primary to secondary heat transfer, but that the predictions obtained with various 
forms if the Thom, Jens Lottes and Rohsenow and Bergles correlations were generally within the uncertainty of the data. Interestingly, it was found that the Chen correlation gave good agreement with the data when the suppression factor was set equal to one. In a subsequent study. Atthey (1990) went on to show that the RELAP5/MOD2 form of the Chen correlation also under-predicted the data by a significant amount (although it performed better than the standard version), but that good agreement with the data could be obtained if the enhancement factor $F$ was modified in the manner suggested by Hassan. Strictly speaking. these comparisons are not an exact reflection of the performance of RELAP5/MOD2, as the void fraction in the modified suppression factor was calculated using the EPRI drift flux correlation - which tends to predict a lower void fraction than the RELAP5/MOD2 interphase drag model and thus a greater boiling heat transfer coefficient.

Although Althey's comparisons are important in that they are based on measurements from a full sized Model F SG. the data considered only covered steady-state operation for reactor powers between 27 and $99 \%$ load. This covers a relatively narrow range of thermal-hydraulic conditions (e.g. SG pressures between 69 and 72 bar and bundle mass fluxes from 295 to $460 \mathrm{~kg} \mathrm{~m}^{2} \mathrm{~s}{ }^{1}$ ). Clearly any boiling heat transfer adopted in RELAP5 for bundle geometries will have to be valid for the full range of SG conditions encountered in plant safety studies, and possibly those present in the core. The basic Thom, Jens Lottes and Rohsenow and Bergles correlations considered by Atthey only depend on the pressure and wall superheat, although a limited mass flux dependence was introduced by combining the correlations with the Dittus-Boelter correlation. In contrast, the Chen correlation depends on pressure, wall superheat, mass flux, quality and diameter. Consequently, there must be a question mark over how well these correlations would perform under abnormal conditions. More importantly, none of the correlations predict the type of variation of heat transfer coefficient with elevation that was apparent in the Semiscale data. ${ }^{32}$

Recent papers which discuss mechanisms governing boiling heat transfer in a tube are those due to Gungor and Winterton (1986). Gungor and Winterton (1987) and Klimenko (1988). These may also provide a useful input to the study.

\subsection{Secondary side inventory under normal operating conditions}

\subsubsection{Code deficiencies}

An assessment of how well RELAP5/MOD2 calculates SG liquid inventory is not particularly straightforward, as in many cases the true inventory is not known accurately. Also, as shown in Appendix A.2. SG inventory depends on both the recirculation ratio and downcomer level, and these parameters are sometimes artificially adjusted in RELAP5/MOD2 analyses to avoid instabilities in the predicted separator behaviour.

Despite these difficulties, the review of RELAP5/MOD2 assessment calculations found clear evidence to support the notion that the code under-predicts SG inventory when the recirculation ratio and downcomer level are calculated correctly. Specific examples include:

- The RELAP5/MOD2 Sizewell ' $B$ ' model has been found to under-predict SG inventory relative to the design value at normal operating conditions (Section 3.2).

32 It is also interesting to note that the dependence on wall superheat is different in each case - the Thum correlation depends linearly on wall superheat (as does the Chen correlation effectively); the Rohsenow and Bergles correlation dopends on wall superheat squared; and the Jens Lottes correlation depends on wall superheat cubed. 
- The initial inventory for ISP-22 (SPES loss of feedwater test) was under-p: dicted by RELAP5/MOD2 (Section 3.10). Also, in the ISP-26 analysis (ROSA-IV 5\% cold leg break), the initial collapsed liquid level in the riser was too low, implying an under-prediction of SG inventory (Section 3.7).

- In the UK and Studsvik analyses of LOFT test L3-6 $(2.5 \%$ cold leg break with delayed reactor trip), RELAP5/MOD2 under-predicted the SG level after the reactor had tripped and the secondary side fluid had settled. Various reasons for this discrepancy were suggested, but the most likely cause is an under-prediction of the liquid fraction in the SG riser at full power conditions (Section 3.8.3).

An under-prediction of initial SG inventory may also be inferred from inaccuracies in the RELAP5/MOD2 predictions of SG level during boildown transients, particularly the early prediction of SG dryout. However, as discussed in Section 5.3, in order to obtain the correct SG level trajectory under fast boildown conditions, it is not sufficient to calculate the correct initial inventory alone.

\subsubsection{Models at fault}

For a given recirculation ratio and downcomer level, the calculation of SG inventory in RELAP5/MOD2 depends, primarily, on the void fraction distribution predicted in the riser section and the geometric modelling of the SG components (e.g. downcomer flow area). Although the information needed to model these components may not always be known accurately and additional errors may be introduced in setting up a 1D representation. the fact that the tendency to under-predict inventory has been observed on a range of plants and facilities suggests that an over-prediction of the riser void fraction is the major cause. This could result from an over-prediction of interphase drag and/or subcooled vapour generation. However, the magnitude of the inventory errors seen are sufficiently large that they cannot be explained by errors in the subcooled boiling regime alone.

A detailed assessment of the wet-wall interphase drag models in RELAP5/MOD2 is presented by Putney (1988; 1989a; 1989b). In particular, it is shown that for low flow conditions in a PWR-type fuel assemblies, there is considerable experimental and theoretical evidence which shows that the code over-predicts the interphase drag force and thus void fraction. The deficiency arises because the code assumes that the flow regime that exists in a bundle is identical to that in a tube having the same hydraulic diameter. As a consequence, a slug flow model is used for the interphase drag model until a transition to annular flow is predicted to occur. Observations made by Bestion (1985) at low void fraction however, indicate a quite different flow regime for a bundle, in which the vapour and liquid phases have a tendency to occupy separate flow paths. Also, at higher void fractions, Venkateswararao, Semiat and Dukler (1982) found that under certain circumstances, large Taylor bubbles can occupy several subchannels. As a result, and confirmed by measurements, the interfacial drag force in a bundle is much less than that associated with slug flow. This fundamental deficiency in the code is exacerbated by the use of slug model which neglects the effects of profile slip.

The hydraulic diameter of a PWR U-tube SG is only a little larger than that associated with the core fuel assemblies. Consequently, RELAP5/MOD2 may be expected to over-predict interphase drag in the SG bundle for the relatively low flow conditions typical of normal operation. Note however, that the region of the SG riser above the U-tube bundle consists of a circular channe' having a diameter of around $3.6 \mathrm{~m}$. In this region, RELAP5/MOD2 will apply a slug ilow model to calculate the interphase drag force, which assumes that the diameter of the Taylor bubbles is equal to the pipe diameter. In reality however, bubbles of this size cannot be sustained due to interfacial stability and they disintegrate into cap bubbles (Kataoka and Ishii, 1987). Since the specific area of a Taylor bubble is inversely proportional to its diameter, the assumption of slug flow in this situation can lead to an under-prediction of interphase drag when the proportion of vapour in the Taylor bubble (relative to the small 
bubbles) becomes significant - and the consequences of neglecting profile slip are outweighed. This effect is clearly demonstrated by Putney (1989b).

It is possible therefore, that whilst RELAP5/MOD2 will over-predict interphase drag in the heated section of the riser, this could be compensated for, to some extent, by an under-prediction in the unheated section. However, for many cases, it is likely that annular flow will be predicted to exist in this section of the riser, and thus the deficiencies in the code's slug flow model will have no effect ${ }^{33}$. Also, the unheated section of the riser is somewhat smaller than the heated section. Thus, in general the net effect of the known deficiencies in the RELAP5/MOD2 interphase drag models will be an under-prediction of SG inventory - although this tendency will clearly reduce as reactor power reduces.

\subsubsection{Implications for PWR safety analysis}

The principal consequences of an under-prediction of initial SG inventory are twofold:

- Following a reactor trip and the settling of the secondary side fluid (i.e. when the recirculation flow in the SG has ceased and the vapour generation rate has fallen off), the fall in the downcomer water level is likely to be over-predicted. As a result, the subsequent auxiliary feedwater flow could be over-predicted - although the net effect might be to make-up for the initial under-prediction of inventory, thereby mitigating the deficiency.

- For transients involving SG boildown, degradation of primary to secondary heat transfer and SG dryout could be calculated to occur too early. The situation is worse for slow transients in which most of the boildown takes place under decay levels, as the excess inventory on the plant can take a long time to boiloff. For example, in the RELAP5/MOD2 analysis of the SPES loss of feedwater test (Section 3.10), SG dryout was predicted to occur more than $1000 \mathrm{~s}$ too early.

The second consequence evidently holds the more serious implications for PWR safety analysis, as it has a dramatic effect on the timings of all subsequent events.

\subsubsection{Techniques for compensating for deficiencies}

As shown in Appendix 2, the tendency for RELAP5/MOD2 to under-predict SG inventory may be reduced by artificially increasing the recirculation ratio, either by raising the downcomer level or reducing the flow losses. Unfortunately, from the analyses reviewed in this report, it would appear that the adjustments required to obtain the correct initial inventory are not physically sensible (and as discussed in Section 5.3, for fast boildown transients it may not be sufficient to calculate the correct inventory alone). The same may be said if an increase in SG inventory is sought by increasing the downcomer flow area. In addition, artificial adjustments of the SG parameters can have undesirable effects. For example, if the reactor and MSIV trips in a boildown transient occur on low downcomer level, raising this level may serve to delay the predicted trip time and result in a greater boiloff in the pre-trip period - thereby exacerbating the effects of an under-prediction of the initial inventory. This dilemma was encountered in the RELAP5/MOD2 analysis of the SPES loss of feedwater test. It was also found that, due to the over-estimation of the frictional pressure losses, the use of a high recirculation ratio prevented the code's values for the downcomer DP measurement being used to determine the downcomer level (as is done on the plant).

An alternative method of increasing the initial SG inventory is to use an artificially large value for the riser hydraulic diameter. This approach will lower the interphase drag calculated in the slug flow regime, by reducing the interfacial area per unit

33 This was the case for example. in the RELAP5/MOD2 analysis of the Wolf Creek commissioning test at $99 \%$ reactor power, but not at $36 \%$ power. 
volume, and was apparently aclopted in the KAERI analysis of the KNU\#1 loss of offsite power transient (Section 3.3). However, the actual value of hydraulic diameter used was around $250 \mathrm{~cm}$, and it is not clear what effect this would have on the interphase drag calculations for the annular and post-dryout flow regimes - both of which will be encountered in the SG bundle during a boildown transient. Consequently, the approach may be difficult to justify, even for sensitivity type calculations.

Finally, note that any modification which increases the SG inventory by reducing the riser void fraction will also tend to enhance the primary to secondary heat transfer although even if the inventory is calculated correctly. SG heat transfer is still likely to be under-predicted.

\subsubsection{RELAP5/MOD3 considerations}

RELAP5/MOD3 incorporates improved interphase drag models for both rod/tube bundles and large diameter vertical pipes (Putney, 1989b). As a result, the code should provide a better prediction of SG inventory than RELAP5/MOD2. Early calculations with MOD3 have shown a $25 \%$ increase in inventory over MOD2 (Coney, 1990).

On the LOBI-MOD2 facility, a series of 'characterisation' tests have been carried out with the specific aim of obtaining accurate data on SG inventory at steady-state full power conditions. In these tests, designated as BC-01 (Sanders, 1988a; 1988b), the rig was first stabilised at normal operating conditions, and then the fluid on the secondary side was trapped by suddenly closing the SG feed and steam valves (within $1 \mathrm{~s}$ ). Tests were performed at four different settings of downcomer water level, and the secondary side inventories were measured in both the intact and broken loop SGs.

These LOBI experiments would clearly provide a good test of SG inventory modelling in a code such as RELAP5 (as well as good data on SG heat transfer). It is therefore recommended that they are used to assess RELAP5/MOD3 in this area.

\subsection{Level trajectories during fast boildown transients}

\subsubsection{Code deficiencies and models at fault}

In the previous section it was shown that RELAP5/MOD2 tends to under-predict SG inventory at full power conditions and that the primary reason for this is an over-prediction of interphase drag in the bundle region. One of the consequences of this deficiency is an early prediction of SG dryout in boildown transients, and this is particularly evident when the boildown occurs under decay heat conditions. For transients in which a significant part of the boildown takes place at full power conditions however, RELAP5/MOD2 has also been found to over-predict the rate at which the downcomer level falls. Particular examples are the UK analyses of LOFT tests LP-FW-01, L9-4 and L9-3 (Section 3.8.4), and the INER-Taiwan analysis of MB-2 LOF test no. 1 (Section 3.9.1). Furthermore, although attempts to artificially increase the initial inventory by increasing the recirculation ratio and downcomer flow area had the affect of delaying the time of SG dryout (i.e. for LOFT tests L9-4 and L9-3), they did not have a significant effect on the rate of boildown. This raises questions over the role played by the code's interphase drag models in determining level behaviour during the boildown process itself.

In order to investigate this phenomenon, Appendix A.3 develops a simple analytical model for calculating mixture and liquid level trajectories during the boildown of a PWR U-tube SG under 'ideal' thermal-hydraulic conditions, following a complete loss of feedwater. The principai assumptions made are as follows. 
1. All fluid on the secondary side is at saturation and the recirculation flow has ceased.

2. The mixture level in the riser has fallen to at least the top of the U-tube bundle.

3. Any liquid entrainment above the mixture level is negligible and no liquid condensate enters the downcomer.

4. The linear power is uniform below the mixture level and does not change with time.

5. The SG pressure does not change with time and spatial variations are very small.

6. Liquid flow rates are small and a quasi-static approximation may be used for vapour mass balances.

It is appreciated that the situation envisaged is somewhat idealised, particularly the restriction to uniform heating conditions. Nevertheless, the general trends indicated by the model should still be representative, at least qualitatively, of those prevailing during $S G$ boildown.

As shown in Appendix A.3, under the above conditions, the water level in the downcomer. $z_{d}$. may be approximated by the collapsed liquid level in the riser, $z_{c}$, which is related to the mixture level in the riser, $z_{m}$, by

$$
z_{c}=\frac{1}{C_{0}}\left[\left(C_{0}-1\right) z_{m}+\frac{1}{B C_{0}} \ln \left\{1+B z_{m}\right\}\right]
$$

where

$$
B=C_{0} \frac{q^{\prime}}{\rho_{g} h_{g^{\prime}} A_{r} v_{g j}}
$$

Here $C_{0}$ and $v_{91}$ are the drift flux parameters (Zuber and Findlay, 1965), $A_{r}$ is the riser flow area, $q^{\prime}$ is the linear power and the rest of the notation is defined in the Nomenclature list.

In addition, the riser mixture level satisfies the differential equation

$$
\frac{d z_{m}}{d t}\left[c_{0}-1+\frac{1}{1+B z_{m}}\right]=-D z_{m}
$$

where

$$
D=\frac{C_{0} q^{\prime}}{\rho_{q} h_{g f} A_{r}\left[1+\frac{A_{d}}{A_{r}}\right]}
$$

which has the analytical solution

$$
\frac{z_{m}^{C_{0}}}{1+B z_{m}}=\frac{z_{m 0}^{C_{0}}}{1+B z_{m 0}} \exp (-D t)
$$

where $Z_{m 0}$ is the initial mixture level and $A_{d}$ is the downcomer flow area.

Finally, the total liquid inventory in the $S G$ is given by

$$
I_{v}=\left(A_{d}+A_{r}\right) \rho_{r} z_{c}
$$

The above results show that for the simple boildown transient considered, the mixture and liquid level trajectories depend on both the initial levels and the drift flux parameters effective during the boildown process. This implies that in a code such as RELAP5, the interphase drag models affect the prediction of boildown phenomena through their offect on both the initial inventory calculation and the level dynamics. 
Thus, under certain circumstances, attempts to artificially compensate for the under-prediction of initial inventory without correcting the interphase models, may not necessarily lead to the correct prediction of the level trajectories. This is most likely to be true for fast boildown transients occurring under full power conditions. If the boildown occurs under decay heat conditions, the errors in the initial inventory calculation, which is generally established at full power conditions, are likely to dominate (since deficiencies in the interphase drag models have a progressively greater effeci as the power is raised and the void fraction in the mixture region becomes more significant). These conclusions are consistent with the results of RELAP5/MOD2 assessment calculations.

Equation (31) also shows that the drift flux parameters have different roles in determining the level trajectory. In particular, the exponential decay term only depends on the distribution coefficient, $C_{0}$, not the vapour drift velocity, $v_{g r}$. This suggests that in order to predict the correct level behaviour during boildown, it is necessary to calculate both the profile and local slip components of the drag force correctly. In contrast, in order to obtain the correct initial inventory, it is only necessary to calculate the total $c^{\prime}$. ag force correctly.

Using appropriate definitions for the drift flux parameters and a suitable numerical solver, equations (27) and (31) may be applied to 'emulate' the modelling of SG boildown behaviour in RELAP5/MOD2 for the conditions considered, and to compare the level trajectories obtained against those predicted by a reference model. This approach was used to study level behaviour in a full size PWR U-tube SG for conditions characteristic of boildown under full power conditions. The results of this analysis are discusse.) in Appenciix A.3.7 and illustrate many of the points made above.

\subsubsection{Implications for PWR safe'y analysis and compensation of deficiencies}

The principal consequence of the direct effect of interphase drag on SG level dynamics is that, for fast boildown transients, an under-prediction of the initial inventory is not the only cause of inaccuracies in the calculated level behaviour. The implication: : of such inaccuracies for PWR safety analysis have already been discussed it Section 5.2.3, and the existence of this additional source of error does not really make these implications any worse - particularly as it is a result of the same fundamenta' deficiency. It does mean however, that attempts to increase the initial inventory by artificially increasing the recirculation ratio or downcomer area may not have the desired effect. As already observed though, the increases necessary to achieve the correct inventory may not be physically sensible.

It was noted in Section 5.2.4 that the interphase drag in the bundle region may be 'corrected' by setting a very large hydraulic diameter. This parameter however, only affects the local drag force. The analysis described above indicates that in order to obtain the correct level behaviour during boildown, it is necessary to calculate both the local and profile slip components of the drag force correctly. Thus, imposing a large hydraulic diameter may also fail to force the correct level behaviour.

For slow boildown transients typical of those occurring under decay heat conditions, the interphase drag calculation will have less influence on the level dynamics, and the errors in the initial inventory will dominate the predicted level behaviour.

\subsubsection{RELAP5/MOD3 censiderations}

As noted in Section 5.2.5, RELAP5/MOD3 incorporates improved interphase drag models for bundle geometries and may therefore be expected to provide a better prediction of level behaviour for fast boildown transients. However, in view of the different roles played by the local and profile slip components of the drag force and the importance of obtaining accurate estimates of each one, this type of problem should provide a good test of the new interphase drag models in RELAP5/MOD3. In 
particular. Putney (1988) has observed that the split between the local and profile components of the total slip may not be well known for bundle geometries.

One of the disadvantages of using results from integral test facilities to assess SG modelling in codes such as RELAP5, is that deficiencies in a specific model are often difficult to identify due to the mutual interaction between different phenomena and the lack of detailed instrumentaicion. This is particularly true for the case of SG boildown. It is therefore suggested that the modelling of this process in RELAP5/MOD3 be assessed against the loss of feedwater tests carried out on the MB-2 facility. These tests provide separate effects type data relevant to both fast and slow boildown transients, as well as data appropriate to the refiling of the $S G$.

\subsection{Wall heat transfer above mixture level}

In the RELAP5/MOD2 analysis of LOFT loss-of-feed water test L9-3 (Section 3.8.4), the predicted primary to secondary heat transfer remained virtually constant during the boildown phase down until the SG side was almost empty, at which point a sudden drop in heat transfer occurred. In the experiment however, a gradual degradation in $S G$ hect transfer occurred as the level fell ${ }^{34}$. Attempts to improve the representation of SG heat transfer in the calculation by adopting a finer nodalisation at the bottom of the bundle had little effect. Closer examination of the results indicated that during boildown, the liquid fraction in the bundle nodes decreased more or less together, so that instead of a sequentially emptying of the nodes, the liquid was smeared along the riser. Evidently, this behaviour is indicative of an over-prediction of liquid entrainment above the riser mixture level. As a result, wet wall conditions were predicted to occur in all nodes until the SG was virtually empty. whereupon the heat transfer fell sharply.

An over-prediction of wall heat transfer above the mixture level was also evident in the RELAP5/MOD2 analyses of the boildown phases of the LOFT LP-FW-01 (Section 3.8.4) and LOBI ST-02 (Section 3.11.3) 10ss-of-feedwater tests, and in the analysis of the blowdown phase of LOBI steam line break test BT-12 (Section 3.11.5). Again an over-prediction of liquid entrainment above the mixture level appeared to be the most likely cause.

It is believed that this deficiency in the code is a consequence of the known deficiencies in the interphase drag model, exacerbated by the absence of a proper vertical stratified flow model and, possibly, the criteria applied to determine wet/dry wall conditions. In particular:

- As discussed in Section 5.1.2, RELAP5/MOD2 over-predicts interphase drag in the bubbly and slug regimes for bundle geometries. If this regime is present at the mixture level, the liquid entrained above the level will be over-predicted.

- The RELAP5/MOD2 vertical stratification model (which may or may not have been invoked in the transients noted above), does not alter the liquid fraction at the junction immediately above the mixture level, which is still assumed to be equal to the average liquid fraction in the node below (donor cell rule). This effectively carries the liquid present in the node into the bottom of the node above. (The same effect will clearly occur if the vertical stratification model is not invoked).

- How far the liquid entrained from the mixture region is carried along the riser evidently depends on the interphase drag calculated in the nodes above the mixture level - the higher the interphase drag, the further the liquid would be expected to be carried. The interphase drag calculated for a node in which wet wall conditions are predicted is likely to be greater than that for a node under dry

34 Since RELAP5/MOD2 does not explicitiy recognise the presence of a mixture level in a node and effectively assumes that the wall is wet until the node is virtually empty, the code would be expected to reflect a gradual reduction in heat transfer with level by a step-wise degradation. 
wall conditions. In RELAP5/MOD2 however, wet wall conditions are assumed to occur unless the vapour fraction is above 0.9999 or the critical heat flux has been exceeded. It is not obvious that the latter will always be true above the mixture level in SG boildown or blowdown transients when significant entrainment is present - i.e. the conditions could be such that the code automatically assumes that any liquid present in a node that has a liquid fraction above 0.0001 completely wets the wall. Thus, a situation could arise in which an over-prediction of liquid entrainment above the mixture not only results in wet wall conditions being assumed and a consequent over-prediction of wall heat transfer, but also creates the conditions for the entrainment to be carried over to the node above.

The consequences of an over-prediction of SG heat transfer above a mixture level in a bundle are that, prior to the primary and secondary sides becoming thermally decoupled on the plant, the primary to secondary temperature difference may be under-predicted. In addition, once the two sides have decoupled, the primary side heat-up may not be calculated correctly. In both cases however, it is unlikely that the implications for PWR safety analysis will be any worse than those already associated with errors in predicted level behaviour itself.

Few options are available for compensating for the over-prediction of heat transfer through changes to the input deck. Setting a very large hydraulic diameter in the bundle region might help by reducing the interphase drag in the bubbly and slug regimes, but it is not clear what effect this would have in other regimes.

Some improvement in the modelling of $S G$ heat transfer above a mixture level may be expected in RELAP5/MOD3 due to the new interphase drag and vertical stratification models. It is suggested that this feature of the code may be assessed when using the MB-2 loss-of-feedwater tests recommended in Section 5.3.3 to examine the code's modelling of SG level behaviour. The results should help to establish whether the criteria used to determine wet or dry wall conditions need to be revised.

\subsection{Dynamic level swell}

A number of the RELAP5/MOD2 assessment studies reviewed in Section 3 revealed deficiencies in the calculation of SG dynamic level shrink and swell; viz.

- For the Doel 2 SGTR accident (Section 3.4), RELAP5/MOD2 over-predicted the downcomer water level swell that occurred in the intact SG when cooldown was initiated by opening the SRV, and also when steam was discharged to the turbine driven auxiliary feedwater pumps.

- For the Doel 4 loss of load test (Section 3.5), the code over-predicted the downcomer level swell that occurred when the steam dump valves opened, and under-predicted the rapid fall in level (shrink) following the sudden increase in SG pressure when the turbine admission valves closed.

- In the analysis of the MB-2 100\% steam line break test T-2013 (Section 3.9.2), the initial level swell calculated by the code was too rapid while single phase steam was being discharged through the break (causing the onset of two-phase break flow to begin too early).

Although the code failed to predict the small level swell that was observed in the Tihange 2 plant trip test following the manual opening of the steam dump valves (Section 3.6), this was believed to be due to an under-prediction of the initial liquid inventory.

Evidently, the level discrepancies noted above may be attributed to the tendency of RELAP5/MOD2 to over-predict interphase drag for low flow conditions in bundle geometries, which was fully discussed in Section 5.2.2. Following a depressurisation 
transient in a SG, this results in an over-prediction of void fraction in the bundle region and leads to excessive mixture level swell being calculated in the riser. This in turn causes an over-estimation of the liquid entrained to the separator, which then falls back into the downcomer and the region where the DP measurement taps are located - resulting in a high water level indication. Conversely, following a repressurisation transient, the over-prediction of interphase drag results in an under-prediction of the void fraction collapse in the bundle, and thus an under-prediction of the downcomer level shrink.

The principal consequences of deficiencies in the modelling of SG level shrink and swell are errors in the predicted actuation and operation of the plant protection and control systems that depend on downcomer level. These are likely to have the greatest effect when simulating normal operational transients (e.g. loss of load. plant trips) and SGTR accidents, but should be less important for the more severe intact primary circuit faults and LOCAs. Note however, that the feedwater systems may act to compensate for an error in the predicted level behaviour, and this could introduce errors in the predicted SG inventory.

As noted for other areas, the only way of forcing the code to calculate SG level shrink and swell correctly, is to artificially reduce interphase drag in the bundle region by specifying a very large hydraulic diameter. Again, however, this could be difficult to justify. Also, the analysis of SG boildown transients presented in Appendix A.3 indicated that the profile and local slip components of the drag force played different roles. This is also likely to be true for depressurisation and repressurisation transients, and thus adjusting the hydraulic diameter, which only affects the local slip component, may not necessarily have the desired effect.

The modelling of SG level shrink and swell may be expected to be more accurate in RELAP5/MOD3 due to the improved interphase drag models - although the comments made in Section 5.3.2 regarding the calculation of the individual components of the drag force should be noted. Note also that when testing these models, Putney (1989b) found that models that gave good agreement with data from tests involving steam bubbling through stagnant water in large diameter vessels, did not perform very well against a test involving the rapid blowdown of a $4 \mathrm{ft}$ diameter vessel. Further investigation indicated that the flow regime below the mixture level in the blowdown experiment had not developed into the maximum sized cap bubble regime that characterised the steam bubbling tests, but was closer to a classical churn turbulent bubbly type regime. This apparent dependence of flow regime on depressurisation rate is likely to be less evident in a SG bundle, as the narrow flow channels may be expected to have a greater influence on constraining the flow regime development. In addition, the depressurisation rates typical during steam discharge from a SG relief valve (or a steam line break transient), are somewhat less than that present in the blowdown experiment considered ( 73 to 20 bar in $20 \mathrm{~s}$ ).

For plant safety studies, an accurate prediction of dynamic level behaviour is particularly important for the range of transients typical of those that could be imposed by the operation of the SG relief or turbine valves. Unfortunately, no separate effects type tests have been identified that are suitable for assessing RELAP5/MOD3 in this area. The Doel 2 SGTR accident and Doel 4 loss of load test would therefore appear to provide the most appropriate data, although being plant transients the quality and quantity of these data is not particularly good.

\subsection{Liquid carryover during steam line break transients}

Section 3 of this report discussed results from RELAP5/MOD2 analyses of $100 \%$ steam line break tests performed on the MB-2 (Section 3.9.2), LOBI (Section 3.11.5) and Semiscale (Section 3.13.2) facilities. In each case, an over-prediction of the liquid carryover to the break was observed. This was initially attributed to shortcomings in the interphase drag models; but further analysis of the MB-2 test using a pre-release version of RELAP5/MOD2 has indicated that this is not the case. The most likely 
explanation is that liquid carryover to the break may have been reduced in the experiment by the accumulation of liquid on structures in the upper part of the SG an effect that was not represented in the RELAP5 analyses. In the MB-2 and Semiscale tests, some of this liquid may have drained back into the top of the riser later in the tests, and been responsible for a period of good heat transfer that was not captured in the calculations.

The main consequence of an over-prediction of liquid carryover in a steam line break transient is an under-prediction of the primary side cooldown ${ }^{35}$ (although for the LOBI test, the overall primary side was actually over-predicted due to an under-estimation of the metalwork heat). Under certain circumstances, this might result in the code failing to predict a return to power after a steam line break due to excessive overcooling and, as such, is therefore nonconservative.

Preliminary RELAP5/MOD3 analysis of the MB-2 steam line break indicates no significant improvement in the modelling of liquid carryover to the break. Indeed if the smaller carryover in the tests is due to the accumulation of liquid on structures in the upper SG, it is difficult to see how this effect could be represented without introducing a special model.

\subsection{Separator performance}

Several RELAP5/MOD2 analysts have reported difficulties in obtaining satisfactory steady-state conditions in SG models due to instabilities in the separator component. Typical problems encountered are the periodic emptying and filling of the separator volume and the steam carryunder to the downcomer. As explained in Section 3.8.2, these problems are probably caused by an over-prediction of the void fraction at the top of the riser, and may therefore be attributed to the known deficiencies in the interphase drag models applied in the bundle region. In fact, many analysts have removed the instabilities by artificially increasing the recirculation ratio, which as shown in Appendix A.2 has the effect of reducing the void fraction at the riser outlet. Since this change also effects the DP level measurement and the SG inventory (albeit in the right direction), a more acceptable approach may be to specify a very small value for the carryunder parameter VUNDER.

Some analysts have also seen instabilities in separator performance during the analysis of SG transients. It has also been noted that results can be sensitive to the separator nodalisation, particularly the value of loss coefficient at the liquid fall back junction. Whilst some of these problems may well be a result of the interphase drag deficiencies, others are more likely to be due to the non-mechanistic nature of the separator model.

As far as can be ascertained, the deficiencies in the RELAP5/MOD2 modelling of the SG separation process do not appear to hold serious implications for PWR safety analysis. In general, either the errors produced are relatively minor, or can be avoided by appropriate adjustments to the input deck.

It is expected that RELAP5/MOD3 will provide a better prediction of separator performance due to the new interphase drag models. Although additional improvements could probably be achieved by the development of a more mechanistic separator model, this is not recommended as a high priority task.

\footnotetext{
35 In theory, the calculation of a low initial SG inventory could also contribute to an under-prediction of the primary side cooldown. However, this effect was not present in the tests examined as they were initiated from very low power conditions.
} 


\subsection{CCFL and liquid hold-up on primary side}

A number of RELAP5/MOD2 analyses of LOCA tests have indicated a tendency for the code to predict excessive liquid hold-up in the SG U-tubes or inlet plenum:

- In the UK analysis of LOFT test L3-6 $2.5 \%$ cold leg break with delayed pump trip - Section 3.8.3), the SG U-tubes drained significantly later than they did in the experiment. This resulted in a late prediction for the decoupling of the primary and secondary sides, causing the secondary side pressure to be systematically under-estimated. A similar effect was apparent in the Studsvik analysis of the test and in the KAERI analysis of test L2-5 (200\% cold leg break).

- For the ROSA-IV 5\% cold leg break test (Section 3.7), the code predicted a period of liquid-up in the SG inlet plena that was observed in the experiment. Use of a modified version of RELAP5/MOD2 which allowed for the existence of stratified flow in the hot leg riser improved the calculation, but the time of draining was still over-predicted - leading to an under-prediction of the core liquid inventory during the boildown phase.

- Excessive liquid hold-up in the SG U-tubes was calculated in the analysis of LOBI SGTR test BL-21 (Section 3.11.4). The analyst attributed this discrepancy to an over-prediction of interphase drag in the vertical section of the hot leg preventing liquid from draining back (but gave no evidence to support this view).

This behaviour of the code indicates a tendency to under-predict the vapour flow at which CCFL occurs at some point in the pipework between the hot inlet and the top of the SG U-tubes, which may be attributed to an over-prediction of the local interphase drag force. It is also consistent with an analysis of UPTF test 11 performed by Dillistone (1990), in which RELAP5/MOD2 was found to under-estimate the steam flow necessary to prevent liquid drainback from the $S G$ inlet plenum by more than a factor of 3. The author shows that this is primarily due to the use of an over-simplified flow regime map which does not allow the possibility of stratified flow in the hot leg riser. As noted above, removing this restriction also helped to improve the results in the ROSA-IV test analysis.

Other deficiencies in the modelling of CCFL and liquid-up on the SG primary side evident from the results of RELAP5/MOD2 assessment studies, that are not totally consistent with the above, are as follows.

- In the analysis of LOBI test BL-02 (3\% cold leg break - Section 3.11.2), there was some evidence that the code was calculating excessive draining from the SG inlet plena. Further investigations indicated that this was due to poor modelling of CCFL along the horizontal part of the hot leg.

- In the analysis of the SPES loss-of-feedwater test (Section 3. i0), the primary side natural circulation mode following core recovery was incorrectly predicted due to shortcomings in the modelling of CCFL in the SG U-tubes. The failure to calculate CCFL in the U-tubes was also evident in the analysis of LOBI SGTR test BL-21.

- Errors were present in the RELAP5 predictions of liquid hold-up in the SG tubes for the Semiscale small break LOCA tests S-LH-1 and S-LH-2 (Section 3.13.1), although no clear systematic trends were eviderit.

These results reflect a general problem in modelling flooding type phenomena in RELAP5/MOD2 for the range of geometries present in the PWR. Some improvement may be expected with RELAP5/MOD3 as a result of the new interphase drag and user controlled CCFL models. 


\subsection{Secondary side condensation effects during repressurisation transients}

Two instances have been uncovered where RELAP5/MOD2 appears to have over-estimated vapour condensation rates on the SG secondary side under repressurisation conditions:

1. In the analysis of the Doel 2 SGTR accident (Section 3.4). RELAP5/MOD2 failed to calculate the increase in secondary side pressure that occurred after the faulted SG had been completely isolated, and resulted from the piston effect of the rising level on the vapour in the steam dome. This discrepancy was traced to the calculation of an excessive vapour condensation rate in the dome, and was believed to be due to the use of constifutive equations appropriate to slug flow under stratified flow conditions. Further calculations however, showed that an increase in pressure could be obtained by subdividing the steam dome into several volumes.

2. In the analysis of the Tihange 2 plant trip test (Section 3.6), the SG pressure was significantly under-predicted in the period immediately following the turbine and reactor trips when the pressure was increasing rapidly (although the final pressure was well predicted). Further investigations indicated that this discrepancy was due to excessive condensation being calculated in the regions where the feedwater was injected, which had the effect of driving the vapour to saturation, leading to a temporary stagnation in the pressure evolution. Since the plant data indicated a similar pressure plateau but at a higher pressure, the analysts deduced that the code's bubbly flow models cannot maintain strong thermal disequilibrium under fast pressurisation conditions, and that due to premature condensation the vapour temperature returns to quasi saturation conditions too quickly.

These two examples of the calculation of excessive vapour condensation are evidently caused by different modelling deficiencies. In addition, the effects seen have not been observed in any other studies and thus it is not possible to say whether they represent general trends. Nevertheless, they are recorded here for the sake of completeness.

\section{CONCLUSIONS}

1. RELAP5/MOD2 under-predicts SG heat transfer under steady-state normal operating and start-up conditions. If the code is initialised with the correct primary side conditions, this is reflected by an under-prediction of the secondary side pressure. The effect is seen in both plant and rig calculations, although it tends to reduce as both reactor power and scale reduce. For the Sizewell ' $B$ ' SG operating at full load conditions, the error in secondary side pressure is around 3.5 bar. The deficiency can be attributed to the application of the Chen correlation, which was developed using data from flows in tubes and annuli, to calculate the boiling heat transfer coefficient on the secondary side of the $U$-tube bundle. Although RELAP5/MOD2 incorporates a modification to this correlation which enhances heat transfer as the void fraction reduces, the enhancement is not sufficient for plant calculations. It also exacerbates an incorrect trend with bundle elevation. Various methods are available for compensating for the deficiency, but in most cases the most defensible approach is to artificially increase the U-tube thermal conductivity. In general, the errors in SG heat transfer behaviour do not hold serious implications for FWR safety analysis, although they are likely to be worse in RELAP5/MOD3 as the Chen correlation is applied in its standard form. 
2. At steady-state normal operating conditions, RELAP5/MOD2 under-predicts the SG secondary side liquid inventory if the recirculation ratio is calculated correctly. The deficiency can be attributed to an over-prediction of void fraction in the SG bundle, caused by an over-prediction of the interphase drag force (which is a known deficiency in the code). The error in inventory that results, which tends to reduce as reactor power reduces, affects the prediction of the downcomer level following a reactor trip and the calculated time of SG dryout in loss of feedwater accidents. The latter holds the more serious implications for PWR safety analysis and is particularly severe for transients in which most of the boildown occurs under decay heat levels - as the excess inventory on the plant takes a long time to boiloff. As a result, the predicted dryout may be advanced by around $1000 \mathrm{~s}$, which has a dramatic affect on the timings of all subsequent events. Although the initial inventory may be artificially increased by increasing the downcomer flow area or the recirculation ratio (through raising the initial SG level or reducing the flow losses), the adjustments required to compensate for the void fraction errors may not be physically sensible. The initial inventory can also be 'corrected' by specifying a very large hydraulic diameter on the secondary side of the U-tube bundle $(\approx 250 \mathrm{~cm})$. However, this may be difficult to justify. The calculation of SG inventory is expected to be better in RELAP5/MOD3 due to the new interphase drag models.

3. For fast SG boildown transients typical of those occurring under full power conditions, RELAP5/MOD2 tends to over-predict the rate at which the downcomer level falls, in addition to under-predicting the initial inventory. Moreover, increasing the initial inventory by increasing the downcomer flow area or recirculation ratio, does not have a significant effect on this rate - it only serves to delay the time at which SG dryout occurs. These effects arise because, in addition to determining the initial inventory, the interphase drag models in the bundle have a direct effect on the mixture and downcomer level trajectories during the boildown process itself. The effect is less noticeable for slow boildown transients where the vapour generation rate is relatively low, as the errors in initial inventory tend to dominate. Theoretical analyses also indicate that in order to predict the correct level behaviour during boildown, it is necessary to calculate both the local and profile slip components of the drag force correctly. In contrast, in order to obtain the correct initial inventory, it is only necessary to calculate the total drag force correctly. This implies that attempts to correct the initial inventory by specifying a large secondary side hydraulic diameter, which only affects the calculation of the local drag force, may not necessarily produce the correct level behaviour. It also means that this type of problem should provide a good test for the new interphase drag models in RELAP5/MOD3.

4. During SG boildown and blowdown transients, RELAP5/MOD2 tends to over-predict wall heat transfer above the mixture level. The evidence available indicates that the code predicts wet wall conditions for the whole of the bundle until the SG has virtually dried out, and that this is due to the calculation of excessive liquid entrainment from the mixture region. It is believed that this problem is a consequence of the known deficiencies in the bundle interphase drag model, exacerbated by the absence of a proper vertical stratified flow model and, possibly, the criteria applied to determine wet/dry wall conditions. Some improvement may be expected in RELAP5/MOD3 due to the new interphase drag and vertical stratification models.

5. The deficiencies in the bundle interphase drag model are believed to be responsible for a tendency of RELAP5/MOD2 to calculate excessive dynamic level swell in response to steam discharge from the SG. They may also be the cause of instabilities seen in the calculated separator performance, although the non-mechanistic nature of the separator model may also be a contributing factor. In the past, a tendency to over-predict liquid entrainment to the break in steam line break transients have been atiribuied to shoricoming in interphase drag modelling. Recent studies however, have indicated that this is not the case, and the most likely explanation is the failure to model the accumulation of liquid on 
structures in the upper SG. Other deficiencies in SG modelling in the code include the modelling of counter current flow limitation (CCFL) and liquid hold-up in the U-tubes and inlet plena. These reflect a general problem in modelling flooding type phenomena in RELAP5/MOD2 over a range of geometries and may be linked to the interphase drag models and flow regime maps - although in many cases the primary source of the deficiency lies outside the area of SG modelling. Nevertheless, some improvement may be expected in RELAP5/MOD3, primarily as a result of the new user controlled CCFL model.

6. In practice, the above deficiencies in SG modelling do not diminish the value of RELAP5/MOD2 for performing safety case calculations for the majority of PWR LOCAs and intact primary fault sequences of interest. The only real exception concerns the modelling of transients in which the SG boils dry very slowly, when the under-prediction of initial inventory will result in the SG being calculated to dry out too early. A typical example is a total loss of feedwater accident with normal reactor trip and closure of the MSIV. Due to the inaccuracies in the timing of major events, it may be difficult to use the results of the calculation for safety assessment purposes.

\section{REFERENCES}

Agar C W, 1990, MB-2 100\% steam line break test T-2013 re-analysis using RELAP5/MOD2.5, PWR/THSG/N(90)2

Atthey D R, 1989, A comparison of wet-wall boiling heat transfer correlations for use with the code NUMAC-PWR, MEL Report RD/M/1856/RR89, PWR/PKWG/P(90)443

Atthey D R, 1990. PKWG Action 66.1 - heat transfer correlations in tube bundles, letter to K.H. Ardron, attached to Minutes of 73rd PKWG Meeting, 13th February, 1990, PWR/PKWG/M(73)

Bang Y S, Lee S Y and Kim H-J, 1990, Assessment of RELAP5/MOD2, cycle 36.04 using LOFT large break experiment L2-5, NUREG/IA-0032, April

Bestion D, 1985, Interfacial Friction determination for the 1D-6 Equations Two Fluid Model used in the CATHARE Code. European Two-Phase Flow Group Meeting, Southampton, England

Birchley J C, 1988, RELAP5/MOD2 analysis of LOFT experiment L9-3, AEEW-R 2435, PWR/PKWG/P(88) 390

Blanchat T and Hassan Y A, 1989, Comparisons of CHF correlations with bundle flows, Trans. Am. Nuc. Soc., Vol. 59, pp.213-215

Boucher T J, 1987a, Results of Semiscale Mod-2C feedwater and steam line break (S-FS) experiment series: bottom main feedwater line break accident experiments, NUREG/CR-4898, EGG-2503

Boucher T J, 1987b, Scale model results for an inverted U-tube steam generator with comparisons to heat transfer correlations, ASME Winter Meeting, Boston, MA, 13-18th December 1987, 87-WA/NE-16

Brodie P, 1989, Analysis of Semiscale test S-LH-2 using RELAP5/MOD2, PWR/HTWG/P(89)708

Chen J C, 1966, Correlation for boiling heat transfer to saturated fluids in convective flow, Process Design and Development, Vol. 5. pp. 322-329 
Chung B-D, Kim H-J and Lee Y-J, 1990, Assessment of RELAP5/MOD2 code using loss of offsite power transient data of KNU \#1 plant, NUREG/IA-0030, April

Coney M W E. 1990, Visit report on the ICAP meeting held in Madrid, May 7-9. 1990. PWR/THSG/N(90)6

Cooper S and Froushan A B, 1990. International Standard Problem 26: Analysis of JAERI LSTF Test SB-CL-18 (5\% cold leg break) using RELAP5/MOD2, PWR/THSG/T(90) 16

Croxford M G. Harwood $C$ and Hall P C, 1988, RELAP5/MOD2 calculation of OECD LOFT test LP-FW-01, GD/PE-N/597, PWR/PKWG/P(88)378

Curlee $N$ J and Preece R J, 1987, Final Report: Model F steam generator field instrumentation program, WCAP-11276-FNP, PWR/SGWG/P(86)361

Davis D, 1984. The Sizewell ' $B$ ' total plant dynamic model SIBDYM, NNC report no. PWR/R912

Dillistone $M$ J. 1990. Simulation of UPTF test 11 with RELAP5/MOD2 and RELAP5/MOD3, PWR/RUG/P(90)38

Dimenna R A, Larson J R, Johnson R W. Larson T K, Miller C S, Streit J E, Hanson R $G$ and Kiser D M, 1988, RELAP5/MOD2 models and correlations, NUREG/CR-5194, EGG-2531

Dimenna R A, Hall D G, Kullberg C M, Larson T K, Larson J R and Watkins J C, 1989, An assessment of RELAP5/MOD2 applicability to loss-of-feedwater transient analysis in a Babcock and Wilcox reactor plant, NUREG/CR-5311, EGG-2560

Dittus $F W$ and Boelter L M K, 1930, Heat transfer in automobile radiators of the tubular type. Publications in Engineering. University of California, Berkeley, Vol. 2, pp. $443-461$

Eriksson J, 1990, Assessment of RELAP5/MOD2, Cycle 36.04 against LOFT small break experiment L3-6, NUREG//A-0033

De Feu M, Firnhaber M. Pochard R and Stubbe E J, 1988, International Standard Problem-20, steam generator tube rupture, nuclear power plant Doel 2 - Belgium, CSNI Report No. 154, December

Forster $\mathrm{H} \mathrm{K}$ and Zuber N, 1955, Dynamics of vapour bubble and boiling heat transfer, A.I.Ch.E. J., Vol. 1, No. 4, pp. 531-535

Groeneveld D C, Cheng S C and Doan T, 1986, 1986 AECL-UO critical heat flux lookup table, Heat Transfer Eng., Vol. 7, No. 1-2, pp. 46

Gungor KE and Winterton R H S, 1986, A general correlation for flow boiling in tubes and annuli, Int. J. Heat Mass Transfer, Vol. 29, No. 3, pp. 351-358

Gungor K E and Winterton R H S, 1987, Simplified general correlation for saturated flow boiling and comparisons of correlations with data, Chem. Eng. Res. Des., Vol. 65 , pp. $148-156$

Hall $P$ C, 1987, RELAP5/MOD2 analysis of OECD LOFT test LP-SB-02, PWR/HTWG/P(87)506, PWR/LCSG/P(87)288

Hall P C and Brown G, 1990, RELAP5/MOD2 calculations of OECD-LOFT test LP-SB-01, NUREG//A-0012, January 
Hall P C and Bull D R, 1989. Analysis of Semiscale test S-LH-1 using RELAP5/MOD2. GD/PE-N/725, PWR/HTWG/P(88)6'29(Rev)

Harwood C, 1986, RELAP5/MOD2 input data for Sizewell 'B'. GD/PE-N/1372 (Issue 1)

Harwood C and Brown G, 1990, RELAP5/MOD2 calculation of OECD-LOFT lest LP-SB-03, NUREG/IA-0013, January

Hassan Y A, 1988, Assessment of boiling heat transfer correlations for once-through steam generators, Nuclear Technoiogy, Vol. 81, pp.446-449

Hassan $Y A$ and Blanchat $T K, 1990$. A modified heat transfer correlation and flow regime map for tube bundles, International Topical Meeting on Nuclear Reactor Thermal Hydraulics (NURETH-4), Karlsruhe, Oct 10-13th, 1989, pp. 528-533

Hassan Y A and Salim P. 1990, Analysis of a nuclear power plant using RELAP5/MOD2 with modified bundle heat transfer correlations, Nuclear Technology, Vol. 92, pp. 141-149

Hirst I L and Keevill M B, 1989, CEGB/Nuclear Electric Technology Division, Station Performance Branch, Progress Report to the PKWG - July 1989, in Minutes of 68th PKWG Meeting, 11th July 1989, PWR/PKWG/M(89)68

Hirst I L and Keevill M B, 1990, CEGB/Nuclear Electric Technology Division, Station Performance Branch, Progress Report to the PKWG - February 1990, in Minutes of 73rd PKWG Meeting, 13th February 1990. PWR/PKWG/M(90)73

Hsu $Y$ Y, 1981, Boiling heat transfer equations, in Thermohydraulics of Two-Phase Systems for Industrial Design and Nuclear Engineering, Edited by Delhaye, J.M., Giot, M. and Riethmuller, M.L., McGraw-Hill, pp.255-296

Ishihara K. Paleo J W and Taborek J, 1980. Critical review of correlations for predicting two-phase pressure drop across tube banks, Heat Transfer Engineering, Vol. 1

Kalyanasundaram K and Hassan Y A, 1988, Analysis of loss-of-feedwater transients in MB-2 using RELAP5/MOD2, Trans. Am. Nuc. Soc., Vol. 57, pp. 143-147

Kao L, 1988, Preliminary analysis results of LOFT L2-5 by RELAP5/MOD2, presented at the 3rd ICAP specialists meeting, Grenoble, France, March 1-3, 1988

Kataoka I and Ishii M, 1987, Drift flux model for large diameter pipe and new correlation for pool void fraction, Int. J. Heat Mass Transfer, Vol 30, No 9, pp $1927-1939$

Keevill M B, 1988, RELAP5/MOD2 analysis of LOFT experiment L9-4, PWR/PKWG/P(88)372

Keevill M B, 1989, RELAP5/MOD2 analysis of a commissioning test involving a 50\% load reduction from $100 \%$ power in the Woif Creek PWR, GD/P-EN/759, PWR/PKWG/P(89)421

Klimenko V V, 1988, A generalized correlation for two-phase forced flow heat transfer, Int. J. Heat Mass Transfer, Vol. 31, No. 3, pp. 541-552

Kumamaru $H$, Koizumi $Y$ and Tasaka $K, 1987$, Investigation of pre- and post-dryout heat-transfer of steam-water two-phase flow in a rod bundle, Nucl. Eng. Des., Vol. 102, pp. 71-84 
Lee E-J, Chung B-D and Kim H-J, 1990. ICAP assessment of RELAP5/MOD2, cycle 36.05 against LOFT small break experiment L3-7. NUREG/IA-0031, April

Preece R J, 1987a, Steady state thermal-hydraulic performance of the Westinghouse Model ' $F$ ' steam generator from plant measurements, CERL report no. TPRD/L/3079/R86

Preece R J. 1987b, Uncertainty bands applying to the Westinghouse Model ' $F$ ' steam generator thermal-hydraulic performance measurements, CERL report no. TPRD/L/3151/R87

Proctor A R, 1990a, RELAP5/MOD2 analysis of a commissioning test involving a plant trip from 100\% power in the Wolf Creek PWR. TD/SPB/REP/0089

Putney J M, 1988. Proposals for improving interfacial drag modelling for the bubbly and slug regimes in RELAP5, CERL report no. RD/L/3306/R88, PWR/HTWG/P(88)597

vtriey J M. 1989a, An assessment of the annular flow transition criteria and interphase friction models in RELAP5/MOD2. CERL report no. RD/L/3451/R89, PWR/HTWG/P(88)653

Putney J M, 1989b, Development of a new bubbly-slug interfacial friction model for RELAP5 - Final Report. NP TEC report no. ESTD/L/0075/R89, PWR/HTWG/P(89)722

Ransom V H, Wagner R J, Trapp J A. Johnsen G W, Miller C S, Kiser D M and Riemke R A, 1987, RELAP5/MOD2 code manual - Volume 1: Code structure, systems models, and solution methods, NUREG/CR-4312, EGG-2396, Rev 1

Rais $O$ and Hassan $Y A, 1990$, Thirty-tube once-through steam generator predictions using the modified RELAP5/MOD2 computer code, Trans. Am. Nuc. Soc., Vol. 61, pp.201-204

Rogers J M, 1989a, An analysis of Semiscale Mod-2C S-FS-1 steam line break test using RELAP5/MOD2. AEEW-R2476, March

Rogers J M, 1989b, An analysis of MB-2 100\% steam line break test T-2013 using RELAP5/MOD2. AEEW-R2477, March

Rouel G P and Stubbe E J, 1989, Assessment study of RELAP5/MOD2 Cycle 36.05 based on the Tihange-2 reactor trip of January 11th, 1983. Private Communication from $E \mathrm{~J}$ Stubbe and L Mampaey to M W E Coney

Salim P and Hassan Y A, 1990, Modelling and loss-of-coolant accident analysis of a nuclear power plant using RELAP5/MOD2, Nuclear Technology, Vol. 90, pp. 275-285

Sanders J, 1988a, Experimental data report on LOBI-MOD2 test BC-01 (steam generator mass inventory), LOBI Project Report LEC 88-53, communication no. 4221

Sanders J, 1988b, Quick look report on LOBI-MOD2 test BC-01 (steam generator mass inventory), LOBI Project Report LQC 88-44, communication no. 4222

Scriven $A H, 1987$, Analysis of LOBI test BLO2 (three percent cold leg break) with the RELAP5 code, CERL report no. TPRD/L/3209/R87, PWR/HTWG/P(87)496

Scriven A H, 1988, Pre- and post-test analysis of LOBI MOD2 test ST-02 (BT-00) with RELAP5 MOD1 and MOD2. (Loss of feed water.), CERL memorandum no. TPRD/L/ES 0754/M87, PWR/HTWG/P(87)562 
Scriven A H, 1990. Application of the RELAP5/MOD2 code to the LOFT tests L3-5 and L3-6. NP TEC report no. ESTD/L/0117/R89. PWR/HTWG/P(89)689

Smethurst A J, 1990. Post-test analysis of LOBI test BT-12 using RELAP5/MOD2, AEEW-R2645

Stubbe $E$ J, 1986, International assessment report: assessment study of RELAP5/MOD2 Cycle 36.01 based on the Doel-2 steam generator tube rupture incident of June 1979, NUREG/IA-0008, October

Stubbe E J. Vanhoenacker L, Moeyaert P and De Schutter P, 1988, Doel 4 - loss of external load transient - simulation and results. ANS Topical Meeting on Anticipated and Abnormal Plant Transients

Sun K H. Duffey R B and Peng C M, 1981. The prediction of two-phase mixture level and hydrodynamically-controlled dryout under low flow conditions, Int. J. Multiphase Flow, Vol. 7, No. 5. pp. 521-543

Venkateswararao P. Semiat $R$ and Dukler A E, 1982, Flow pattern transition for gas-liquid flow in a vertical rod bundle, Int. J. Multiphase Flow, Vol. 8, No. 5, pp. 509-524

Wang S-F and Wu C-C, 1988, Evaluation of a heat transfer package in RELAP5/MOD2 under steam generator conditions, Trans. Am. Nuc. Soc., Vol. 56, pp. 620-621

Weisman J, 1959, Heat transfer to water flowing parallel to tube bundles, Nuclear Science and Engineering, Vol. 6

Whittall W C, 1990, RELAP5/MOD2 analysis of LOBI LONOP-ATWS experiment A2-90, PWR/THSG/T(90)2

Willmott G N, 1989, Post test analysis of LOBI test BL-21 $(0.4 \%$ steam generator tube rupture) with RELAP5/MOD2, PWR/HTWG/P(89)703

Willmott G N, 1990, Post-test analysis of ISP22 (loss of feed test on SPES rig) with RELAP5/MOD2, PWR/THSG/T(90)6

Wu C-C and Wang S-F, 1988, A RELAP5/MOD2 model for MB-2 loss-of-feedwater tests. Trans. Am. Nuc. Soc., Vol. 56, pp. 619-620

Zuber $\mathrm{N}$ and Findlay J, 1965, Average volumetric concentrations in two-phase flow systems, J. Heat Trans., Vol 87, pp. 453-468 


\section{NOMENCLATURE}

The following lists the general notation used throughout the report. Other symbols used are defined when they appear.

All variables relate to a 10 (channel averaged) flow. SI units are assumed throughout.

k

$a_{k}$

$\rho_{k}$

$\rho_{\mathrm{ks}}$

$v_{k}$

$v_{k s}$

$h_{k}$

$h_{k s}$

$\mathrm{p}$

$T_{k}$

Ts

$T_{w}$

$\Delta \mathrm{T}_{\text {sat }}$

$\Delta P_{\text {sat }}$

$q^{\prime \prime}{ }_{w}$

$\mu_{k}$

$k_{k}$

$\mathrm{C}_{\text {pk }}$

$\mathrm{Pr}_{\mathrm{k}}$

$v_{k}$

$j_{k}$

$\rho$

G

$x$

$\Gamma$
Phase index $=g($ vapour $) / f($ liquid $)$

Volume fraction $\left(\alpha \equiv \alpha_{q}\right)$

Density

Density at saturation conditions

Specific volume

Specific volume at saturation conditions

Specific enthalpy

Specific enthalpy at saturation conditions

Pressure (equal for both phases)

Temperature

Saturation temperature

Wall temperature

$=T_{w}-T_{s}$

Difference between saturation pressure at $T_{w}$ and saturation pressure at $T$,

Wall heat flux

Dynamic viscosity

Thermal conductivity

Specific heat at constant pressure

Prandtl number $\left(=C_{p k} \mu_{k} / k_{k}\right)$

Velocity

Superficial velocity $\left(j_{k}=\alpha_{k} v_{k}\right)$

Mixture density $\left(\rho=\alpha_{9} \rho_{9}+\alpha_{1} \rho_{1}\right)$

Mixture mass flux ( $\left.G=\rho_{9} j_{a}+\rho_{1} j_{1}\right)$

Quality

Vapour generation rate per unit volume 


$\begin{array}{ll}\Delta r & \text { Phase density difference }\left(\Delta /=\rho_{f}-\rho_{g}\right) \\ h_{g l} & \text { Latent heat of vaporisation }\left(h_{g l}=h_{g s}-h_{f s}\right) \\ v_{r} & \text { Relative velocity }\left(v_{r}=v_{g}-v_{f}\right) \\ g & \text { Acceleration of gravity } \\ \sigma & \text { Surface tension } \\ v_{g i} & \text { Dapour drift velocity (in drift flux model) } \\ C_{0} & \text { Flow area } \\ A & \text { Equivalent heated diameter } \\ D_{e} & \end{array}$




\section{Appendix A CONCEPTUAL STEAMI GENERATOR MODELS}

This appendix develops simple, analytical models of some of the main phenomena which control SG performance during normal and abnormal operating conditions. The particular areas addressed are

- Primary to secondary heat transfer.

- Steady-state operation and effect of recirculation flow.

- Steam generator boildown.

Results from these models are used in the main body of this report.

Although the models developed are very simple and somewhat idealistic, they are still believed to be representative. In the context of the present study, they are particularly useful for interpreting the results of RELAP5 analyses and for identifying modelling deficiencies responsible for apparent code deficiencies.

\section{A.1 Primary to secondary heat transfer}

Consider a short length, $\delta \mathrm{L}$, of a single $S G$ tube having internal radius $R_{p}$, wall thickness $t$ and thermal conductivity $k$. If the wall and bulk fluid temperatures on the primary side of the tube are denoted by $T_{W p}$ and $T_{p}$, the heat flux at the wall, $q_{p}^{\prime \prime}$ may be written as

$$
q_{p}^{\prime \prime}=H_{p}\left(T_{p}-T_{W P}\right)
$$

where $H_{p}$ is the primary side heat transfer coefficient.

Likewise, the wall heat flux on the secondary side of the tube is given by

$$
q_{s}^{\prime \prime}=H_{S}\left(T_{w s}-T_{S}\right)
$$

Under steady-state conditions, continuity arguments demand that

$$
2 \pi R_{p} \delta L q^{\prime \prime} p=2 \pi\left(R_{p}+t\right) \delta L^{\prime \prime}{ }_{s}=Q
$$

where $Q$ is the total heat transfer rate across the length of tube (in $\mathrm{W} \mathrm{m}^{-2}$ ).

Integrating the steady-state heat conduction equation across the tube wall and neglecting effects due to axial conduction and the variation of tube thermal conductivity with temperature, leads to

$$
T_{w S}-T_{W P}=-\frac{R_{p} q_{p}^{\prime \prime}}{k} \ln \left[1+\frac{t}{R_{P}}\right]
$$

Since $t / R_{p}$ is small, the In term may be approximated by the first term in its Taylor series expansion, giving

$$
T_{W S}-T_{W P}=-\frac{t}{k} q_{p}^{\prime \prime}
$$

Combining equations (A1.1), (A1.2), (A1.3) and (A1.5) to eliminate $q^{\prime \prime} p, q{ }^{\prime \prime}, T_{w p}$ and $T_{w s}$, results in the relationship

$$
Q=\frac{2 \pi R_{p} \delta L\left(T_{P}-T_{S}\right)}{\left[\frac{R_{P}}{R_{P}+t}\right] \frac{1}{H_{S}}+\frac{1}{H_{P}}+\frac{t}{k}}
$$

This equation shows how various SG parameters affect the heat transfer across a short length of tube. It is used in Section 2.3 to demonstrate the sensitivity of SG heat transfer to changes in these parameters. 


\section{A.2 Steady-state operation and effect of recirculation flow}

\section{A.2.1 Conceptual model}

At the simplest level, the secondary side of a PWR SG may be modelled using three basic components: Riser, Separator and Downcomer. Under ideal normal operating conditions, the thermal-hydraulic conditions in each component may be described as follows.

\section{Riser}

Subcooled (or saturated) water enters the bottom of the riser, boils as it flows upwards through the U-tube bundle, producing a saturated two-phase mixture which enters the separator.

\section{Separator}

Assuming perfect separation (no water carryover or steam carryunder), saturated steam passes from the separator to the SG steam dome and saturated water returns to the top of the downcomer (via the recirculation flow).

\section{Downcomer}

In the downcomer. the recirculation flow mixes uniformly with the feedwater flow, which is sufficient to maintain a constant water level.

The situation described is shown schematically in Fig. A.1. The notation used is as follows.

$W_{F} \quad$ Feedwater flow rate $(\mathrm{kg} \mathrm{s}$ ')

$W_{c} \quad$ Recirculation flow rate

$W_{R} \quad$ Total riser flow rate

$W_{\mathrm{s}} \quad$ Steam outlet flow rate

$h_{\text {Is }} \quad$ Saturated liquid enthalpy $\left(\mathrm{J} \mathrm{kg}^{-1}\right)$

$h_{g s} \quad$ Saturated vapour enthalpy

$h_{F} \quad$ Feedwater enthalpy

$h_{R I} \quad$ Riser inlet enthalpy

$X_{\text {Ro }} \quad$ Equilibrium quality at riser outlet

$\alpha_{R O} \quad$ Void fraction at riser outlet

Q Total primary to secondary heat transfer rate (W)

$q^{\prime}(z) \quad$ Linear power in tube bundle at elevation $z\left(W^{\prime}{ }^{\prime}\right)$

$\phi(z)$ Normalised axial heat flux profile in bundle at elevation $z$

$Z_{o c} \quad$ Elevation of water level in downcomer $(m)$

$Z_{\text {sat }} \quad$ Elevation at beginning of saturated boiling 
$Z_{B} \quad$ Elevation at top of tube bundle

$Z_{R O} \quad$ Elevation at riser outlet

$Z_{S P} \quad$ Elevation at top of separator

$A_{R} \quad$ Flow area of riser

$\mathrm{K}_{\mathrm{RI}} \quad$ Effective loss coefficient at bottom of riser

Other notation used in this appendix is defined in the Nomenclature list. 


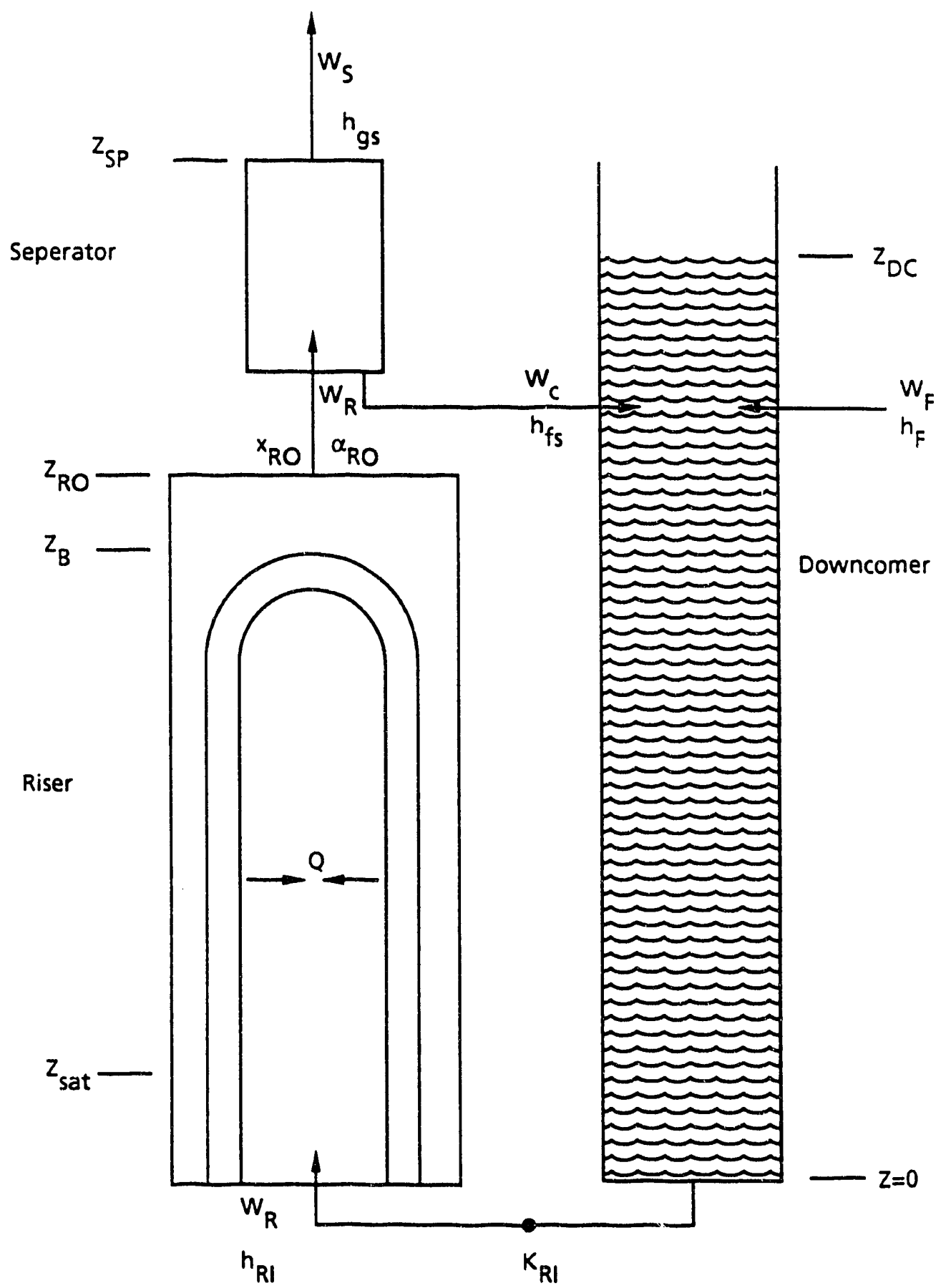

Figure A1 Conceptual model of SG secondary side 


\section{A.2.2 Steady-state conditions}

Imposing steady-state mass conservation for the model described above gives

$$
W_{S}=W_{F}
$$

and

$$
W_{R}=W_{F}+W_{C}
$$

i.e. the feedwater flow must be equal to the steam flow and the total riser flow must equal the feedwater flow plus the recirculation flow.

From an energy balance across the downcomer, the liquid enthalpy at the riser inlet is given by

$$
h_{R 1}=\frac{W_{C} h_{f s}+W_{F} h_{F}}{W_{C}+W_{F}}
$$

while an energy balance across the riser and separator gives

$$
W_{F}=\frac{Q}{h_{g s}-h_{F}}
$$

which is a condition for steady-state operation.

The mass flowing quality at the riser outlet is defined by

$$
x_{R O}=\frac{W_{F}}{W_{C}+W_{F}}
$$

To model the recirculation flow, it is convenient to represent all the frictional resistance around the recirculation loop using an effective loss coeffic:ent, $K_{R 1}$, defined at the junction between the downcomer and riser. Then, ignoring acceleration and inertial terms, and the vapour head between $Z_{o c}$ and $Z_{s p}$ in the downcomer, $a$ momentum balance around the loop gives

$$
\int_{0}^{Z_{D C}} \rho_{i} g \mathrm{dz}=\int_{0}^{Z_{R O}} \rho \mathrm{gdz}+\int_{Z_{R O}}^{Z_{S P}} \rho \mathrm{gdz}+K_{R I} W_{R}^{2}
$$

In the above equations, $W_{F} / Q$ a id $h_{F}$ are usually specified as boundary conditions for a RELAP5 simulation. The recirculation flow, $W_{c}$, however, is sometimes specified independently from the plant value (if known) to achieve the desired separator performance and/or the correct SG liquid inventory. The following sections show how these effects come about.

\section{A.2.3 Effect of recirculation flow on RELAP5 separator performance}

Consider the case when $Q, W_{F}$ and $h_{F}$ are specified and satisfy equation (A2.4).

Equation (A2.6) shows that an increase in the recirculation flow may be obtained by raising the liquid level in the downcomer or by artificially reducing the frictional losses in the recirculation loop (by specifying a low value of $\left.K_{R 1}\right)^{36}$. The equation also shows that an over-prediction of interphase drag and thus voidage in the riser will demand a lower SG level or a greater friction loss to achieve a particular recirculation flow.

The liquid enthalpy at the riser inlet (equation (A2.3)) may be expressed as

\footnotetext{
36 In Appendix (A2.4), it is shown that an increase in the recirculation flow will lead to an increase in the liquid fraction in the riser and separator regions. This will result in an increase in the local mixture density, which will tend to check the initial increase in mixture level.
} 


$$
h_{R I}=h_{t s}\left[\frac{1-\frac{h_{F}}{h_{t s}}}{1+\frac{W_{F}}{W_{C}}}+\frac{h_{F}}{h_{t s}}\right]
$$

Under normal operating conditions $h_{F}<h_{1 s}$ (i.e. both terms in equation (A2.7) will be positive), and thus an increase in the recirculation flow will result in an increase in the riser inlet enthalpy. (If $h_{F}=h_{i s}, h_{R l}=h_{i s}$ for alt values of $W_{C}$.)

Equation (A2.4) on the other hand, shows that an increase in the recirculation flow will result in a decrease in the riser outlet quality. Furthermore, from the drift flux model (Zuber and Findlay, 1965), the void fraction at the riser outlet is given by

$$
\alpha_{R O}=\frac{\left[\frac{x_{R O}}{\rho_{g s}}\right]\left[\frac{W_{C}+W_{F}}{A_{R}}\right]}{C_{O}\left[\frac{x_{R O}}{\rho_{g s}}+\frac{1-x_{R O}}{\rho_{\mathrm{is}}}\right]\left[\frac{W_{C}+W_{F}}{A_{R}}\right]+v_{g j}}
$$

which after eliminating $x_{R O}$ using equation (A2.4) may be written as

$$
\alpha_{R O}=\frac{v_{g s}}{C_{O}\left[v_{g s}+v_{f s} \frac{W_{C}}{W_{F}}\right]+\frac{v_{g i} A_{R}}{W_{F}}}
$$

Assuming that $C_{0}$ and $v_{g j}$ are not strongly dependent on $W_{c}$ or $\alpha$, this result shows that an increase in the recirculation flow will result in a decrease in the void fraction at the riser outlet.

The average void fraction in the SG separator is approximately equal to the void fraction at the riser outlet. In RELAP5/MOD2, the separation process is represented using the following non-mechanistic model:

- The vapour fraction of the outlet 'steam' flow is set to one if the separator vapour fraction is greater than a user supplied parameter VOVER (i.e. no carryover), but ramped to zero if the separator vapour fraction falls below this.

- The liquid fraction of the outlet 'water' flow is set to one if the separator liquid fraction is greater than a user supplied parameter VUNDER (i.e. no carryunder), but ramped to zero if the separator liquid fraction falls below this.

Consequently, for a given value of VUNDER which is greater than zero, RELAP5 may predict vapour carryunder to the downcomer if the void fraction calculated at the riser outlet is sufficiently high. The above analysis sho'ws that this carryunder may be eradicated by increasing the recirculation flow, either by raising the liquid level in the downcomer or reducing the friction losses in the resirculation loop.

Conversely, any liquid carryover to the steam dome may be removed by reducing the recirculation flow.

\section{A.2.4 Effect of recirculation flow on SG inventory}

In the following analysis, the effects of subcooled boiling are ignored and it is assumed that no vapour is present in the riser until after the bulk fluid has become saturated at elevation $Z_{\text {sat }}$.

Denoting the height of the tube bundle as $Z_{B}$, the linear power $\left(W m^{-1}\right)$ at elevation $Z$ may be written as 


$$
q^{\prime}(z)=\frac{Q}{Z_{B}} \phi(z)
$$

where $\phi(z)$ is the axial heat flux profile.

Integrating the steady-state energy equation between the riser inlet and the beginning of saturated boiling gives

$$
W_{F}\left(h_{f s}-h_{F}\right)=\frac{Q}{Z_{B}} \int_{0}^{Z_{s a t}} \phi(z) d z
$$

or, from equation (A2.4)

$$
\left(h_{\mathrm{fs}}-h_{\mathrm{F}}\right)=\frac{h_{\mathrm{gs}}-h_{\mathrm{F}}}{\mathrm{Z}_{\mathrm{B}}} \int_{0}^{z_{\text {sat }}} \phi(z) d z
$$

Since any dependence of $\phi(z)$ on the recirculation flow is likely to be small, these equations show that, to a first approximation, the beginning of saturated boiling is not affected by changes in the recirculation flow.

Thus, the region of the SG riser over which changes in the liquid fraction may result from variations in the recirculation flow, viz. $Z_{s \text { nt }}$ to $Z_{B}$, is independent of the recirculation flow itself. Integrating the steady-state energy equation over this region, and neglecting variations of the fluid properties with pressure (which are very smali), gives

$$
x(z)=\frac{W_{F}}{W_{C}+W_{F}} \Phi(z)
$$

where

$$
\Phi(z)=\frac{h_{g s}-h_{F}}{h_{g f} z_{B}} \int_{z_{\text {snt }}}^{z} \phi(z) d z
$$

Substituting this result in the drift flux equations and rearranging then gives

$$
\alpha(z)=\frac{v_{g s}}{C_{0}\left[v_{g s}+v_{f s}\left\{\frac{W_{C}+W_{F}}{W_{F} \Phi(z)}-1\right\}\right]+\frac{v_{g l} A_{R}}{W_{F}} \Phi(z)}
$$

Assuming again that any dependence of $\phi(z), C_{0}$ and $v_{g i}$ on $W_{c}$ or $\alpha$ are small, equation (A2.15) indicates that an increase in the recirculation flow results in a decrease in the local void fraction at all elevations above $Z_{s \text { nt }}$ (including the $u$ nheated region of the riser above the top of the tube bund 2 ). Since $Z_{\text {sat }}$ was shown to be largely unaffected by changes in the recirculation flow, this implies that, for a fixed water level in the downcomer, an increase in recirculation flow will result in an increase in the total SG inventory. Of course, if the increase in recirculation flow is obtained by raising the downcomer level (rather than reducing the frictional losses), the increase in inventory will be even greater.

It is appreciated that the above analysis is rather crude in that it completely neglects the effects of subcooled boiling and makes a number of assumptions regarding the dependence of certain parameters on the recirculation flow and local void fraction. Also, no account was taken of the affect of changes in the recirculation flow on the secondary side heat transfer coefficient and thus pressure. Nevertheless, none of these effects are likely to alter the overall conclusion regarding the relationship between recirculation ratio and $S G$ inventory. 


\section{A.3 Steam generator boildown}

This section presents an analytical model for calculating the mixture and collapsed liquid level trajectories during the boildown of a PWR SG. Although the derivation of the model equations involves a number of simplifying assumptions, the result is sufficiently representative to allow the key parameters to be identified and for carrying out sensitivity calculations.

The model presented is based on a two-phase level theory developed by Sun, Duffey and Peng (1981). However, in order to obtain explicit analytical solutions for the mixture and collapsed liquid level trajectories, the authors iniroduced a number of assumptions that are not valid under SG boildown conditions. The present model avoids these assumptions at the expense of obtaining analytical solutions that are not explicit, although they are relatively easy to evaluate using a standard numerical solver.

\section{A.3.1 Modelling assumptions}

The boildown model developed here applies to the situation following a complete loss of feedwater in a PWR U-tube SG and when the following conditions exist

- The liquid in the system is at saturation and the recirculation flow has ceased (so that the liquid flow from the downcomer to the riser is very low).

- The mixture level in the riser has fallen to at least the top of the U-tubes (i.e. the fluid in the riser is heated at all elevations).

The situation envisaged is shown schematically in Fig. A.2, where the symbols used are defined as follows:

$\begin{array}{ll}z & \text { Elevation } \\ z_{d} & \text { Downcomer level } \\ z_{m} & \text { Riser mixture level } \\ z_{c} & \text { Riser collapsed liquid level } \\ z_{0} & \text { Riser equilibrium level }{ }^{37} \\ A_{d} & \text { Downcomer flow area } \\ A_{r} & \text { Riser flow area } \\ q^{\prime} & \text { Bundle linear power }\left(W^{-1}\right) \\ W_{f, 1 n} & \text { Riser inlet liquid mass flow rate }\left(\mathrm{kg} \mathrm{s}^{-1}\right) \\ W_{g, \text { out }} & \text { Riser outlet vapour mass flow rate }\end{array}$

Other notation used in this appendix is defined in the Nomenclature list.

37 The equilibrium level is defined as the elevation at which the vapour flow rate equals the inlet liquid flow rate, and above which the liquid flow rate is zero. In practice, the equilibrium level is the lowest level of uncovery for a given inlet flow and subcooling. 


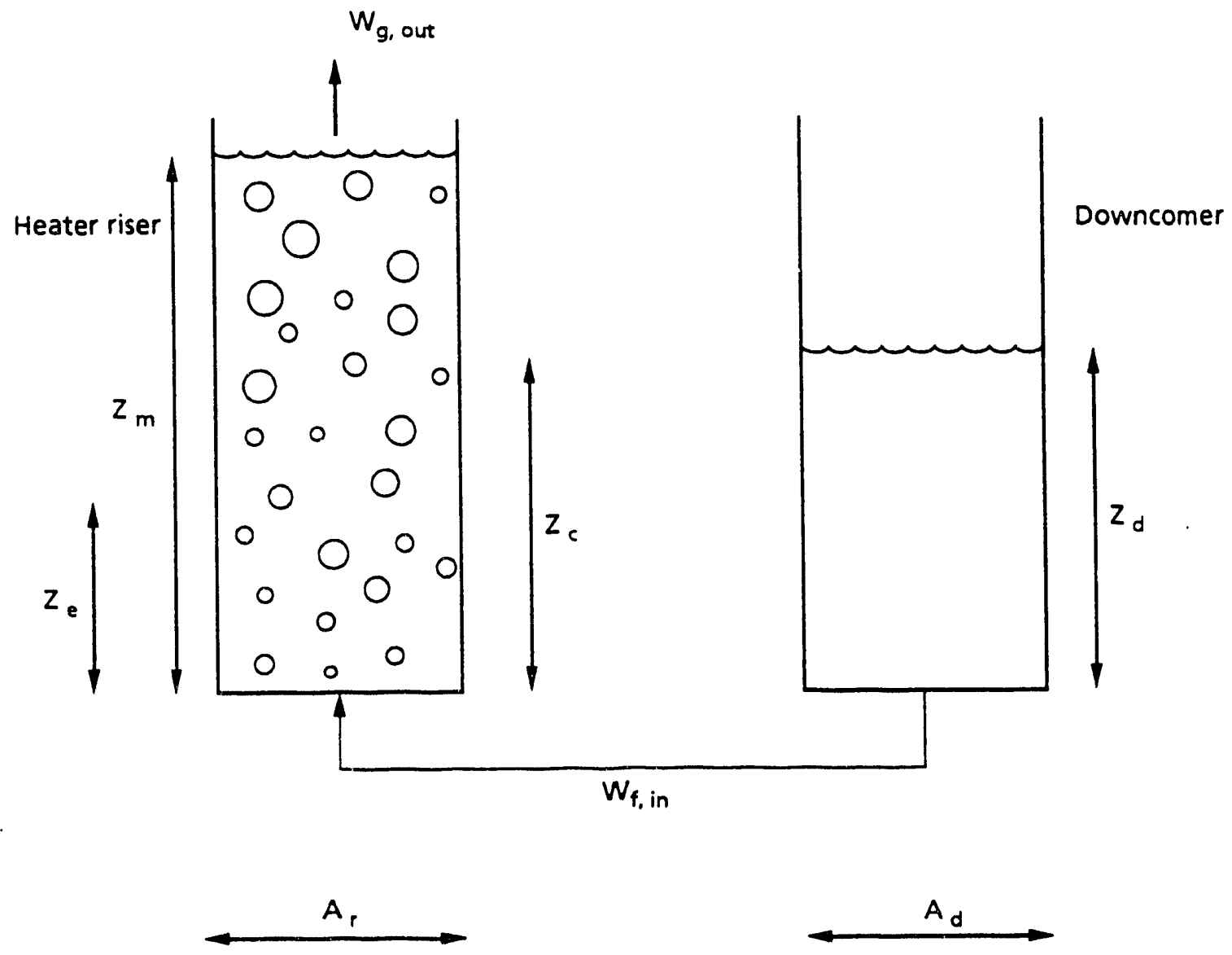

Figure A.2. Simple model of SG boildown 
The principal assumptions made in the model are as follows

- Thermal equilibrium conditions exist below the mixture level.

- The SG pressure does not change with time and spatial variations may be neglected in the calculation of fluid properties.

- Any liquid entrainment above the mixture level is negligible and no liquid condensate enters the downcomer.

- The drift flux parameters $C_{0}$ and $v_{g j}$ are independent of flow rate and void fraction.

- The boildown is sufficiently slow that $\frac{\partial \alpha}{\partial t} \ll \frac{\partial j_{g}}{\partial z}$, so that the vapour volumetric flow may be obtained from a quasi-statit vapodf mass balance.

- Flow rates are sufficiently small for the liquid flow rate to be ignored when calculating void fraction from the drift flux equation, and for momentum balances to be dominated by gravitational forces.

- The linear power is uniform below the mixture level and does not change with time.

It is appreciated that the restriction to uniform heating conditions is somewhat idealised and is not particularly representative of the boildown of a PWR SG. However, the general trends indicated by the model are still likely to be appropriate.

\section{A.3.2 Vapour generation rate}

In the riser region, the enthalpy of the fluid below the mixture level satisfies the equation

$$
\begin{aligned}
\frac{\partial}{\partial t}\left\{\alpha_{g} \rho_{g} h_{g}+\alpha_{f} \rho_{f} h_{f}\right\} & +\frac{\partial}{\partial z}\left\{\alpha_{g} \rho_{g} v_{g} h_{g}+\alpha_{f} \rho_{f} v_{f} h_{f}\right\} \\
& =\frac{\partial p}{\partial t}+\frac{q^{\prime}}{A_{r}}
\end{aligned}
$$

where the small contributions due to viscous dissipation and the $\mathrm{j} \partial \mathrm{p} / \partial \mathrm{z}$ term have been ignored. Expanding the derivatives on the left hand side and introducing the vapour and liquid mass balance equations:

$$
\begin{aligned}
& \frac{\partial}{\partial t}\left\{\alpha_{g} \rho_{g}\right\}+\frac{\partial}{\partial z}\left\{\alpha_{g} \rho_{g} v_{g}\right\}=\Gamma_{g} \\
& \frac{\partial}{\partial t}\left\{\alpha_{f} \rho_{f}\right\}+\frac{\partial}{\partial z}\left\{\alpha_{f} \rho_{f} v_{f}\right\}=-\Gamma_{g}
\end{aligned}
$$

then gives

$$
\begin{aligned}
\alpha_{g} \rho_{g}\left\{\frac{\partial h_{g}}{\partial t}\right. & \left.+v_{g} \frac{\partial h_{g}}{\partial z}\right\}+\alpha_{f} \rho_{f}\left\{\frac{\partial h_{f}}{\partial t}+v_{f} \frac{\partial h_{f}}{\partial z}\right\}=\frac{\partial p}{\partial t}+\frac{q^{\prime}}{A_{r}^{(A 3.4)}} \\
& +\left(h_{g}-h_{f}\right) \Gamma_{g}
\end{aligned}
$$

Under thermal equilibrium conditions and the coristant and uniform pressure assumptions, this equation reduces to the following expression for the vapour generation rate

$$
\Gamma_{g}=\frac{q^{\prime}}{h_{g t} A_{r}}
$$




\section{A.3.3 Vapour volumetric flux equation}

For slow boildown transients

$$
\frac{\partial \alpha}{\partial t} \ll \frac{\partial j_{g}}{\partial z}
$$

so that the vapour mass balance equation (A3.2) may be approximated by the quasi-static expression

$$
\frac{\partial \rho_{\mathrm{g}} \dot{j}_{\mathrm{g}}}{\partial \mathrm{z}}=\Gamma_{\mathrm{g}}
$$

Introducing equation ( $\mathrm{A} 3.5$ ) and noting that the modelling assumptions imply uniform properties, leads to an equation for the vapour volumetric flux of the form

$$
j_{g}(z)=\frac{q^{\prime} z}{\rho_{g} h_{g r} A_{r}}
$$

\section{A.3.4 Void fraction equation}

From the drift flux model (Zuber and Findlay, 1965), the void fraction below the mixture level is given by

$$
\alpha_{g}=\frac{j_{g}}{C_{0} j+v_{g j}}
$$

For low liquid flow conditions typical of those encountered during SG boildown, it is reasonable to set $j_{1}=0$ in the above equation ${ }^{38}$ to obtain

$$
\alpha_{g}=\frac{j_{g}}{C_{0} j_{g}+v_{g l}}
$$

\section{A.3.5 Level and inventory equations}

The collapsed liquid level in the riser, $z_{c}$, is usually defined as the equivalent hydrostatic head; i.e.

$$
\int_{0}^{z_{m}} \rho \mathrm{gdz}=\int_{0}^{z_{\mathrm{c}}} \rho_{\mathrm{f}} \mathrm{gdz}
$$

Under the modelling assumptions in use, this reduces to

$$
\begin{aligned}
z_{c} & =\int_{0}^{z_{m}}\left\{1-\alpha_{g}+\alpha_{g} \frac{\rho_{g}}{\rho_{f}}\right\} d z \\
\simeq \int_{0}^{z_{m}}\left(1-\alpha_{g}\right) d z &
\end{aligned}
$$

as $\rho_{g} / \rho_{l}$ is small for the conditions of interest ${ }^{39}$. For a uniform flow channel, the latter equation also represents the liquid column height that would result if all the vapour were removed.

The downcomer and riser level are related by system momentum effects. However. since flow rates considered are small, it is reasonable to neglect the inertial, acceleration and loss terms. Integrating the momentum equations over the downcomer and riser mixture regions then gives

38 This will always be true above the equilibrium level.

39 $\rho_{\mathrm{g}} / \rho_{\mathrm{f}}=0.05$ at 70 bar pressure and reduces with decreasing pressure. 


$$
\int_{0}^{z_{d}} \rho_{\mathrm{f}} g \mathrm{dz}=\int_{0}^{z_{m}} \rho \mathrm{gdz}
$$

which reduces to

$$
z_{d}=z_{c}
$$

i.e. the collapsed liquid levels in downcomer and riser are equal.

The total liquid inventory in the system is defined by

$$
\begin{aligned}
I_{v} & =\int_{0}^{z_{d}} \rho_{f} A_{d} d z+\int_{0}^{z_{m}}\left(1-\alpha_{g}\right) \rho f A_{r} d z \\
& =\left(A_{d}+A_{r}\right) \rho_{f} z_{c}
\end{aligned}
$$

from equation (A3.14)

An equation describing the transient level behaviour may be obtained from the total mass balance equations for the downcomer and mixture regions; viz.

$$
\frac{d}{d t} \int_{0}^{z_{d}} \rho_{f} A_{d} d z=-W_{f, \text { in }}
$$

for the downcomer and

$$
\frac{d}{d t} \int_{0}^{z_{m}} \rho A_{r} d z=W_{t, \text { in }}-W_{g, \text { out }}
$$

for the mixture region. Using equations (A3.11) and (A3.14), these equation may be combined to give

$$
\left[1+\frac{A_{d}}{A_{r}}\right] \frac{d z_{c}}{d t}=-\frac{W_{g, \text { out }}}{\rho_{f} A_{r}}
$$

Finally, introducing the volumetric flux equation (A3.8) leads to the level differential equation:

$$
\left[1+\frac{A_{d}}{A_{r}}\right] \frac{d z_{c}}{d t}=\frac{q^{\prime} z_{m}}{\rho_{g} h_{g l} A_{r}}
$$

\section{A.3.6 Model solution}

The final boildown model derived above is defined by equations (A3.19), (A3.12), (A3.9) and (A3.8), which are repeated below for convenience

$$
\begin{aligned}
& {\left[1+\frac{A_{d}}{A_{r}}\right] \frac{d z_{c}}{d t}=\frac{q^{\prime} z_{m}}{\rho_{g} h_{g t} A_{r}}} \\
& z_{c}=\int_{0}^{z_{m}}\left(1-\alpha_{g}\right) d z \\
& \alpha_{g}=\frac{j_{g}}{C_{0} j+v_{g j}} \\
& j_{g}(z)=\frac{q^{\prime} z}{\rho_{g} h_{g l} A_{r}}
\end{aligned}
$$

These equations constitute a system of four equations ir four unknownis: $z_{c}, z_{m}, \alpha_{\theta}$ and $j_{g}$. To obtain solutions for $z_{c}$ and $z_{m}$, it is nectssary to eliminate the parameters $j_{g}$ and $\alpha_{g}$. This can be achieved by combining equation (A3.8) and (A3.9) 
to obtain an expression for $\alpha_{9}$ as a function of $z$, and then inserting the result into equation (A3.12). Integration then leads to the following relation between $z_{c}$ and $z_{m}$

$$
z_{c}=\frac{1}{C_{0}}\left[\left(C_{0}-1\right) z_{m}+\frac{1}{B C_{0}} \ln \left\{1+B z_{m}\right\}\right]
$$

where

$$
B=C_{0} \frac{q^{\prime}}{\rho_{g} h_{g f} A_{r} v_{g l}}
$$

and the drift flux parameters have been assumed to be independent of flow rate and void fraction.

Taking the derivative of this equation with respect to time and introducing equation (A3.19) to eliminate $z_{c}$, leads to the following expression for $z_{m}$

$$
\frac{d z_{m}}{d t}\left[C_{0}-1+\frac{1}{1+B z_{m}}\right]=-D z_{m}
$$

where

$$
D=\frac{C_{0} q^{\prime}}{\rho_{r} h_{g r} A_{r}\left[1+\frac{A_{d}}{A_{r}}\right]}
$$

Equation (A3.22) has the analytical solution

$$
\frac{z_{m}^{C_{0}}}{1+B}=\frac{z_{m 0}^{C_{0}}}{1+B z_{m 0}} \exp (-D t)
$$

where $z_{m o}$ is the initial mixture level.

Using a standard numerical solver (e.g. NAG routine), the above result may be used to determine to mixture level trajectory during the boildown of a PWR SG. The corresponding collapsed liquid level (in the riser and downcomer) may then be obtained from equation (A3.20) and the SG inventory from equation (A3.15).

The basic model equations (A3.19), (A3.12), (A3.9) and (A3.8) were presented by Sun et al. (1981) as a special case of a more general two-phase level theory. The derivation presented in this appendix clearly shows the assumptions and simplifications inherent in this model. In order to solve the equations, Sun et al. (1981) introduced the additional assumptions that

$$
B z_{m} \gg 1 \text { and } C_{0}-1 \gg \frac{1}{B z_{m}}
$$

and, as a result, were able to obtain an explicit solution for $z_{m}$. Unfortunately, the above assumptions cannot be justified in gelleral for a SG boildown situation, and thus the more exact (but implicit) solution is preferred for the present study. For example, in Appendix A.3.7 below, the boildown model is used to emulate the behaviour of RELAP5/MOD2 for which the appropriate value of $C_{0}$ is one, so that the second condition could never be satisfied.

\section{A.3.7 Sample calculations}

For low flows in a PWR U-tube SG, the interphase drag models in RELAP5/MOD2 are approximately equivalent to the use of a drift flux model with the following parameters (Putney, 1988).

$$
C_{0}=1.0 \quad v_{g j}=0.43\left[\frac{g \Delta \rho D_{h}}{\rho_{l}}\right]^{1 / 2}
$$


Bestion (1985) has shown however, that theoretical and experimental results support the parameters

$$
C_{0}=1.2 \quad v_{g j}=0.188\left[\frac{g \Delta f, D_{h}}{\rho_{g}}\right]^{1 / 2}
$$

Using these definitions and a suitable numerical solver, equations (A3.20) and (A3.23) may be applied to 'emulate' the modelling of SG boildown behaviour in RELAP5/MOD2 for the conditions considered, and to compare the level trajectories obtained against those predicted by a reference model.

This approach was used to study level behaviour in a full size PWR U-tube SG for conditions characteristic of boildown under full power conditions. Geometric data for the analysis were taken from the UK RELAP5/MOD2 deck for Sizewell ' $B$ '. The SG

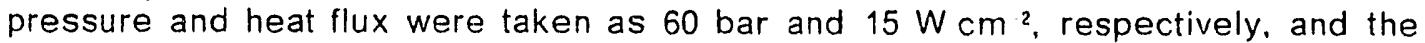
calculations were begun with the mixture level nominally set at the top of the U-bend. Solutions were generated using the following models:

1. Drift flux parameters equivalent to the RELAP5/MOD2 interphase drag models (i.e. equation (A3.25)). This solution will be referred to as the 'RELAP5 equivalent' calculation.

2. The Bestion drift flux model (i.e. equation (A3.26)) - the 'reference' calculation.

3. The RELAP5/MOD2 equivalent drift flux model with the downcomer flow area adjusted to give the same initial liquid inventory as the Bestion model.

4. The RELAP5/MOD2 equivalent drift flux model with the initial mixture level raised to give the same initial liquid inventory as the Bestion model.

Note that calculations 1 and 2 do not provide an exact representation of the situation typically encountered in a RELAP5/MOD2 analysis of a SG boildown transient. In particular, the RELAP5 equivalent and reference calculations are begun with the same mixture level (at the top of the bundle) and different downcomer levels. In reality, a RELAP5 analysis of SG boildown would normally begin with the downcomer level equal to the plant value and a different volume of liquid above the bundle. For the same reason, the effect of increasing the downcomer area in calculation 3 is not an exact representation of its effect in a plant or rig calculation. Unfortunately, the type of situation normally encountered in a boildown test carinot be simulated with the simple model, due to the requirement for the whole of the mixture to be heated (at a uniform heat flux). Consequently, calculation 4 is also somewhat unrepresentative as the effective heated length is extended to cover the liquid added to make-up for the under-prediction of the initial inventory. Despite these uncharacteristic features, the calculations should still exhibit effects that are relevant to the modelling of boildown phenomena in RELAP5/MOD2.

In calculations 3 and 4 , it was found that in order to force the RELAP5/MOD2 models to calculate the same initial inventory as the Bestion models:

(a) the downcomer flow area had to be increased from $0.732 \mathrm{~m}^{2}$ to $5.363 \mathrm{~m}^{2}$,

or

(b) the initial mixture level had to be increased from $8 \mathrm{~m}$ to $56.3 \mathrm{~m}$.

Clearly, these adjustments are not physically sensible and should be regarded only as a device for compensating for errors. They also give some indication of the magnitude of the initial void fraction error in the bundle region.

The level and inventory trajectories obtained from the four calculations are shown in Fig. 15 to Fig. 17. Examination of these results reveals the following effects.

- Compared with the Bestion model, the RELAP5/MOD2 models under-predict the initial liquid level (in riser and downcomer) and inventory by a significant amount. 
As a res!llt, the SG is predicted to emnty eallier. Closer examination of the results reveals that the liquid level and inventory also fail at a more rapid rate in the RELAP5/MOD2 calculation, although the rates of fall in the two calculations tend to converge as the transient proceeds ${ }^{40}$. The initial mixture is the same for both calculations but falls more rapidly in the RELAP5/MOD2 calculation. indicating an earlier degradation in primary to secondary heat transfer.

- If the downcomer area in the RELAP5/MOD2 calculation is increased to obtain the same initial inventory as the Bestion calculation, the initial mixture and liquid levels are unchanged. During the boildown however, the ievels fall more slowly than those from the unmodified RELAP5/MOO2. Eventually, the levels are over-predicted with respect to the Bestion calculation. indicating a possible late prediction of SG dryout. The inventory obtained from the modified RELAP5/MOD2 calculation is always greater than that associated with the Bestion calculation.

The above behaviour occurs because, although the under-prediction of the initial inventory arises from an under-prediction of the liquid fraction in the bundle. the liquid added to compensate for this does not change the liquid content in the bundle (viz. the initial collapsed liquid level). Consequently, the extra liquid is held away from the boiling region, but provides a greater reservoir from which liquid can be drawn to replenish the liquid boiled off. A similar effect would result if the downcomer area were artificially increased in a RELAP5/MOD2 analysis of a real boildown transient.

- If the initial mixture in the RELAP5/MOD2 calculation is increased to obtain the same initial inventory as the Bestion calculation, the same liquid level is also obtained. During the boildown however, the liquid level, mixture level and inventory fall very rapidly and tend to converge to the trajectories obtained in the unmodified calculation - which is controlled by the equivalent RELAP5/MOD2 drift flux parameters.

This effect occurs because the liquid added to compensate for the initial under-prediction of inventory increases the effective boiling length and is therefore boiled off very quickly. Evidently, this type of situation could be encountered in a RELAP5/MOD2 analysis of a plant boildown transient, if the initial inventory is artificially increased by increasing the recirculation ratio. When the recirculation flow has ceased, this additional liquid will exist above the bundle causing the bundle to uncover later in the calculation. When it does uncover therefore, the true mixture level will be lower, and thus the excess liquid in the calculation will boiloff rapidly leaving the subsequent boildown behaviour to be controlled by the interphase drag models.

40 This was confirmed by normalising the RELAP5/MOD2 trajectories to coincide with the Bestion curves at îme zero. 


\section{Appendix B MEASUREMENT UNCERTAINTIES FROM COMBINED ERRORS}

The general equation for estimating the steam generator restrictor nozzle outlet steam pressure is given by Preece (1987a):

$$
P_{e}=P_{1}-\frac{1.311}{10^{3}} v_{1}+\frac{8.451}{10^{5}} w_{s}^{2} v_{1}
$$

where the steam flow. $w_{s}=\left(w_{f}-w_{b}\right)$ and $v_{1}$ is the specific volume of saturated water vapour at the steam line pressure $P_{1}$. The constants $1.311 \times 10^{-3} \mathrm{bar} \mathrm{m}^{3} \mathrm{~kg}{ }^{1}$ and $8.451 \times 10^{-5}$ bar $\mathrm{s}^{2} \mathrm{~kg}^{-1} \mathrm{~m}^{3}$ represent the hydrostatic and dynamic head loss components respectively. Similarly, the pressure drop across the steam flow restrictor nozzle, $P_{n}$, is found from:

$$
P_{n}=0.299 w_{s}^{2} v_{1}
$$

The steam dome pressure at iniet to the restrictor nozzle is thus:

$$
P_{d}=P_{e}+P_{n}
$$

For the general case of:

$$
F_{d .}=P_{d}\left(P_{1}, v_{1}, W_{s}\right)
$$

the unknown uncertainty, $X_{d}$ in $P_{d}$ can be found in terms of the known uncertainties, $X_{p_{1}}, X_{v 1}$ and $X_{w s}$ to the components represented in equations (B1.1) and (B1.2). This leads to the following general expression:

$$
\left|X_{P_{d}}\right|=\left\{\left(\frac{P_{1}}{P_{d}} X_{P_{1}} \frac{d P_{d}}{d P_{1}}\right)^{2}+\left(\frac{v_{1}}{P_{d}} X_{v 1} \frac{d P_{d}}{d v_{1}}\right)^{2}+\left(\frac{w_{s}}{P_{d}} X_{w s} \frac{d P_{d}}{d w_{s}}\right)^{2}\right\}^{0.5}
$$

or more specifically:

$$
\begin{gathered}
\left|X_{P d}\right|=\frac{1}{P_{d}^{2}}\left\{\left(P_{1} X_{P_{1}}\right)^{2}+\left(\left(\frac{1.1441}{10^{4}} v_{1} w_{s}^{2}-\frac{1.311}{10^{3}} v_{1}\right) X_{v 1}\right)^{2}+\ldots\right. \\
\left.\ldots .+\left(\frac{2.2882}{10^{4}} v_{1} w_{s}^{2} X_{w s}\right)^{2}\right\}^{0.5}
\end{gathered}
$$

Values of $X_{p_{1}}, X_{v 1}$ and $X_{w s}$ can be found in Preece (1987b) for the Wolf Creek steam generator plant. 


\begin{tabular}{|c|c|c|c|c|c|c|c|c|}
\hline $\begin{array}{l}\text { Plant/ } \\
\text { Facility }\end{array}$ & $\begin{array}{l}\text { Ref } \\
\text { Plant }\end{array}$ & Scale & $\begin{array}{l}\text { Nominal } \\
\text { Thermal } \\
\text { Power } \\
\text { (MW) }\end{array}$ & $\begin{array}{l}\text { No. of } \\
\text { Loops }\end{array}$ & $\begin{array}{l}\text { No. of } \\
\text { Tubes } \\
\text { per SG }\end{array}$ & $\begin{array}{l}\text { OD of } \\
\text { SG } \\
\text { Tubes } \\
(\mathrm{cm})\end{array}$ & $\begin{array}{l}\text { Average } \\
\text { Length } \\
\text { of SG } \\
\text { Tubes } \\
\text { (m) }\end{array}$ & $\begin{array}{c}\text { SG } \\
\text { Model }\end{array}$ \\
\hline $\begin{array}{c}\text { Sizewell 'B' } \\
\text { Wolf } \\
\text { Creek } \\
\end{array}$ & $\begin{array}{c}\text { W SNUPPS } \\
\text { PWR }\end{array}$ & Full & 3425 & 4 & 5626 & 1.748 & 16.756 & $\begin{array}{l}\text { U-lype } \\
\text { Model F }\end{array}$ \\
\hline KNU \#1 & $\begin{array}{c}\text { W PWR } \\
\text { (BECHTEL) }\end{array}$ & Full & 1724 & 2 & 3386 & 2.2 & 22.831 & $\begin{array}{l}\text { U-type } \\
\text { Model } 51\end{array}$ \\
\hline Doel 2 & $\begin{array}{c}\text { W PWR } \\
\text { (TRACTEBEL) }\end{array}$ & Full & 1192 & 2 & 3260 & 2.22 & 18.16 & $\begin{array}{l}\text { U-type } \\
\text { Model } 44\end{array}$ \\
\hline Doel 4 & $\begin{array}{c}\text { W PWR } \\
\text { (TRACTEBEL) }\end{array}$ & Fu.l & 3000 & 3 & $?$ & $?$ & $?$ & $\begin{array}{c}\text { U-type } \\
\text { Model E } \\
\text { (preheater) }\end{array}$ \\
\hline Tihange 2 & $\begin{array}{c}\text { Framatome } \\
\text { PWR } \\
\text { (TRACTEBEL) }\end{array}$ & Full & 2785 & 3 & 3361 & 2.22 & 20.4 & $\begin{array}{c}\text { U-type } \\
\text { Series } 51 \mathrm{M}\end{array}$ \\
\hline ROSA-IV & $\begin{array}{c}\text { 4-loop } \\
\text { W-type } \\
\text { PWR }\end{array}$ & $\frac{1}{48}$ & $\begin{array}{c}10 \\
(14 \% \text { of } \\
\text { scaled } \\
\text { ref power }) \\
\end{array}$ & 2 & 141 & 2.54 & 19.71 & U-type \\
\hline LOFT & $\begin{array}{l}\text { Typical } \\
\text { 4-loop } \\
\text { PWR }\end{array}$ & $\frac{1}{68}$ & 50 & 2 & $\begin{array}{c}1845 \\
0\end{array}$ & 1.27 & 4.578 & U-type \\
\hline MB-2 & $\begin{array}{l}\text { Single } \\
\text { W SG }\end{array}$ & $\frac{1}{125}$ & 10 & 1 & 52 & 1.75 & 13.905 & $\begin{array}{l}\text { U-type } \\
\text { Model F }\end{array}$ \\
\hline SPES & $\begin{array}{c}\text { W } 312 \text { type } \\
\text { PWR }\end{array}$ & $\frac{1}{427}$ & 6.5 & 3 & 13 & 1.746 & 16.564 & U-type \\
\hline LOBI & $\begin{array}{c}\text { 4-loop } \\
\text { KWU Biblis } \\
\text { PWR }\end{array}$ & $\frac{1}{712}$ & 5.3 & 2 & $\begin{array}{c}24 \\
8\end{array}$ & 2.2 & 14.279 & U-type \\
\hline OTIS & $\begin{array}{l}\text { Raised } \\
\text { Loop } \\
\text { B\&W PWR }\end{array}$ & $\frac{1}{1632}$ & $\begin{array}{l}1-5 \% \text { of } \\
\text { scaled } \\
\text { ref power }\end{array}$ & 1 & 19 & 1.587 & 15.9 & OTSG \\
\hline $\begin{array}{l}\text { Semi- } \\
\text { scale } \\
\text { Mod 2C }\end{array}$ & $\begin{array}{l}\text { 4-loop } \\
\text { PWR }\end{array}$ & $\frac{1}{1706}$ & 2 & 2 & $\begin{array}{l}6 \\
2\end{array}$ & 2.22 & 18.5 & $\begin{array}{l}\text { U-type } \\
\text { Model } 51\end{array}$ \\
\hline
\end{tabular}

Table 1. Summary of PWR plants and facilities considered in review 


\begin{tabular}{|c|c|c|c|c|c|c|c|}
\hline $\begin{array}{l}\text { Plant/ } \\
\text { Facility }\end{array}$ & Test & $\begin{array}{c}\text { Average } \\
\text { SG Heat } \\
\text { Flux } \\
\left(W \mathrm{~cm}^{-2}\right)\end{array}$ & $\begin{array}{c}\text { Error in } \\
\text { Calculated } \\
\text { Value of } \\
\text { HTC-A } \\
(\%) \\
\end{array}$ & $\begin{array}{c}\text { Uncertainty in } \\
\text { Measured } \\
\text { Value of } \\
\text { HTC-A } \\
(\%) \\
\end{array}$ & $\begin{array}{l}\text { Organisation } \\
\text { and Ref }\end{array}$ & $\begin{array}{c}\text { Code } \\
\text { Version }\end{array}$ & SG Modelling \\
\hline \multirow[t]{8}{*}{$\begin{array}{l}\text { Wolf } \\
\text { Creek }\end{array}$} & $\begin{array}{l}\text { SS at } \\
30.1 \% \\
\text { Load }\end{array}$ & 5.9 & -4.9 & -4.905 .2 & $\begin{array}{l}\text { NP TEC } \\
\text { (1) }\end{array}$ & $\begin{array}{l}36.04 \\
\text { IBM }\end{array}$ & $\begin{array}{c}D_{A}=O D \\
C_{R}=V\end{array}$ \\
\hline & $\begin{array}{l}\text { SS at } \\
51.5 \% \\
\text { Load } \\
\end{array}$ & 8.3 & .8 .5 & -3.8103 .9 & $"$ & . & 。 \\
\hline & $\begin{array}{r}\text { SS at } \\
73.3 \% \\
\text { Load } \\
\end{array}$ & 12.1 & -6.6 & -2.7 to 2.8 & * & 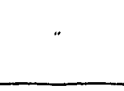 & " \\
\hline & $\begin{array}{l}\text { SS at } \\
81.4 \% \\
\text { Load } \\
\end{array}$ & 13.4 & -8.6 & -2.4102 .5 & “ & $"$ & * \\
\hline & $\begin{array}{r}\text { SS at } \\
98.9 \% \\
\text { Load } \\
\end{array}$ & 16.2 & -11.5 & -2.2102 .2 & “ & $\sim$ & - \\
\hline & $\begin{array}{r}55 \text { at } \\
98.9 \% \\
\text { Load } \\
\end{array}$ & 16.2 & -8.2 & -2.2 to 2.2 & - & - & $\begin{array}{c}D_{Q}=\text { gap } \\
C_{R}=f\end{array}$ \\
\hline & $\begin{array}{c}\text { LR from } \\
100 \text { to } \\
50 \%\end{array}$ & 16.1 & $\cdot 9.6$ & -2.5 to 2.5 & $\begin{array}{l}\text { NE TD } \\
(2)\end{array}$ & $\begin{array}{l}36.05 \\
\text { UK E04 }\end{array}$ & $\begin{array}{l}D_{n}=O D \\
C_{R}=H\end{array}$ \\
\hline & $\begin{array}{c}\text { Trip from } \\
100 \% \\
\text { Power } \\
\end{array}$ & 16.1 & -5.1 & -3.3 to 3.5 & $\begin{array}{l}\text { NE TD } \\
\text { (3) }\end{array}$ & $\begin{array}{l}36.05 \\
\text { UK EO5 }\end{array}$ & $\begin{array}{l}D_{\theta}=O D \\
C_{R}=1\end{array}$ \\
\hline KNU \#1 & LOP & 16.2 & $\begin{array}{l}\equiv 9 \% \\
\text { increase } \\
\text { in HT area }\end{array}$ & $?$ & $\begin{array}{l}\text { KAERI } \\
\text { (4) }\end{array}$ & 36.05 & $\begin{array}{c}D_{A}=D_{h} \\
C_{R}=J \\
\text { Drag } D_{h} V L\end{array}$ \\
\hline ROSA.IV & $\begin{array}{c}\text { ISP-26 } \\
5 \% \mathrm{Cl} . \mathrm{B}\end{array}$ & $\begin{array}{l}2.4 \\
2.3\end{array}$ & $\begin{array}{l}-7.4 \\
-6.6\end{array}$ & $\begin{array}{l}-12.1 \text { to } 13.2 \\
-12.4 \text { to } 13.5\end{array}$ & $\underset{(5)}{N E}$ & $\begin{array}{l}36.05 \\
\text { UK EO3 }\end{array}$ & $\begin{array}{l}D_{R}=D_{h} \\
C_{R}=H\end{array}$ \\
\hline \multirow[t]{13}{*}{ LOFT } & $\begin{array}{l}\text { L3-7 } \\
1 " \mathrm{CLB}\end{array}$ & 15.3 & -17.7 & -8.5108 .8 & $\begin{array}{l}\text { KAERI } \\
(6)\end{array}$ & 36.05 & $\begin{array}{l}D_{0}=D_{n} \\
C_{R}=?\end{array}$ \\
\hline & $\begin{array}{c}\text { L2.5 } \\
200 \% \text { CLB }\end{array}$ & 10.4 & -2.7 & -10.3 to 10.7 & $\begin{array}{l}\text { KAERI } \\
(7)\end{array}$ & 36.04 & $\begin{array}{l}D_{0}=D_{n} \\
C_{R}=?\end{array}$ \\
\hline & $\stackrel{L 2.5}{200 \% \text { CLB }}$ & 10.4 & -8.9 & -10.3 to 10.7 & $\begin{array}{l}\text { INER-China } \\
\text { (8) }\end{array}$ & $?$ & $\begin{array}{l}D_{0}=? \\
C_{R}=?\end{array}$ \\
\hline & $\begin{array}{l}\text { LP-SB-03 } \\
0.4 \% \text { CLB }\end{array}$ & 15.2 & -12.4 & .5 .9106 .2 & $\begin{array}{l}\text { NE TD } \\
\text { (9) }\end{array}$ & 36.01 & $\begin{array}{c}D_{0}=\text { Gap } \\
C_{R}=?\end{array}$ \\
\hline & $\begin{array}{l}\text { LP-SB-01 } \\
1 \% \text { HLB }\end{array}$ & 14.1 & 0.0 & -8.7109 .0 & $\begin{array}{l}\text { NE TO } \\
110\end{array}$ & 36.02 & $\begin{array}{c}D_{0}=\text { Gap } \\
C_{R}=?\end{array}$ \\
\hline & $\begin{array}{l}\text { LP-SB-02 } \\
1 \% \text { HLB }\end{array}$ & 14.1 & -6.1 & -8.8 to 9.1 & $\begin{array}{l}\text { NETD } \\
(11)\end{array}$ & 36.04 & $\begin{array}{c}D_{0}=\text { Gap } \\
C_{R}=?\end{array}$ \\
\hline & $\begin{array}{l}\text { LP-FW-01 } \\
\text { LOFW }\end{array}$ & 14.9 & -1.4 & -5.1 to 5.3 & $\begin{array}{l}\text { NETD } \\
(12)\end{array}$ & 36.04 & $\begin{array}{c}D_{0}=\text { Gap } \\
C_{R}=?\end{array}$ \\
\hline & $\begin{array}{c}\text { L9-4 } \\
\text { LOP-ATWS }\end{array}$ & 14.7 & -5.9 & -8.3 to 8.7 & $\begin{array}{l}\text { NETL } \\
(13)\end{array}$ & $\begin{array}{l}36.05 \\
\text { UK EO3 }\end{array}$ & $\begin{array}{l}D_{e}=\text { Gap } \\
C_{R}=5.1\end{array}$ \\
\hline & $\begin{array}{c}\text { L9-3 } \\
\text { LOFW-ATWS }\end{array}$ & 14.3 & -7.6 & .8 .6 to 9.0 & $\begin{array}{l}\text { WTC } \\
(14\}\end{array}$ & $\begin{array}{l}36.05 \\
\text { UK EO3 }\end{array}$ & $\begin{array}{c}D_{0}=\text { Gap } \\
C_{R}=?\end{array}$ \\
\hline & $\begin{array}{c}\text { L9.3 } \\
\text { LOFW.ATWS }\end{array}$ & 14.3 & .6 .2 & -8.6 to 9.0 & $\begin{array}{c}\text { WTC } \\
\text { (Revised) } \\
\text { (14) }\end{array}$ & $\begin{array}{l}36.05 \\
\text { UK EO3 }\end{array}$ & $\begin{array}{c}\mathrm{D}_{0}=\mathrm{Gap} \\
\mathrm{C}_{\mathrm{R}}=>\end{array}$ \\
\hline & $\begin{array}{l}\text { L3.5, L3.6 } \\
2.5 \% \text { CLB }\end{array}$ & 15 & $\begin{array}{l}\text { Good } \\
\text { Agreement }\end{array}$ & - & $\begin{array}{l}\text { NPTEC } \\
(15)\end{array}$ & $\begin{array}{c}36.05 \\
\text { UK E03 }\end{array}$ & $\begin{array}{c}D_{0}=\text { Gap } \\
C_{R}=?\end{array}$ \\
\hline & 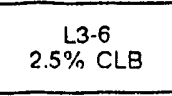 & 14.7 & .7 .4 & -14.5 to 15.4 & $\begin{array}{c}\text { Studsvik } \\
\text { (Case A) } \\
\text { (16) }\end{array}$ & 36.04 & $\begin{array}{c}D_{0} \simeq D_{h} \\
C_{R}=4.7\end{array}$ \\
\hline & $\begin{array}{c}\text { L3-6 } \\
2.5 \% \text { CLB }\end{array}$ & 14.7 & -9.6 & -14.5 to 15.4 & $\begin{array}{c}\text { Studsvik } \\
\text { (Case B) } \\
\text { (16) }\end{array}$ & 36.04 & $\begin{aligned} D_{0} & \simeq D_{h} \\
C_{R} & =4.7\end{aligned}$ \\
\hline
\end{tabular}




\begin{tabular}{|c|c|c|c|c|c|c|c|}
\hline $\begin{array}{l}\text { Plant/ } \\
\text { Facility }\end{array}$ & Test & $\begin{array}{c}\text { Average } \\
\text { SG Heat } \\
\text { Flux } \\
\left(W \mathrm{~cm}^{-2}\right)\end{array}$ & $\begin{array}{l}\text { Error in } \\
\text { Calculated } \\
\text { Value of } \\
\text { HTC-A } \\
(\%)\end{array}$ & $\begin{array}{l}\text { Uncertainty in } \\
\text { Measured } \\
\text { Value of } \\
\text { HTC-A } \\
(\%)\end{array}$ & $\begin{array}{l}\text { Organisation } \\
\text { and Ref }\end{array}$ & $\begin{array}{c}\text { Code } \\
\text { Version }\end{array}$ & SG Modelling \\
\hline MB-2 & LOFW & 2 & $\begin{array}{c}\equiv 23 \% \\
\text { increase } \\
\text { in HT area }\end{array}$ & 2 & $\begin{array}{c}\text { INER-Taiwan } \\
(17)\end{array}$ & 36.00 & $\begin{array}{l}\mathrm{D}_{\mathrm{e}}=? \\
\mathrm{C}_{\mathrm{R}}=?\end{array}$ \\
\hline SPES & $\begin{array}{l}\text { ISP-22 } \\
\text { LOFW }\end{array}$ & $\begin{array}{l}18.6 \\
17.8 \\
17.7\end{array}$ & $\begin{array}{l}2.9 \\
4.9 \\
4.9\end{array}$ & $\begin{array}{l}-6.4 \text { to } 6.5 \\
-6.8 \text { to } 6.9 \\
-6.5 \text { to } 6.7\end{array}$ & $\begin{array}{c}\text { NE PPG } \\
(18)\end{array}$ & $\begin{array}{l}36.05 \\
\text { UK E04 }\end{array}$ & $\begin{array}{l}D_{\theta}=D_{h} \\
C_{R}=H\end{array}$ \\
\hline LOBI & $\begin{array}{c}\text { A2-90 } \\
\text { LONOP-ATWS }\end{array}$ & $\begin{array}{l}16.1 \\
17.8\end{array}$ & $\begin{array}{l}10.3 \\
-1.7\end{array}$ & $?$ & $\begin{array}{l}\text { WTC } \\
\text { (19) }\end{array}$ & $\begin{array}{l}36.05 \\
\text { UK EO? }\end{array}$ & $\begin{array}{c}D_{e}=\text { Gap } \\
C_{R}=\end{array}$ \\
\hline oris & LOFW & 0.5 & $\cdot 10.0$ & $?$ & $\begin{array}{l}\text { INEL } \\
(20)\end{array}$ & 36.04 & $\begin{array}{l}D_{0}=? \\
C_{R}=?\end{array}$ \\
\hline \multirow[t]{2}{*}{$\begin{array}{l}\text { Semi- } \\
\text { scale }\end{array}$} & $\begin{array}{l}\text { S-LH-1 } \\
5 \% \text { CLB }\end{array}$ & $\begin{array}{l}19.9 \\
19.9\end{array}$ & $\begin{array}{l}5.1 \\
-3.9\end{array}$ & $\begin{array}{l}-6.1 \text { to } 6.3 \\
-6.2 \text { to } 6.5\end{array}$ & $\begin{array}{c}\text { NE TD } \\
(21)\end{array}$ & $\begin{array}{l}36.05 \\
\text { UK E03 }\end{array}$ & $\begin{array}{l}D_{0}=? \\
C_{R}=?\end{array}$ \\
\hline & $\begin{array}{l}\text { S-LH-2 } \\
5 \% \text { CL.B }\end{array}$ & $\begin{array}{l}20.2 \\
16.6\end{array}$ & $\begin{array}{c}5.9 \\
10.3\end{array}$ & $\begin{array}{l}-6.2 \text { to } 6.4 \\
-6.2 \text { to } 6.4\end{array}$ & $\begin{array}{c}\text { NE TD } \\
(22)\end{array}$ & $\begin{array}{c}36.05 \\
\text { UK E03 }\end{array}$ & $\begin{array}{l}D_{0}=? \\
C_{R}=?\end{array}$ \\
\hline
\end{tabular}

Table 2. Errors in total SG heat transfer coefficient HTC-A

The parameter HTC-A is defined in Section 2.7

For nonsymmetrical systems, the first entry refers to the intact loop.

\section{SG Modelling parameters}

D. Equivalent heated diameter on secondary side

$C_{R} \quad$ Circulation ratio

OD Tube outer diameter

$D_{h} \quad$ Hydraulic diameter on secondary side

Gap Inter-tube gap

$\checkmark \quad$ Calculated correctly

H Calculated high

VL Set very large

? Unknown

$>\quad$ Unknown, but greater than entry above

Other symbols used in the table are defined on the next page. 
Organisations

$\begin{array}{ll}\text { Abbreviation } & \text { Organisation } \\ \text { NP TEC } & \text { National Power Technology and Environmental Centre } \\ \text { NE TD } & \text { Nuclear Electric Technology Division } \\ \text { NE HSD } & \text { Nuclear Electric Health and Safety Division } \\ \text { NE PPG } & \text { Nuclear Electric PWR Project Group } \\ \text { WTC } & \text { Winfrith Technology Centre } \\ \text { KAERI } & \text { Korea Advanced Energy Research Institute } \\ \text { INER-China } & \text { Institute of Nuclear Energy Research, China } \\ \text { INER-Taiwan } & \text { Institute of Nuclear Energy Research, Taiwan } \\ \text { Studsvik } & \text { Studsvik Engineering AB, Sweden } \\ \text { INEL } & \text { Idaho National Engineering Laboratory } \\ \text { Refer inces } & \end{array}$

Number Reference

(1) This report (Section 4)

(2) Keevill (1989)

(3) Proctor (1990a)

(4) Chung et al. (1990)

(5) Cooper and Froushan (1990)

(6) Lee et al. (1990)

(7) Bang et al. (1990)

(8) Kao (1988)

(9) Harwood and Brown (1990)

(10) Hall and Brown (1990)

(11) Hall (1987)

(12) Croxford et al. (1988)

(13) Keevill (1988)

(14) Birchley (1988)

(15) Scriven (1990)

(16) Eriksson (1990)

(17) Wu and Wang (1988)

(18) Willmott (1990)

(19) Whittall (1990)

(20) Willmott (1990)

(21) Hall and Bull (1989)

(22) Brodie (1989) 


\begin{tabular}{|c|c|c|c|c|c|c|c|}
\hline $\begin{array}{l}\text { Plantl } \\
\text { Facility }\end{array}$ & Test & $\begin{array}{c}\text { Average } \\
\text { SG Heat } \\
\text { Flux } \\
\left(W \mathrm{~cm}^{-2}\right)\end{array}$ & $\begin{array}{c}\text { Error in } \\
\text { Calculated } \\
\text { Value of } \\
\text { HTC.0 } \\
(\%) \\
\end{array}$ & $\begin{array}{l}\text { Uncertainty in } \\
\text { Measured } \\
\text { Value of } \\
\text { HTC.0 } \\
(\%) \\
\end{array}$ & $\begin{array}{l}\text { Organisation } \\
\text { and Ref }\end{array}$ & $\begin{array}{c}\text { Code } \\
\text { Version }\end{array}$ & SG Modelling \\
\hline \multirow[t]{8}{*}{$\begin{array}{c}\text { Wolf } \\
\text { Creek }\end{array}$} & $\begin{array}{c}S S \text { at } \\
36.1 \% \\
\text { Load } \\
\end{array}$ & 5.9 & -12.9 & -11.9 in 17.4 & $\begin{array}{l}\text { NP TEC } \\
\text { (1) }\end{array}$ & $\begin{array}{l}36.04 \\
18 M\end{array}$ & $\begin{array}{l}D_{B}=O D \\
C_{R}=v\end{array}$ \\
\hline & $\begin{array}{l}\text { SS at } \\
51.5 \% \\
\text { Load }\end{array}$ & 8.3 & -2.3 .2 & $-10.2 \ln 14.3$ &. & - & $\cdot$ \\
\hline & $\begin{array}{c}55 \text { at } \\
73.3 \% \\
\text { Load } \\
\end{array}$ & 12.1 & -18.1 & .72108 .9 & $*$ & “ & - \\
\hline & $\begin{array}{c}\text { SS at } \\
81.4 \% \\
\text { Load } \\
\end{array}$ & 13.4 & -23.6 & .6 .9 to 8.6 & . & - & - \\
\hline & $\begin{array}{c}\text { SS at } \\
98.9 \% \\
\text { Load }\end{array}$ & 16.2 & -23.3 & .6 .3 to 7.7 &. & . & $\begin{array}{c}\mathrm{O}_{\mathrm{Q}}=\mathrm{gap} \\
\mathrm{C}_{\mathrm{R}}=1\end{array}$ \\
\hline & $\begin{array}{c}S S \text { at } \\
98.9 \% \\
\text { Load } \\
\end{array}$ & 16.2 & .30 .4 & .6 .3107 .7 & $\sim$ & . & * \\
\hline & $\begin{array}{c}\text { LR from } \\
100 \text { to } \\
50 \%\end{array}$ & 16.1 & -24.4 & .6 .3 to 7.6 & $\begin{array}{l}\text { NE TD } \\
\text { (2) }\end{array}$ & $\begin{array}{l}36.05 \\
\text { UK E04 }\end{array}$ & $\begin{array}{l}D_{A}=O D \\
C_{R}=H\end{array}$ \\
\hline & $\begin{array}{c}\text { Trip from } \\
100 \% \\
\text { Power } \\
\end{array}$ & 16.1 & -13.3 & .7 .6 to 9.8 & $\begin{array}{l}\text { NE TD } \\
\text { (3) }\end{array}$ & $\begin{array}{l}36.05 \\
\text { UK EO5 }\end{array}$ & $\begin{array}{l}D_{B}=O C \\
C_{R}=V^{\prime}\end{array}$ \\
\hline KNU \#1 & LOP & 16.2 & $\begin{array}{c}\equiv 9 \% \\
\text { increase } \\
\text { in HT area }\end{array}$ & $?$ & $\begin{array}{l}\text { KAERI } \\
\left(4^{\prime}\right)\end{array}$ & 36.05 & $\begin{array}{c}D_{B}=D_{h} \\
C_{R}=V \\
\text { Drag } D_{h} V L\end{array}$ \\
\hline ROSA-IV & $\begin{array}{c}1 S P-26 \\
5 \% C L B\end{array}$ & $\begin{array}{l}2.4 \\
2.3\end{array}$ & $\begin{array}{l}-63.7 \\
-57.4\end{array}$ & $\begin{array}{l}.44 .4 \text { to int. } \\
.43 .3 \text { to int. }\end{array}$ & $\begin{array}{c}\text { NE TD'HSD } \\
(5)\end{array}$ & $\begin{array}{l}36.05 \\
\text { UK EO3 }\end{array}$ & $\begin{array}{l}D_{0}=D_{h} \\
C_{R}=H\end{array}$ \\
\hline \multirow[t]{13}{*}{ LOFT } & $\begin{array}{c}\text { L3-7 } \\
1 . \mathrm{CLBB} \\
\end{array}$ & 15.3 & -28.3 & -12.31014 .8 & $\begin{array}{l}\text { KAERI } \\
(6)\end{array}$ & 36.05 & $\begin{array}{l}D_{0}=D_{h} \\
C_{R}=?\end{array}$ \\
\hline & $\begin{array}{c}\text { L2-5 } \\
200 \% \text { CLB }\end{array}$ & 10.4 & -6.9 & -18.5 to 28.8 & $\begin{array}{l}\text { KAERI } \\
\text { (7) }\end{array}$ & 36.04 & $\begin{array}{l}D_{e}=D_{h} \\
C_{R}=?\end{array}$ \\
\hline & $\begin{array}{c}\text { L2.5 } \\
200 \% \text { CLB }\end{array}$ & 10.4 & -22.6 & -18.5 to 28.8 & $\begin{array}{l}\text { INER-China } \\
\text { (8) }\end{array}$ & ? & $\begin{array}{l}D_{0}=? \\
C_{R}=?\end{array}$ \\
\hline & $\begin{array}{l}\text { LP.SB-03 } \\
0.4 \% \text { CLB }\end{array}$ & 15.2 & -20.7 & .9 .2 to 10.9 & $\begin{array}{l}\text { NE TD } \\
(9)\end{array}$ & 36.01 & $\begin{array}{c}D_{Q}=\text { Gap } \\
C_{R}=?\end{array}$ \\
\hline & $\begin{array}{l}\text { LP-SB-01 } \\
1 \% \text { HLB }\end{array}$ & 14.1 & -0.5 & -11.91013 .7 & $\begin{array}{l}\text { NE TD } \\
(10)\end{array}$ & 36.02 & $\begin{array}{c}\mathrm{D}_{\mathrm{e}}=\mathrm{Gap} \\
\mathrm{C}_{\mathrm{R}}=?\end{array}$ \\
\hline & $\begin{array}{c}\text { LP-SB-02 } \\
1 \% \text { HLB }\end{array}$ & 14.1 & $\cdot 10.5$ & -12.2 to 14.2 & $\begin{array}{l}\text { NE TD } \\
(11)\end{array}$ & 36.04 & $\begin{array}{c}\mathrm{D}_{\mathrm{Q}}=\text { Gap } \\
\mathrm{C}_{\mathrm{R}}=?\end{array}$ \\
\hline & $\begin{array}{l}\text { LP.FW-01 } \\
\text { LOFW }\end{array}$ & 14.9 & -2.4 & -8.3 to 9.6 & $\begin{array}{l}\text { NE TD } \\
(12)\end{array}$ & 36.04 & $\begin{array}{c}D_{0}=\text { Gap } \\
C_{R}=?\end{array}$ \\
\hline & $\begin{array}{c}\text { L9-4 } \\
\text { LOP-ATWS }\end{array}$ & 14.7 & -10.4 & -11.7 to 13.7 & $\begin{array}{l}\text { NE TD } \\
(13)\end{array}$ & $\begin{array}{l}36.05 \\
\text { UK EO3 }\end{array}$ & $\begin{array}{c}D_{0}=\text { Gap } \\
C_{R}=?\end{array}$ \\
\hline & $\begin{array}{c}\text { L9.3 } \\
\text { LOFW.ATWS }\end{array}$ & 14.3 & $\cdot 13.2$ & -12.2 to 14.4 & $\begin{array}{l}\text { WTC } \\
(14)\end{array}$ & $\begin{array}{l}36.05 \\
\text { UK E03 }\end{array}$ & $\begin{array}{l}D_{0}=G a p \\
C_{R}=5.1\end{array}$ \\
\hline & $\begin{array}{c}\text { L9-3 } \\
\text { LOFW.ATWS }\end{array}$ & 14.3 & $\cdot 10.9$ & -12.2 to 14.4 & $\begin{array}{c}\text { WTC } \\
\text { (Revised) } \\
(14)\end{array}$ & $\begin{array}{l}36.05 \\
\text { UK E03 }\end{array}$ & $\begin{array}{c}\mathrm{D}_{\mathrm{B}}=\text { Gap } \\
\mathrm{C}_{\mathrm{R}}=>\end{array}$ \\
\hline & $\begin{array}{l}\text { L3-5, L } 3-6 \\
2.5 \% \text { CLB }\end{array}$ & 15 & $\begin{array}{c}\text { Good } \\
\text { Agreement }\end{array}$ & $\cdot$ & $\begin{array}{c}\text { NPTEC } \\
(15)\end{array}$ & $\begin{array}{l}36.05 \\
\text { UK EO3 }\end{array}$ & $\begin{array}{c}D_{0}=\text { Gap } \\
C_{R}=?\end{array}$ \\
\hline & $\begin{array}{c}\stackrel{L 3-6}{2.6} \text { CLB }\end{array}$ & 14.7 & -12.2 & -18.2 to 22.1 & $\begin{array}{c}\text { Studsuik } \\
\text { (Case A) } \\
(16)\end{array}$ & 36.04 & $\begin{array}{c}D_{0} \simeq D_{h} \\
C_{R}=4.7\end{array}$ \\
\hline & $\begin{array}{c}\stackrel{L 3-6}{2.5 \%} \text { CLB }\end{array}$ & 14.7 & -15.7 & -18.2 to 22.1 & $\begin{array}{c}\text { Studsvik } \\
\text { (Case B) } \\
(16)\end{array}$ & 36.04 & $\begin{array}{c}D_{0} \simeq D_{h} \\
C_{R}=4.7\end{array}$ \\
\hline
\end{tabular}




\begin{tabular}{|c|c|c|c|c|c|c|c|}
\hline $\begin{array}{l}\text { Plant/ } \\
\text { Facility }\end{array}$ & Test & $\begin{array}{c}\text { Average } \\
\text { SG Heat } \\
\text { Flux } \\
\left.\left(W \mathrm{~W}^{-2}\right)^{-2}\right)\end{array}$ & $\begin{array}{c}\text { Error in } \\
\text { Calculated } \\
\text { Value of } \\
\text { HTC.0 } \\
(\%) \\
\end{array}$ & $\begin{array}{l}\text { Uncertainty in } \\
\text { Measured } \\
\text { Value of } \\
\text { HTC-O } \\
(\%)\end{array}$ & $\begin{array}{l}\text { Organisation } \\
\text { and Ref }\end{array}$ & $\begin{array}{c}\text { Code } \\
\text { Version }\end{array}$ & SG Modelling \\
\hline MB-2 & LOFW & $?$ & $\begin{array}{c}\equiv 23 \% \\
\text { Increase } \\
\text { in HT area }\end{array}$ & $?$ & $\begin{array}{c}\text { INER-Taiwan } \\
\text { (17) }\end{array}$ & 36.00 & $\begin{array}{l}D_{0}=? \\
C_{R}=?\end{array}$ \\
\hline SPES & $\begin{array}{l}\text { ISP-22 } \\
\text { LOFW }\end{array}$ & $\begin{array}{l}18.6 \\
17.8 \\
17.7\end{array}$ & $\begin{array}{c}9.5 \\
14.1 \\
14.2\end{array}$ & $\begin{array}{l}-11.4 \text { to } 14.7 \\
-11.7 \text { to } 15.0 \\
-11.5 \text { to } 14.7\end{array}$ & $\begin{array}{c}\text { NE PPG } \\
(18)\end{array}$ & $\begin{array}{l}36.05 \\
\text { UK EO4 }\end{array}$ & $\begin{array}{l}D_{A}=D_{h} \\
C_{R}=H\end{array}$ \\
\hline LOBI & $\begin{array}{c}\text { A2-90 } \\
\text { LONOP-ATWS }\end{array}$ & $\begin{array}{l}16.1 \\
17.8\end{array}$ & $\begin{array}{l}18.7 \\
-4.1\end{array}$ & $?$ & $\begin{array}{l}\text { WTC } \\
\text { (19) }\end{array}$ & $\begin{array}{l}36.05 \\
\text { UK EO? }\end{array}$ & $\begin{array}{c}D_{e}=\text { Gap } \\
C_{R}=?\end{array}$ \\
\hline OTIS & LOFW & 0.5 & -52.5 & $?$ & $\begin{array}{l}\text { INEL } \\
(20)\end{array}$ & 36.04 & $\begin{array}{l}D_{e}=? \\
C_{R}=?\end{array}$ \\
\hline \multirow[t]{2}{*}{$\begin{array}{l}\text { Semi- } \\
\text { scale }\end{array}$} & $\begin{array}{l}\text { S-LH-1 } \\
5 \% \text { CLB }\end{array}$ & $\begin{array}{l}19.9 \\
19.9\end{array}$ & $\begin{array}{l}12.8 \\
.9 .6\end{array}$ & $\begin{array}{l}-9.7 \text { to } 11.4 \\
-10.4 \text { to } 12.6\end{array}$ & $\begin{array}{l}\text { NE TD } \\
(21)\end{array}$ & $\begin{array}{l}36.05 \\
\text { UK E03 }\end{array}$ & $\begin{array}{l}D_{a}=? \\
C_{R}=?\end{array}$ \\
\hline & $\begin{array}{c}\text { S.LH-2 } \\
5 \% \text { CLB }\end{array}$ & $\begin{array}{l}20.2 \\
16.6\end{array}$ & $\begin{array}{l}13.8 \\
25.7\end{array}$ & $\begin{array}{l}-9.7 \text { to } 11.5 \\
-9.8 \text { to } 11.6\end{array}$ & $\begin{array}{l}\text { NE TD } \\
(22)\end{array}$ & $\begin{array}{l}36.05 \\
\text { UK EO3 }\end{array}$ & $\begin{array}{l}D_{e}=? \\
C_{R}=?\end{array}$ \\
\hline
\end{tabular}

Table 3. Errors in total SG heat transfer coefficient HTC-O

The parameter HTC-O is defined in Section 2.7

For nonsymmetrical systems, the first entry refers to the intact loop.

Other symbols used in the table are defined under Table 2. 


\begin{tabular}{|c|c|c|c|c|c|}
\hline Test Run Number & WC046 & WC047 & WC049 & WC051 & WC068 \\
\hline Reactor Power, \% & 36.1 & 50.5 & 73.3 & 81.4 & 98.9 \\
\hline Feedwater temperature, $\mathrm{K}$ & 452.6 & 467.3 & 484.8 & 489.3 & 496.9 \\
\hline Feedwater flow, kg/s & 152.5 & 221.5 & 335.3 & 376.6 & 467.1 \\
\hline Total downcomer flow, kg/s & 1554.9 & 1642.7 & 1686.6 & 1680.5 & 1684.4 \\
\hline Blowdown flow, $\mathrm{kg} / \mathrm{s}$ & 5.23 & 5.14 & 5.03 & 5.36 & 3.91 \\
\hline $\begin{array}{l}\text { Primary hot leg } \\
\text { temperature, } \mathrm{K}\end{array}$ & 576.1 & 581.5 & 589.4 & 591.9 & 597.0 \\
\hline Primary fluid pressure. bar & 154.77 & 154.77 & 155.18 & 155.18 & 155.32 \\
\hline Primary fluid flow, $\mathrm{kg} / \mathrm{s}$ & 4592.0 & 4675.3 & 4666.0 & 4612.8 & 4745.0 \\
\hline SG water level, $\%$ & 50 & 50 & 50 & 50 & 49 \\
\hline $\begin{array}{c}\text { Steam nozzle inlet pressure, } \\
\text { bar }\end{array}$ & 71.39 & 71.87 & 70.69 & 70.10 & 70.61 \\
\hline $\begin{array}{l}\text { Primary pump suction } \\
\text { leg temperature, } \mathrm{K}\end{array}$ & 563.6 & 564.6 & 565.4 & 565.1 & 566.1 \\
\hline
\end{tabular}

Table 4. Wolf Creek SG data

In the above table the effective values of the feed flow and downcomer flow are the measured plant values reduced by the value of the blowdown flow. The primary fluid flow is that deduced using the method outlined in Section 4.1. 


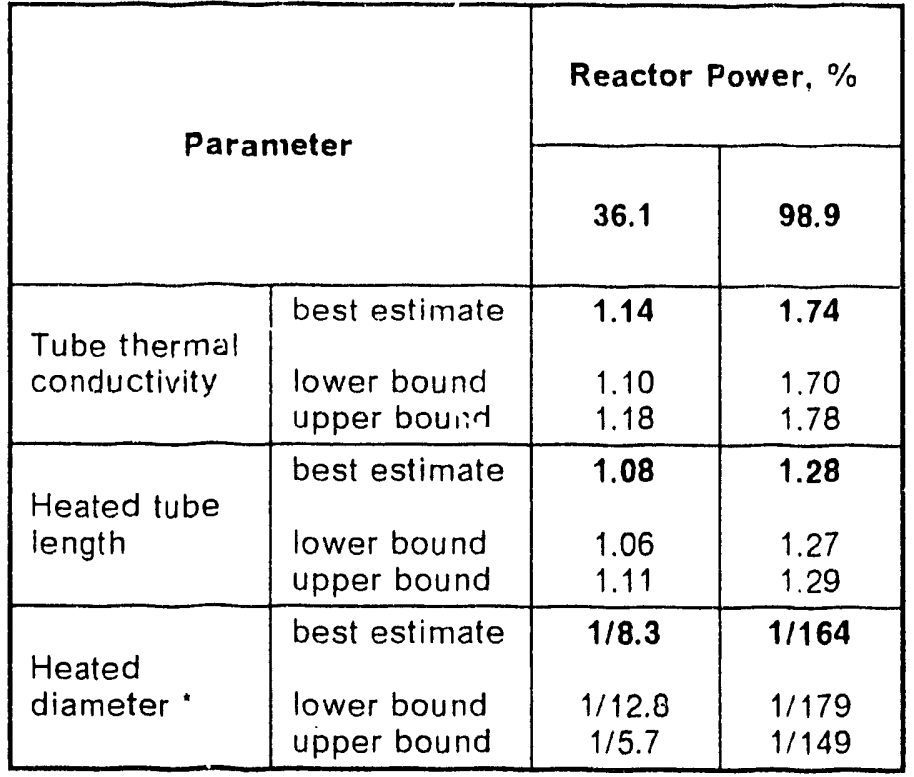

Table 5. SG heat transfer adjustment factors for Wolf Creek analysis

- Expressed as a fraction of the inter-tube gap 
Fig. 1. Sensitivity of increasing SG heat transfer

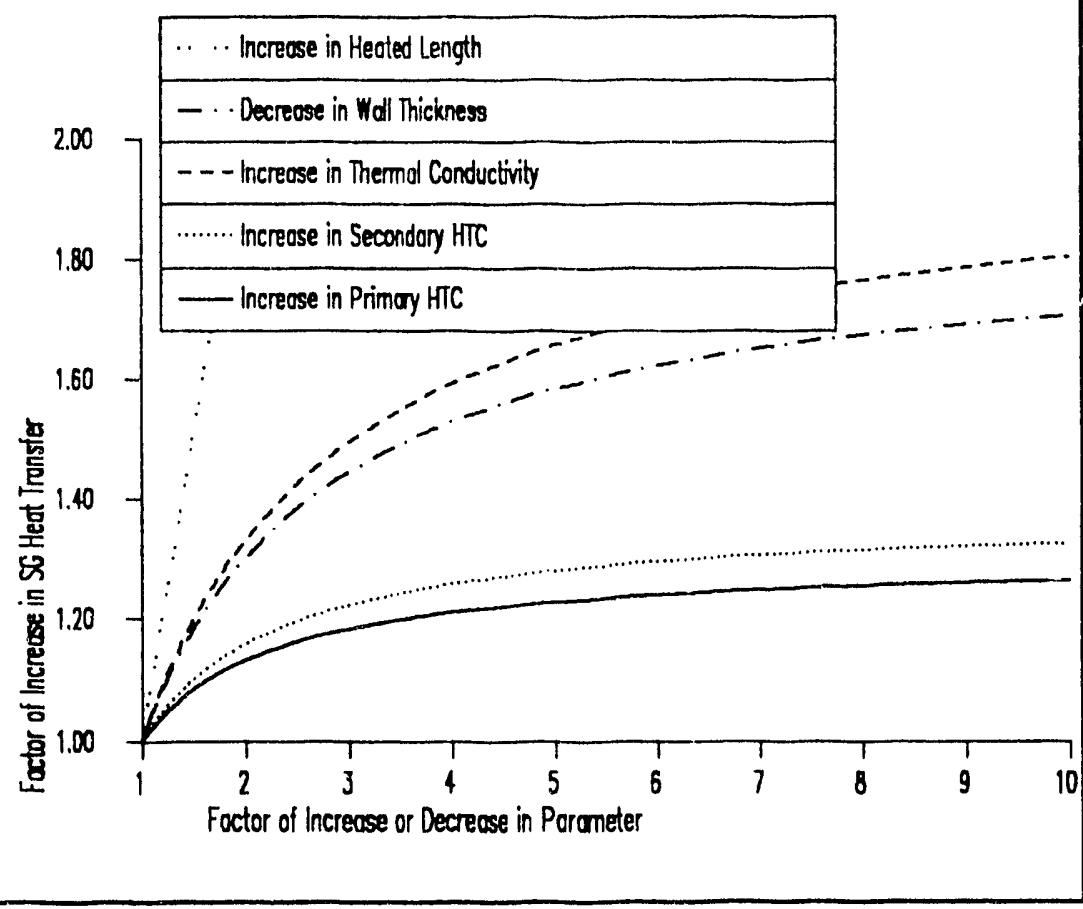

Fig. 2. Sensitivity of decreasing SG heat transfer

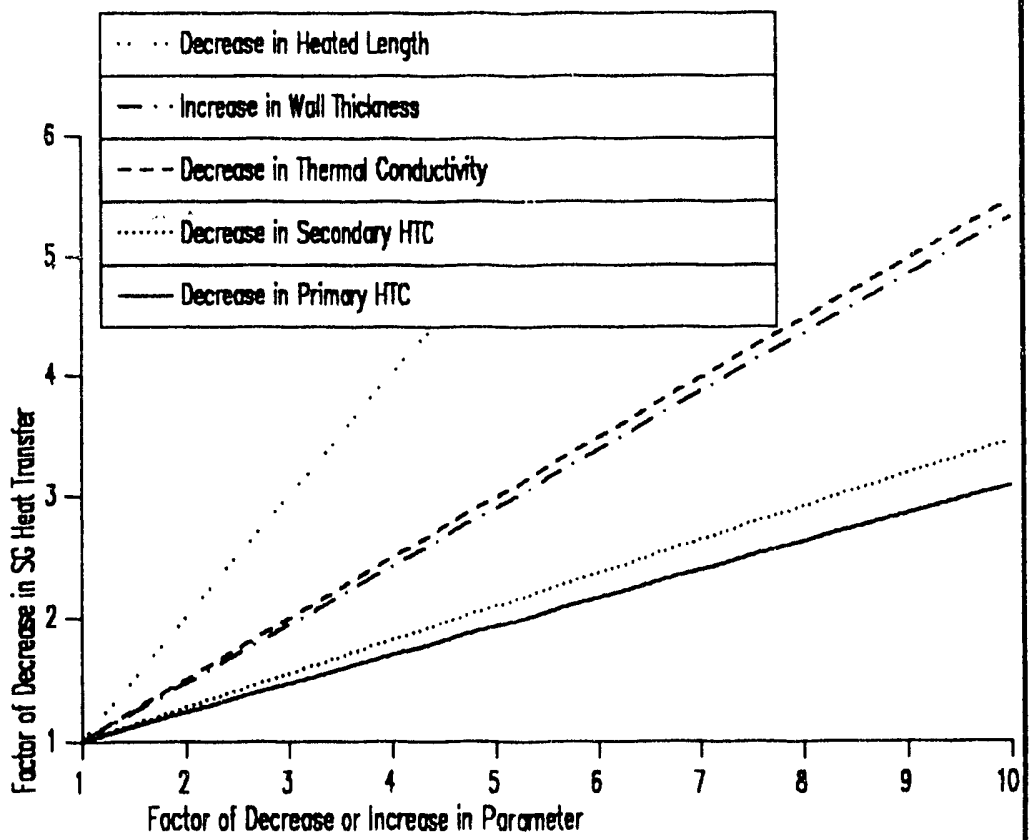


Fig. 3. Variation of boiling heat transfer coefficient with heated diameter $P=68$ bor $G=331 \mathrm{~kg} / \mathrm{m2}-\mathrm{s} \quad$ DTS $=7$ Deg C $X=0.17$

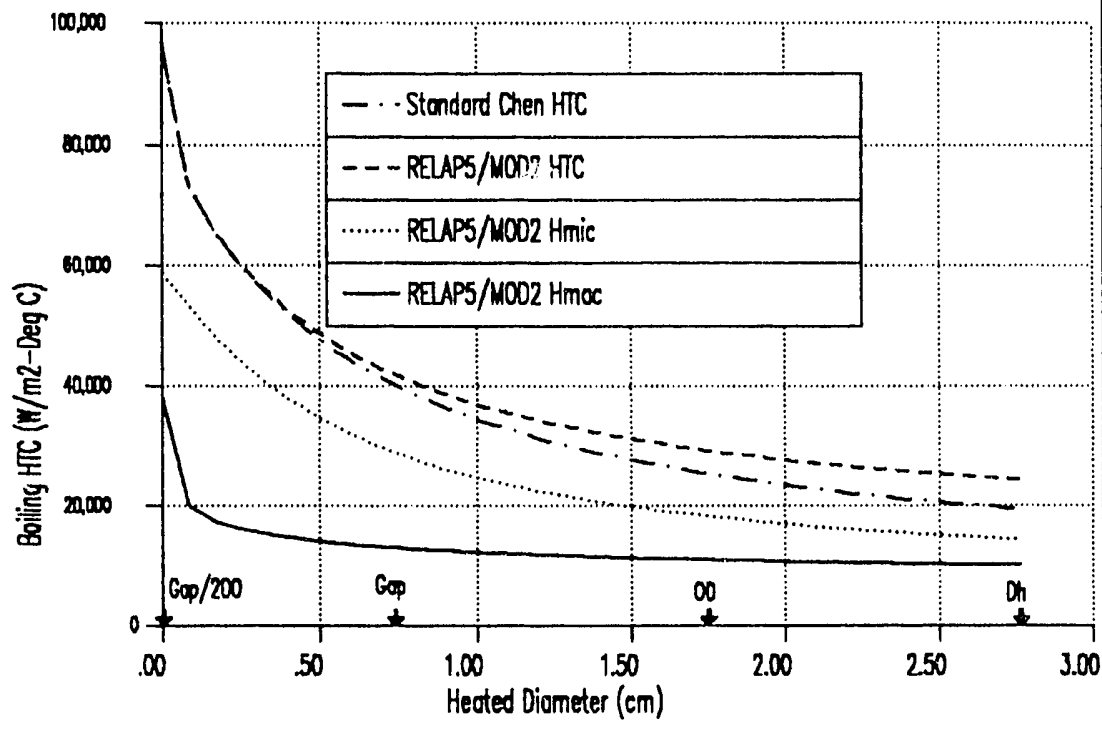

Fig. 4. Variation of boiling heat transfer coefficient with mass flux $P=68$ bor $\quad$ DTS $=7$ Deg $C \quad X=0.17 \quad D H=1.7 \mathrm{~cm}$

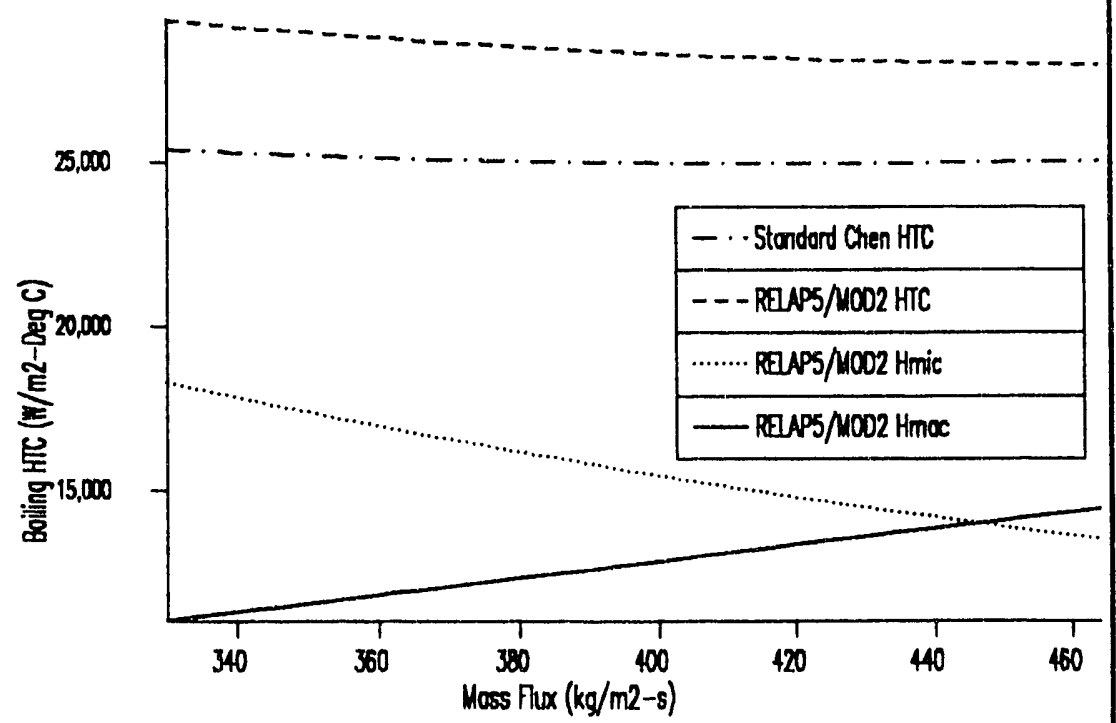


Fig. 5. Variation of boiling heat transfer coefficient with quality $P=68.0$ bor $G=400.0 \mathrm{~kg} / \mathrm{m2}-\mathrm{g}$ DTS $=7.0$ Deg $\mathrm{C} \mathrm{DH}=1.7 \mathrm{~cm}$

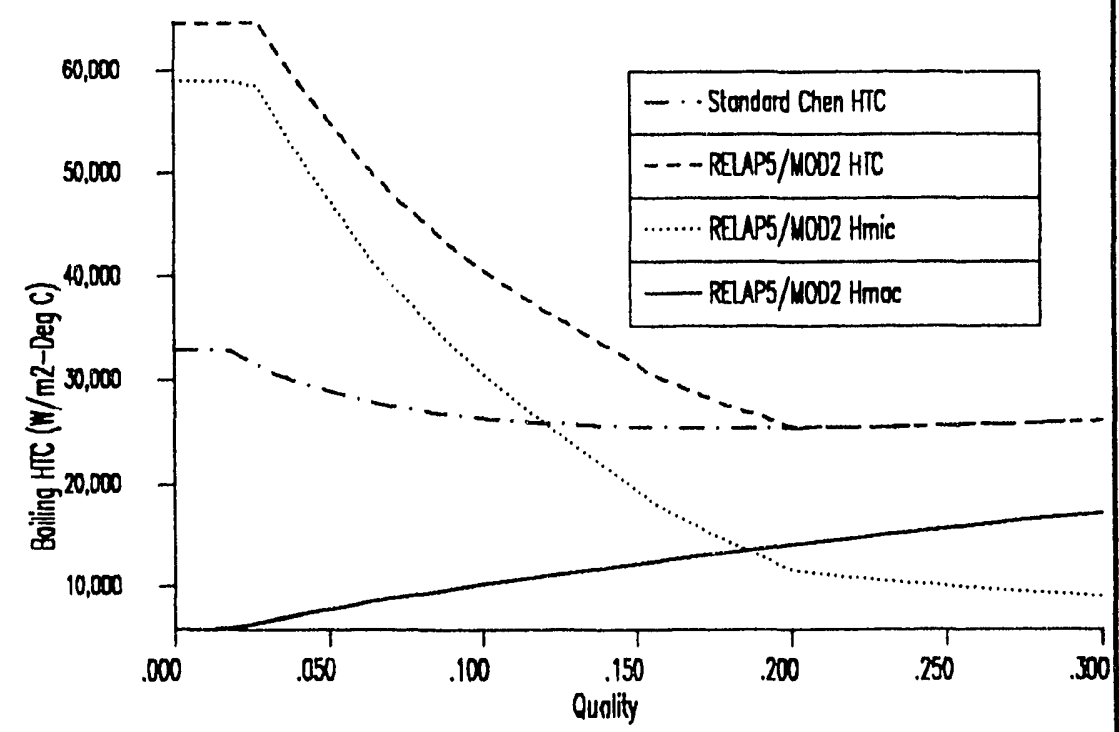




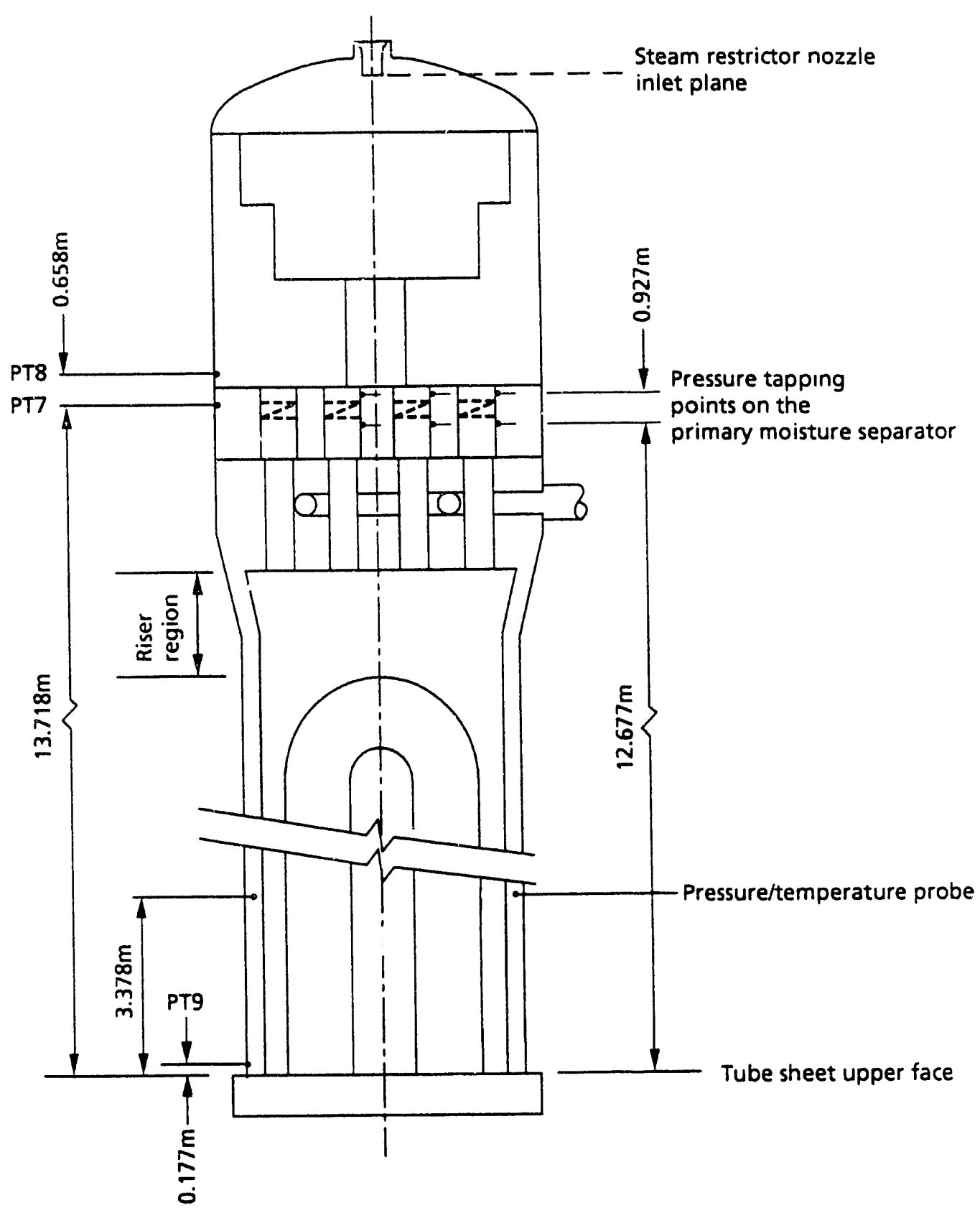

Figure 6 Locations of special instrumentation in Wolf Creek steam generator 


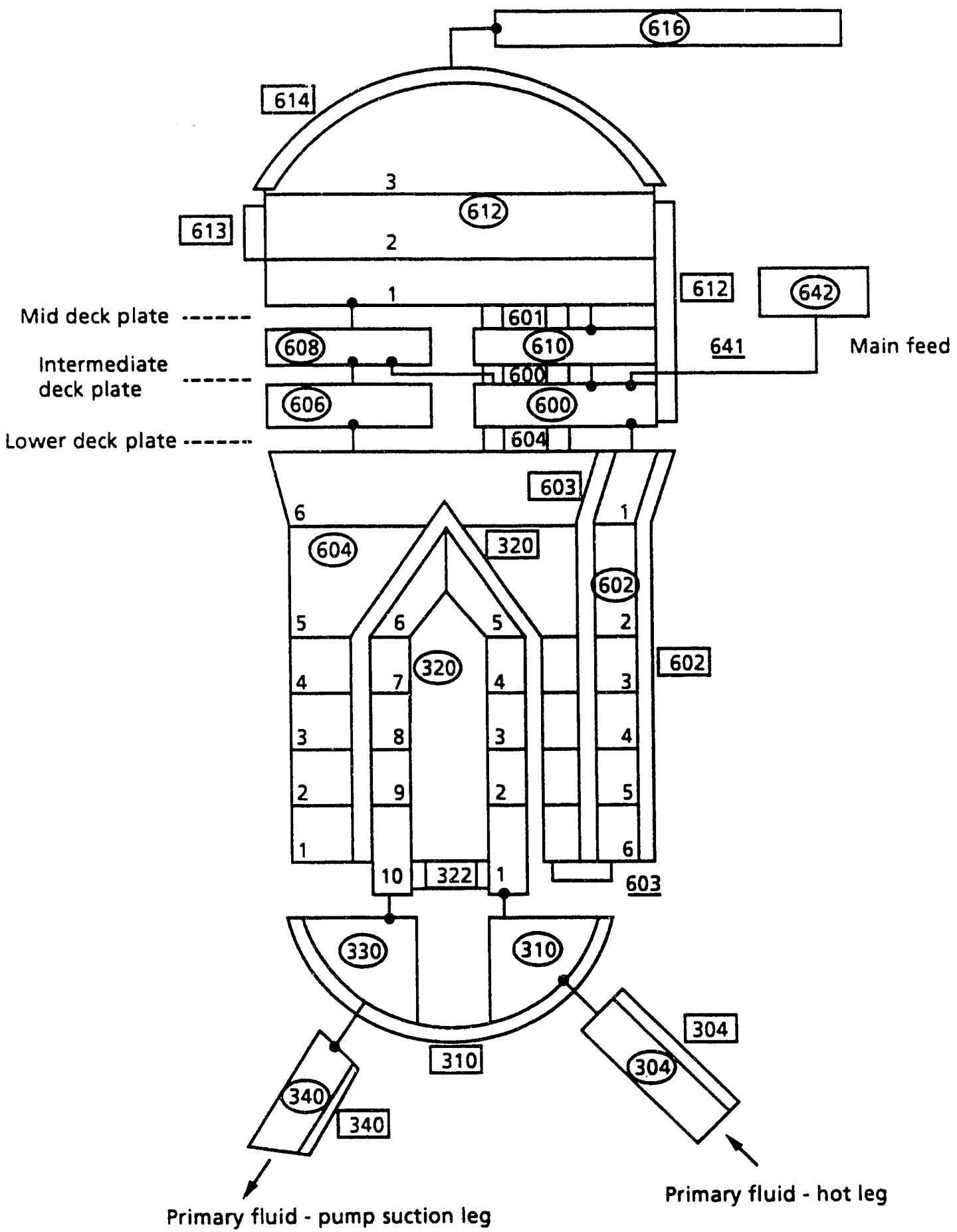

Figure 7 Nodalisation of the model 'F' steam generator 
Fig. 8. Errors in the calculated SG dome pressure, Wolf Creek DIFFERENCE BETWEEN MEASURED AND CALCULATED STEAM PRESSURE, DELTA P, IN SG DOME

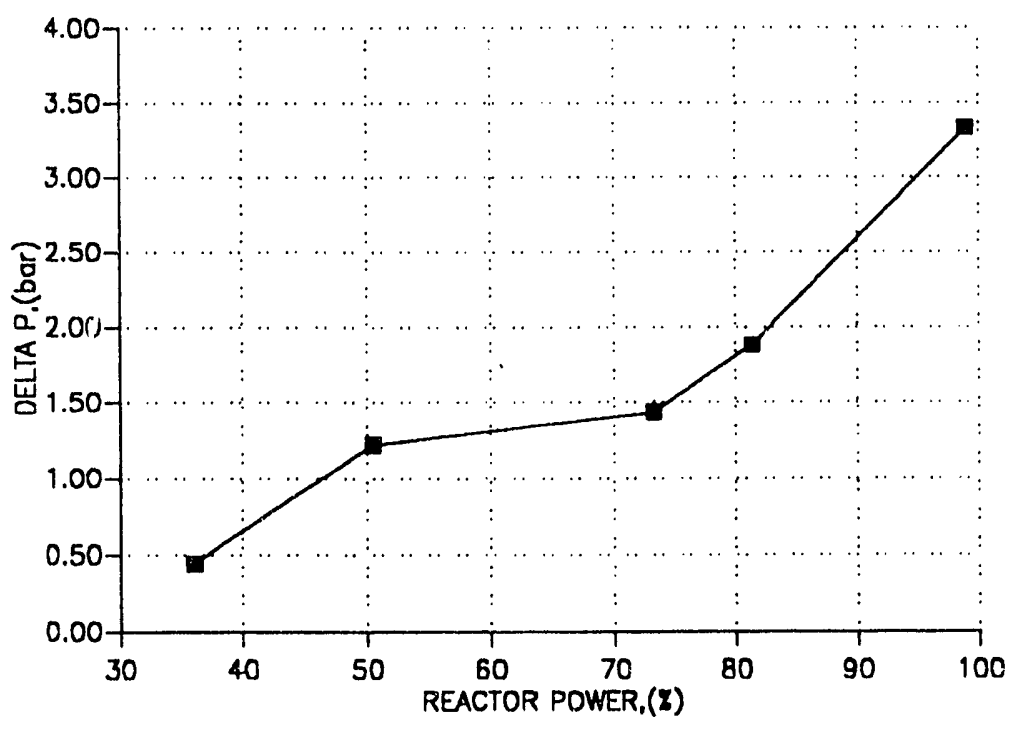

Fig. 9. Component pressure drop below mid-deck plate level, Wolf Creek PRESSURE DIFFERENCE BETWEEN BOTTOM OF DOWNCOMER AND MID-DECK PLATE LEVEL

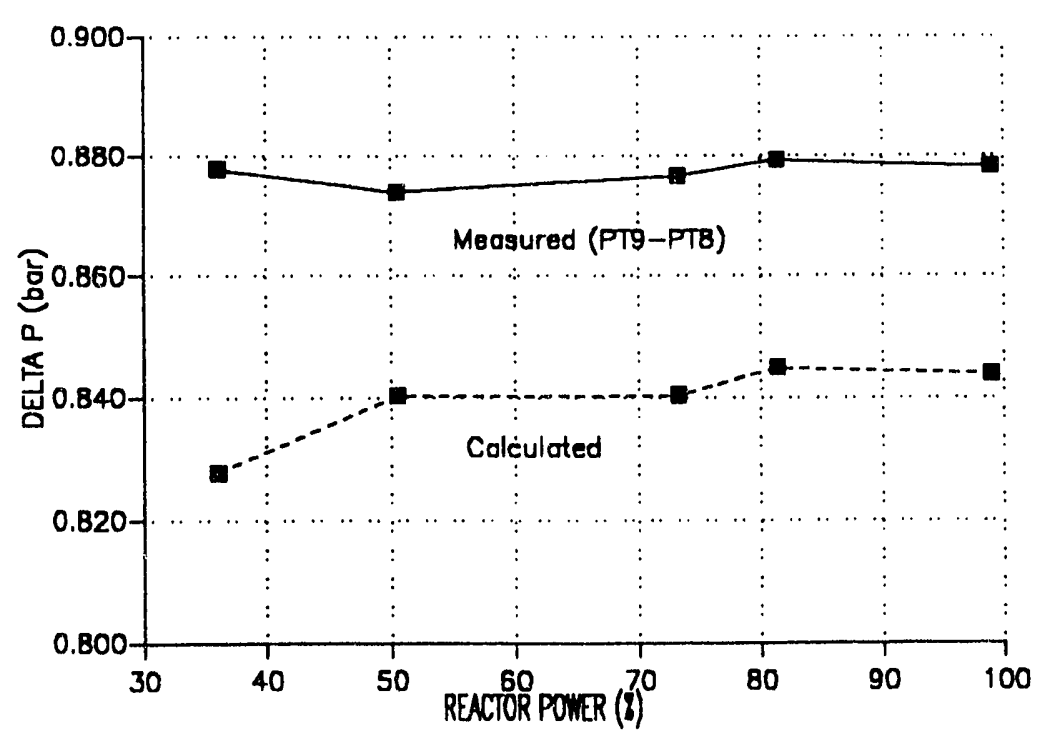


Fig. 10. Component pressure drop above mid-deck plate level, Wolf Creek PRESSURE DIFFERENCE BETWEEN MID-DECK PLATE AND INLET TO SG RESTRICTOR NOZZLE

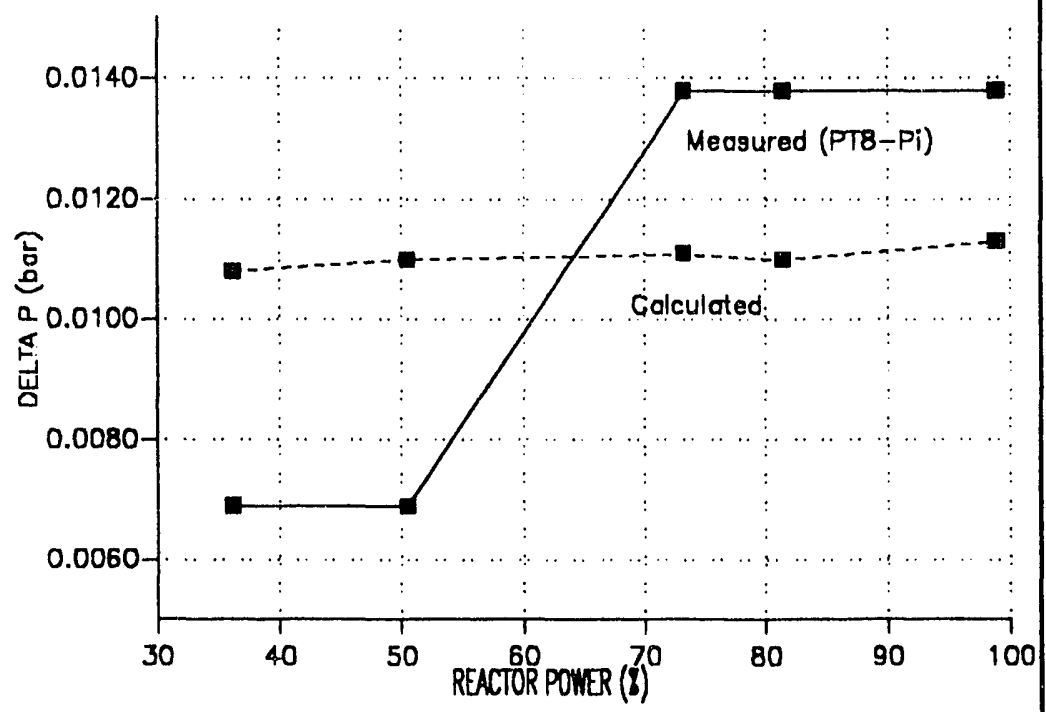

Fig. 11. Component pressure drop across the mid-deck plate, Wolf Creek PRESSURE DROP ACROSS THE MID-DECK PLATE

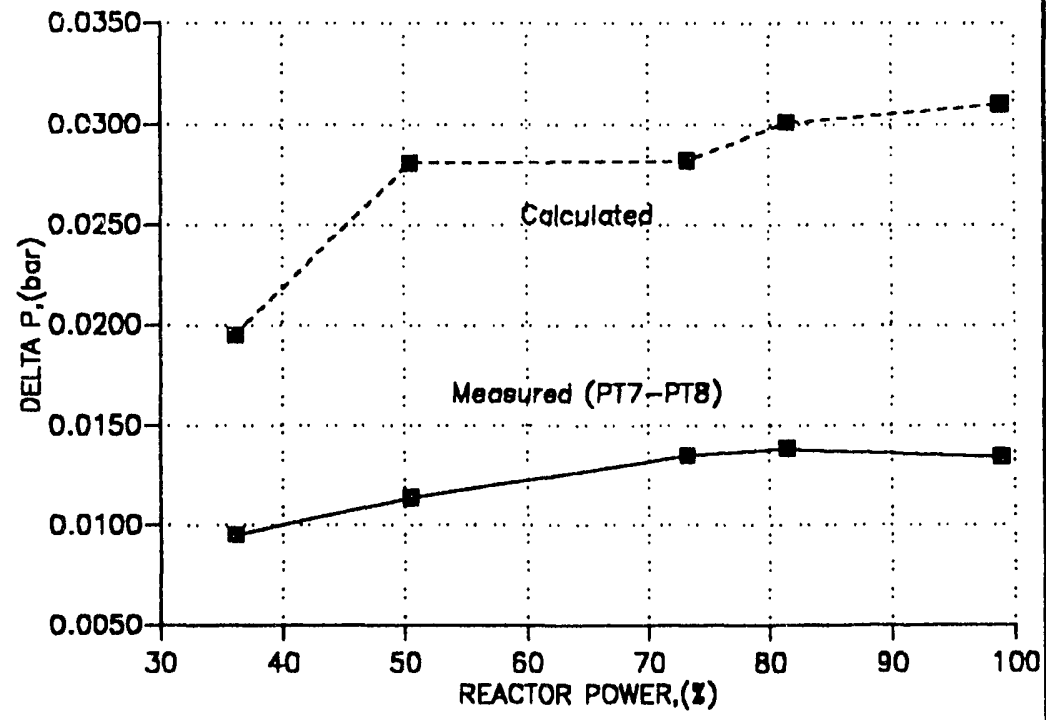


Fig. 12. RELAP5/MOD2 SG secondary side HTC for Wolf Creek at $99 \%$ load

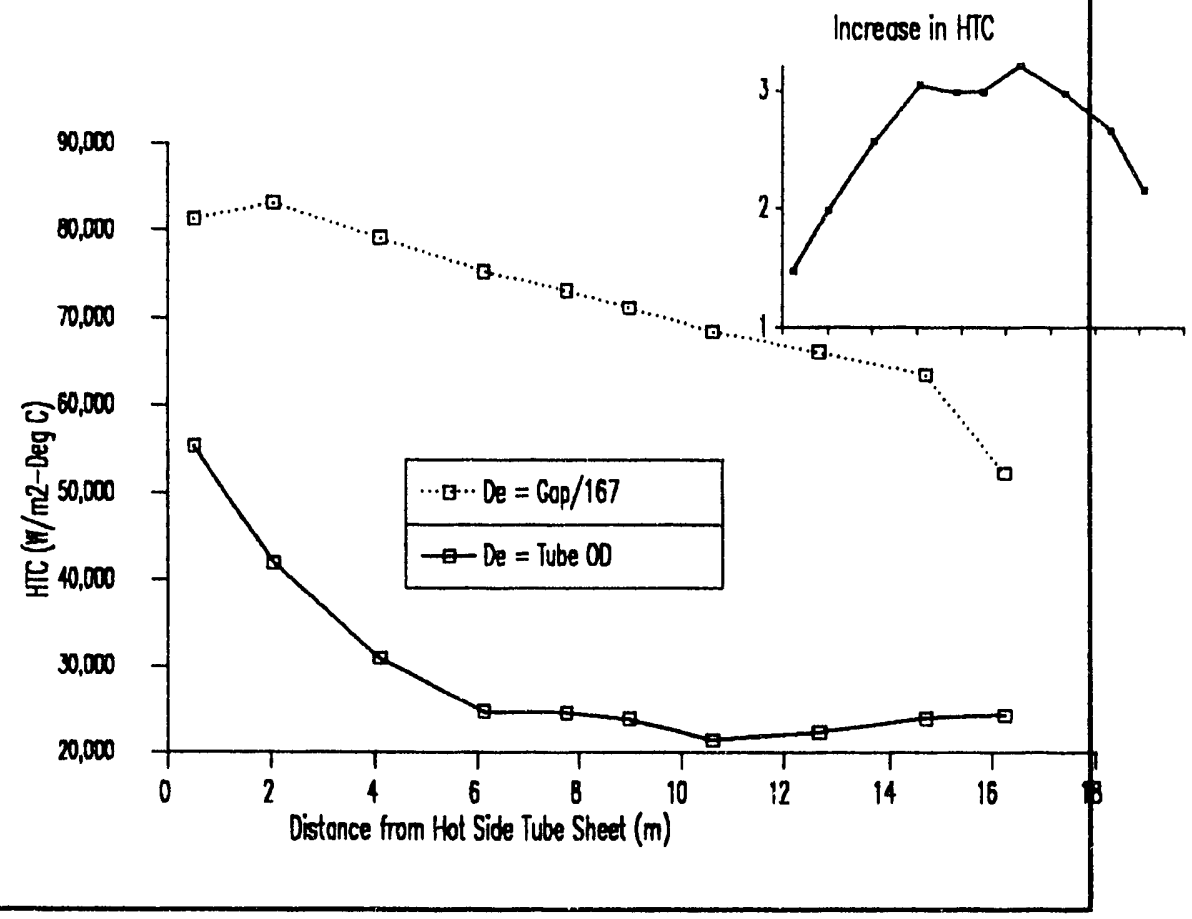

Fig. 13. RELAP5/MOD2 SG secondary side HTC for Wolf Creek at $36 \%$ load

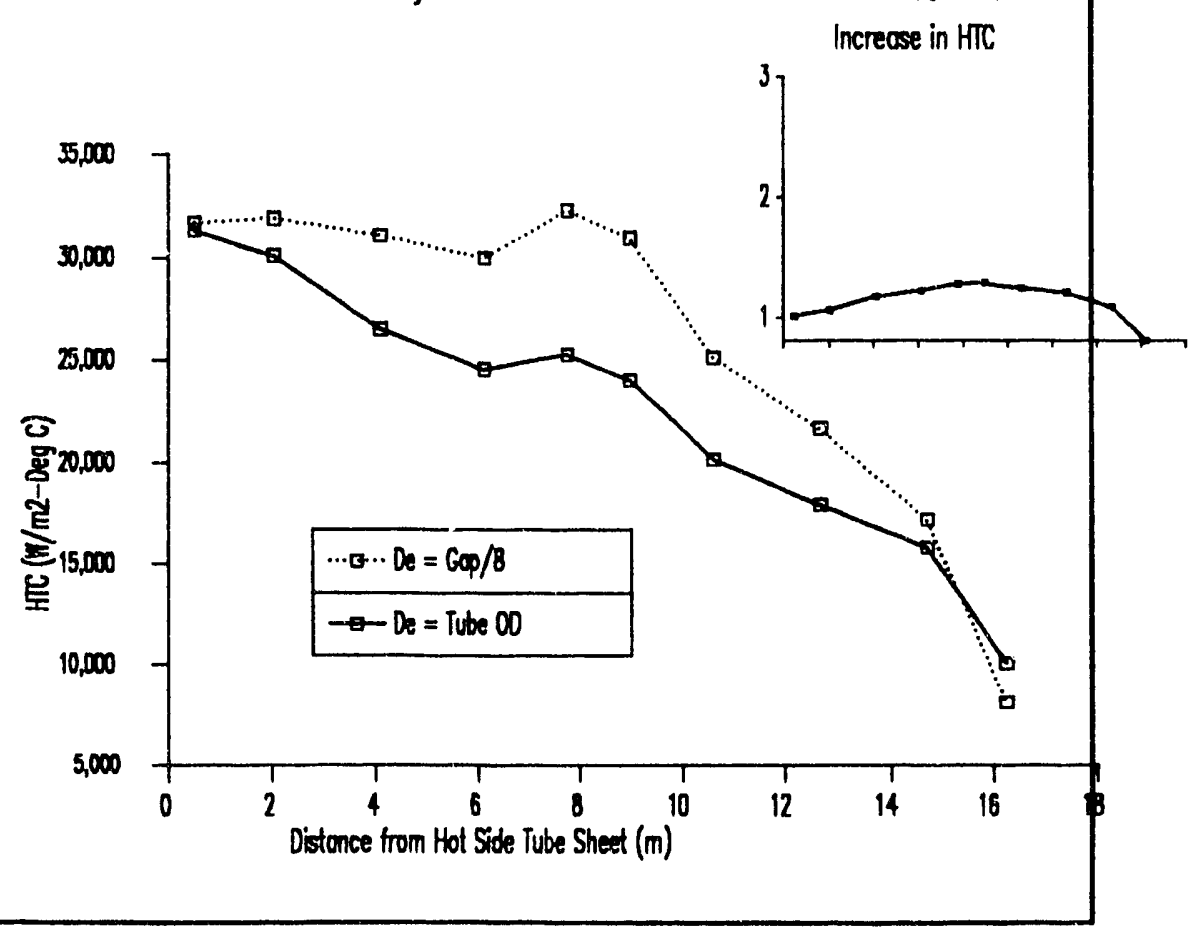


Fig. 14. Comparison of Chen correlation with data from Semiscale SG: Semiscale results taken from broken loop long tube

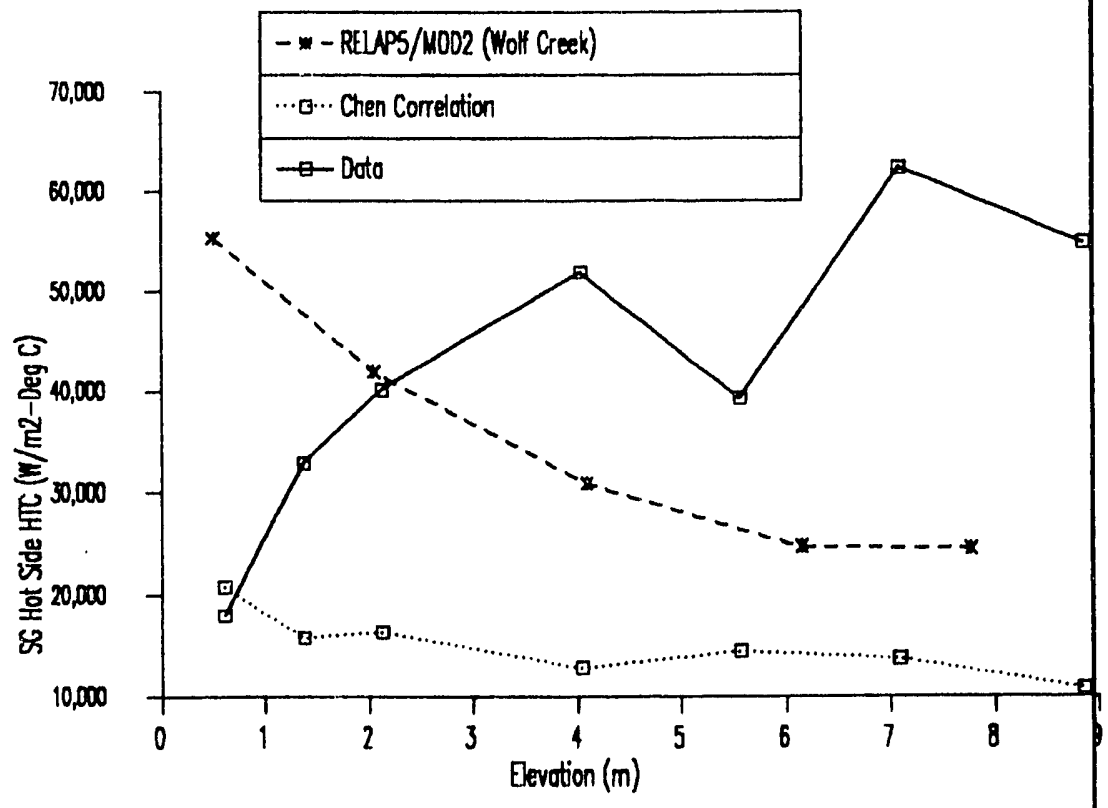

Fig. 15. Liquid level trajectories for simple SG boildown transient $P=60.0$ bor $Q=15.00 \mathrm{H} / \mathrm{cm}^{2}$-tube

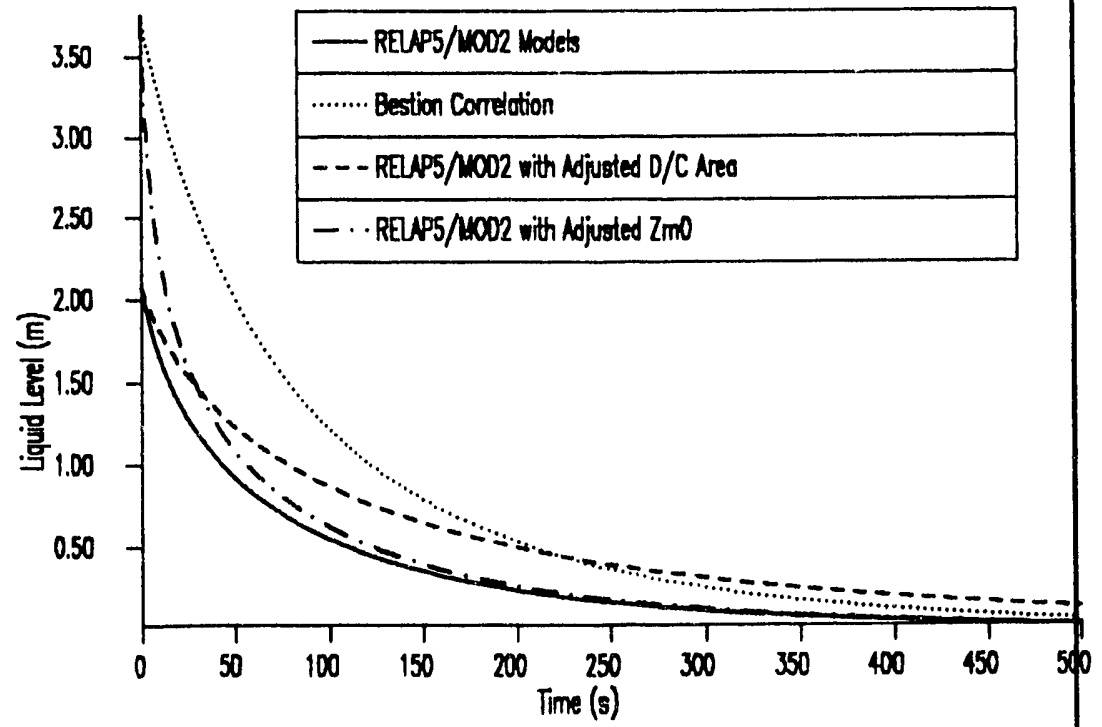


Fig. 16. Inventory trajectories for simple $S G$ boildown transient $P=60.0$ bor $Q=15.00 \mathrm{~W} / \mathrm{cm}^{2}-$ tube

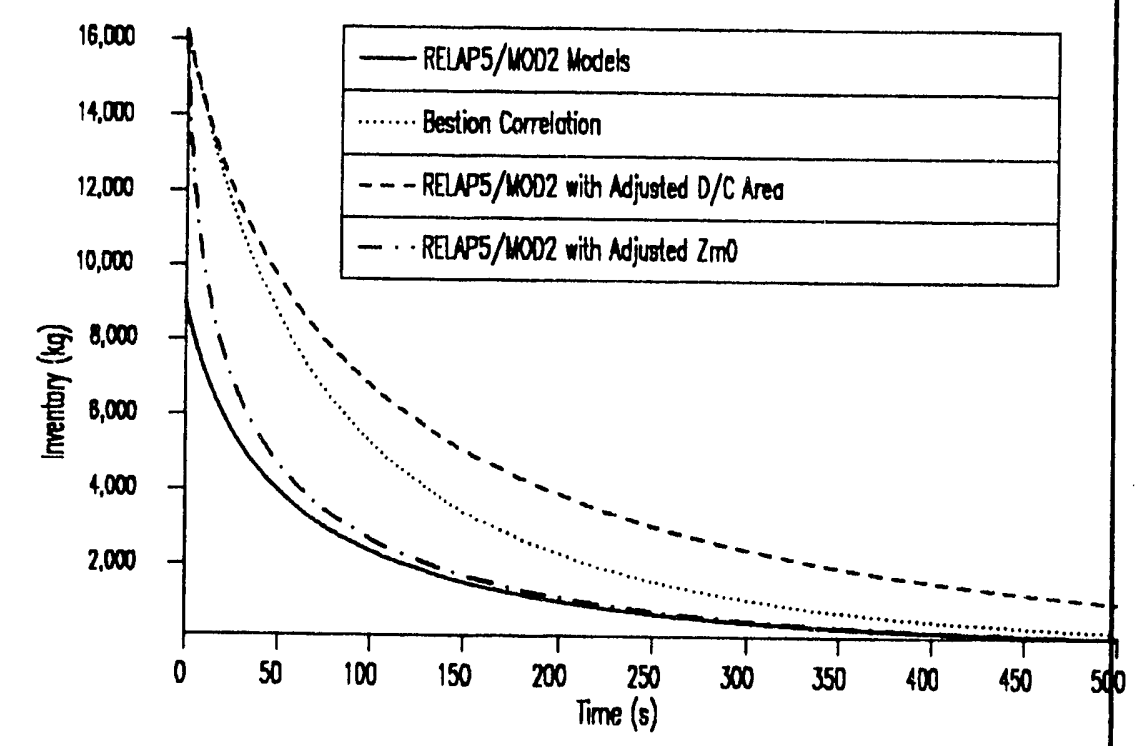

Fig. 17. Mixture level trajectories for simple SG boildown transient $P=60.0$ bor $Q=15.00 \mathrm{~W} / \mathrm{cm} 2-$ tube

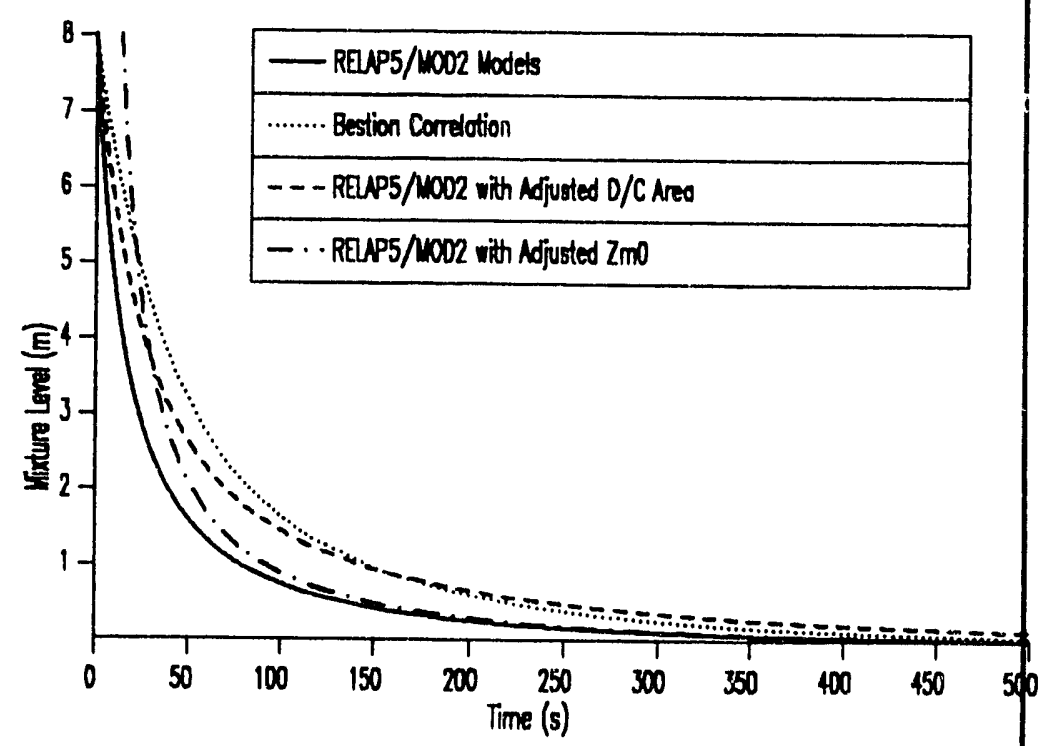




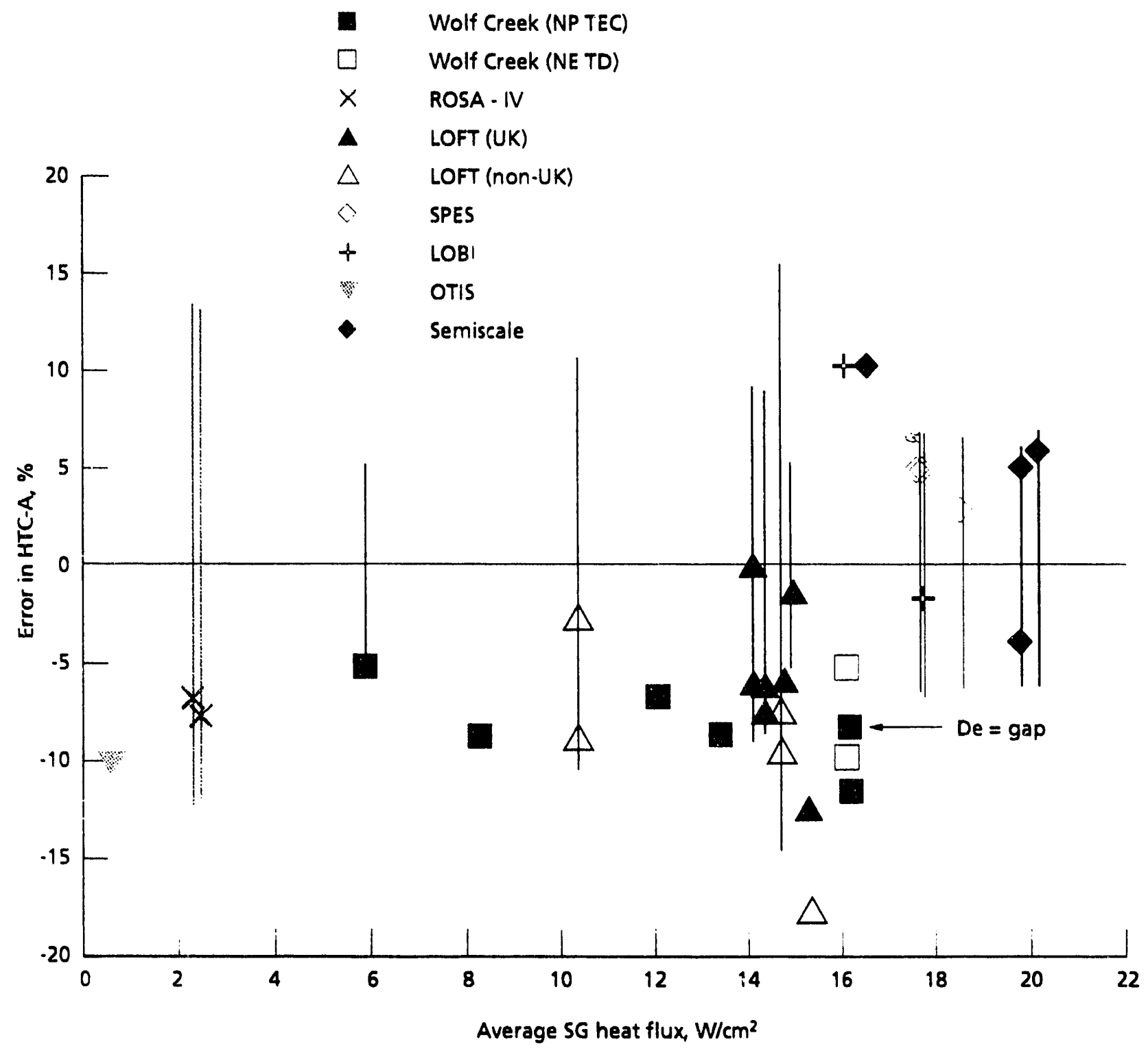

Figure 18 Errors in HTC-A vs SG heat flux 


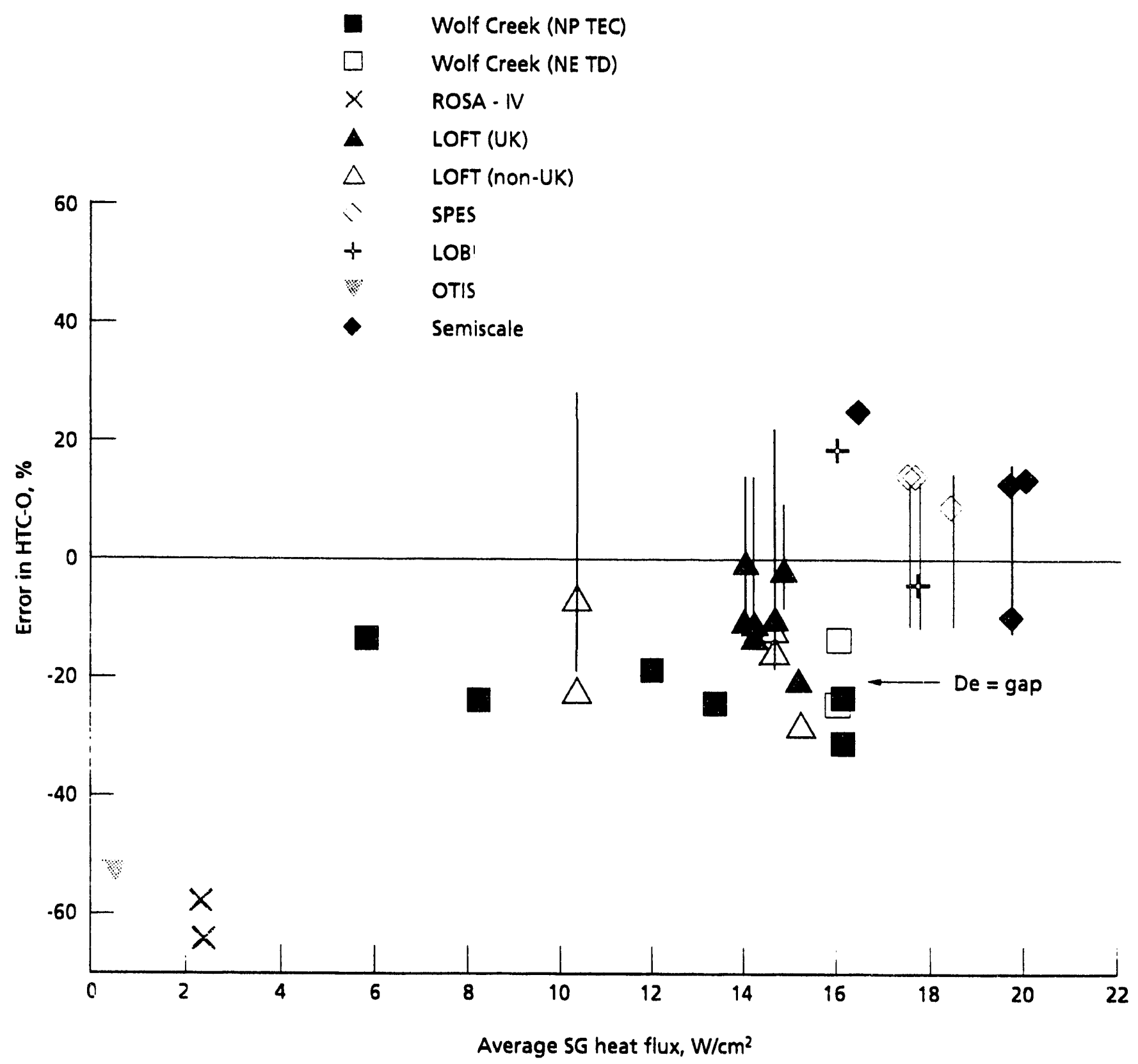

Figure 19 Errors in HTC-O vs SG heat flux 


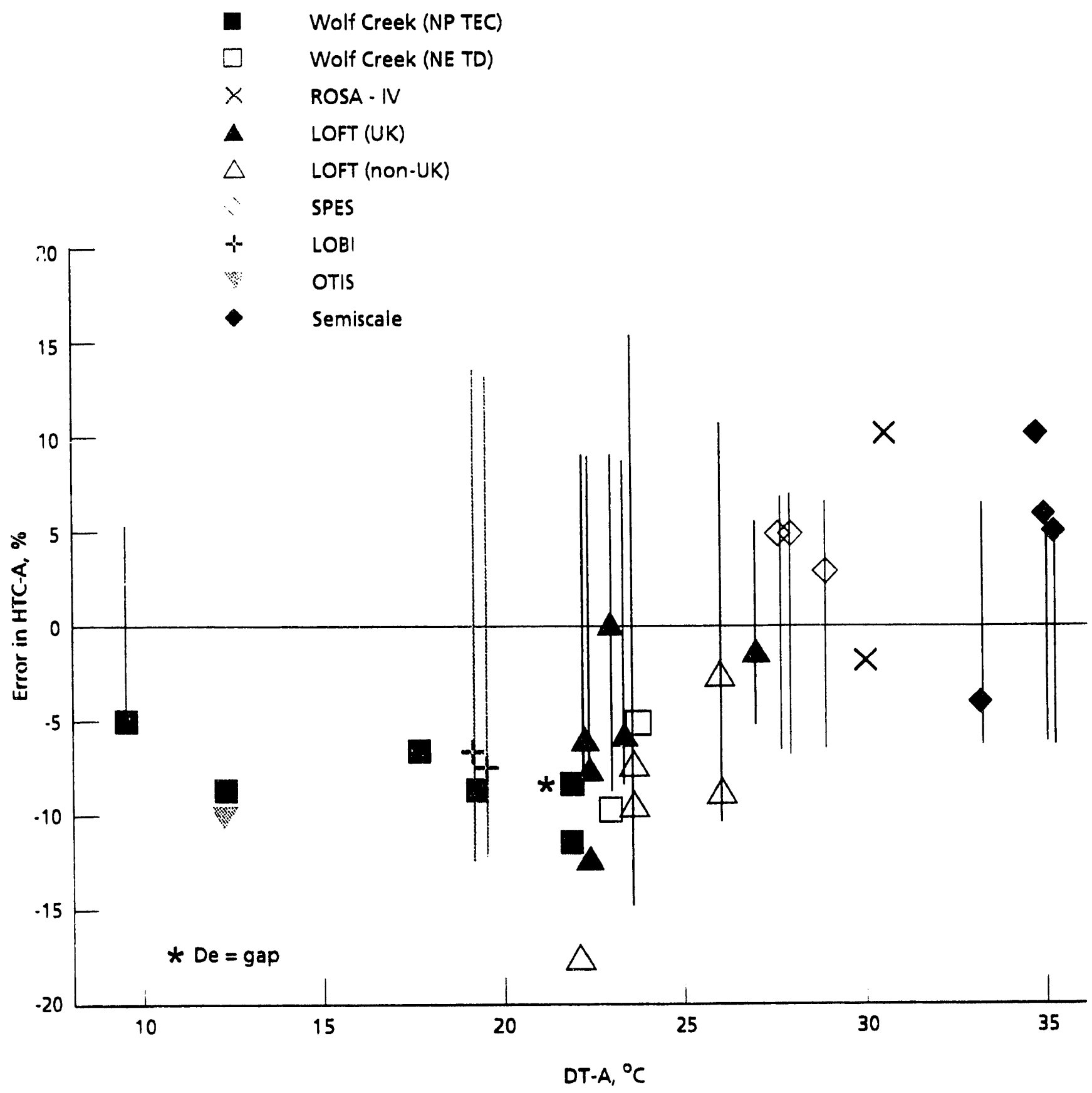

Figure 20 Error in HTC-A vs primary to secondary temperature difference 


\section{Distribution}

Copies to:

Addressee

Mr P Lightfoot

Nuclear Electric. PPG

S Dr C. Lopez-Cacicedo

NP TEC

Dr R.S. Adrain

Dr I.Milne

Mr M.W.E. Coney

Dr J.M. Putney

Mr A.H. Scriven

Document Retrieval Centre

Dr P.R. Farmer

NE HSD

Dr N.E. Buttery

NE PPG

Mr K.H. Ardron

Mr P.C. Hall

NE TD

Mr I.L. Hirst

Dr G. Ahmed

NE ITD

Dr D.R. Atthey

NE BNL

Mr B. Chojnowski

Mr D. Withrington

NNC

Mr K.T. Routledge

AEA Winfrith

Mr I. Brittain

NP Oakdale. Harrogate 


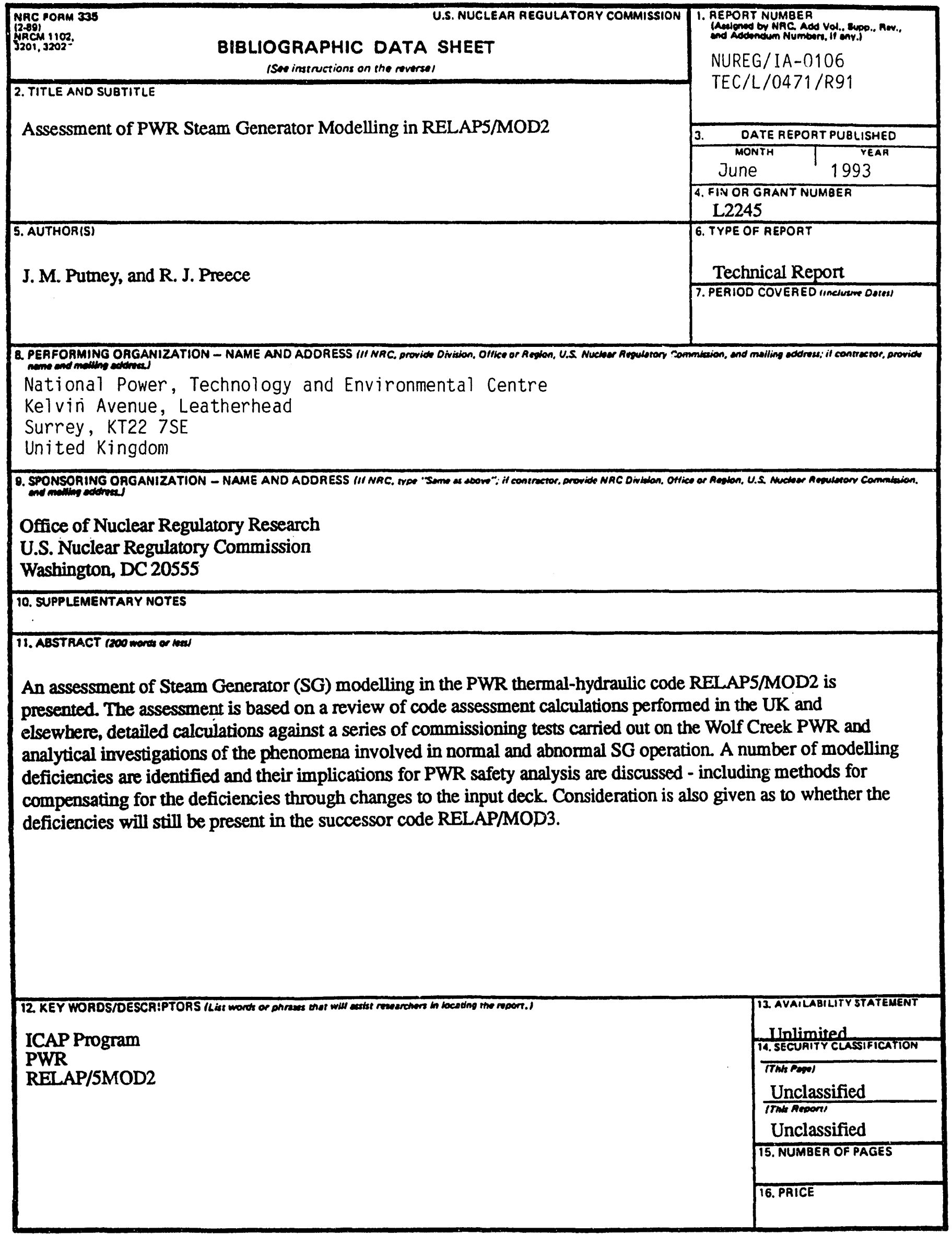



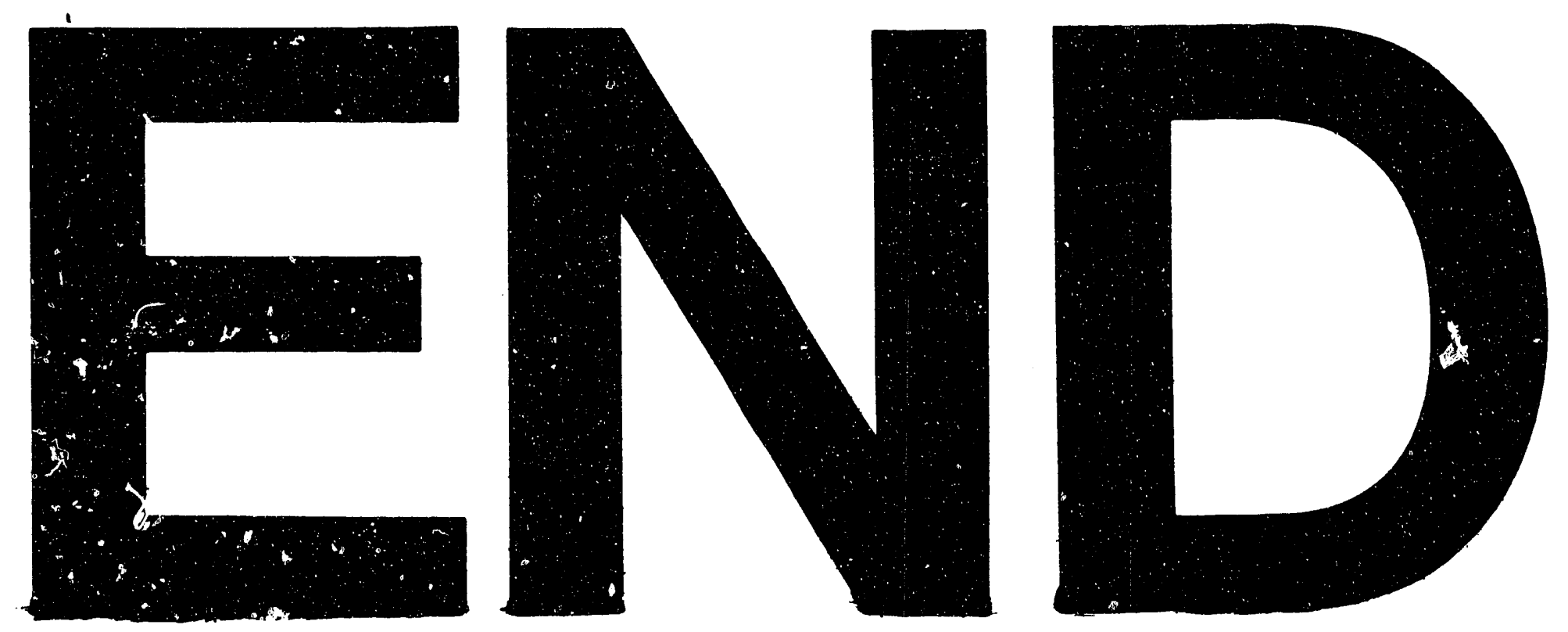

and

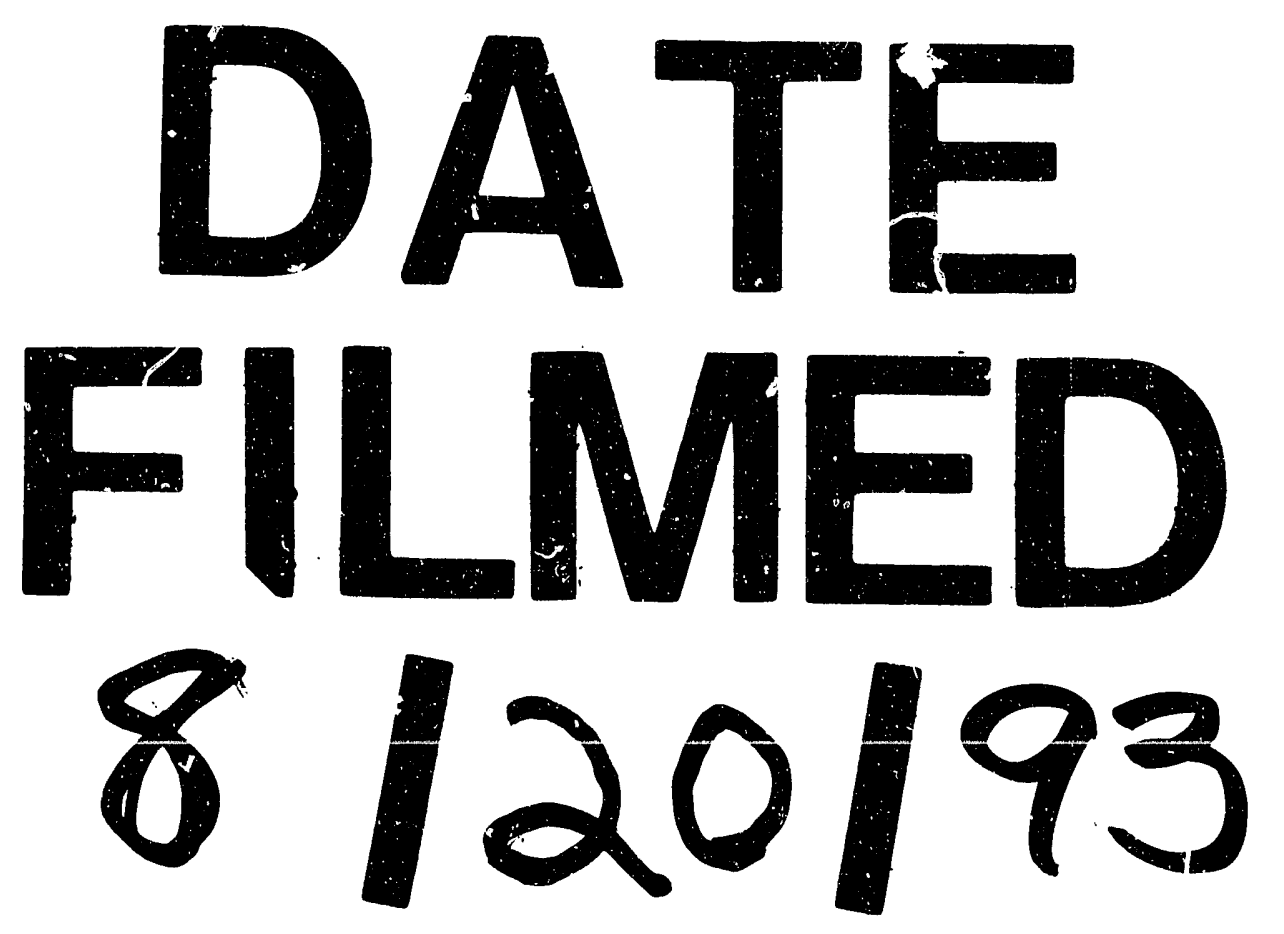


